\title{
Manipulating co-regulators of RUNX2 and SOX9 to enhance the chondrogenic potential of chondrogenic progenitor cells in osteoarthritis
}

\author{
Dissertation \\ for the award of the degree \\ “Doctor rerum naturalium” (Dr. rer.nat) \\ of the Georg-August-Universität Göttingen
}

\begin{abstract}
within the doctoral program
Molecular Biology of Cells

of the Göttingen Graduate Center for Neurosciences, Biophysics and Molecular Biosciences (GGNB)
\end{abstract}

\author{
Submitted by \\ Jérôme Janßen \\ born in Goch, Germany
}

Göttingen, October 2020 


\section{Thesis Committee}

Prof. Dr. Nicolai Miosge (Reviewer), Tissue Regeneration Work Group, University Medical Center Göttingen

Prof. Dr. Jörg Stülke (Second reviewer), Department of General Microbiology, Georg-August University Göttingen

Prof. Dr. Sigrid Hoyer-Fender, Johann-Friedrich-Blumenbach Institute for Zoology and Anthropology, Georg-August University Göttingen

\section{Examination Board}

Prof. Dr. Nicolai Miosge (Reviewer), Tissue Regeneration Work Group, University Medical Center Göttingen

Prof. Dr. Jörg Stülke (Second reviewer), Department of General Microbiology, Georg-August University Göttingen

Prof. Dr. Sigrid Hoyer-Fender, Johann-Friedrich-Blumenbach Institute for Zoology and Anthropology, Georg-August University Göttingen

Prof. Dr. Detlef Doenecke, Department for Molecular Biology, Georg-August University Göttingen

Prof. Dr. Susanne Lutz, Department of Pharmacology and Toxicology, University Medical Center Göttingen

Prof. Dr. Gerhard Braus, Department of Molecular Microbiology and Genetics, Georg-August University Göttingen 


\section{Table of content}

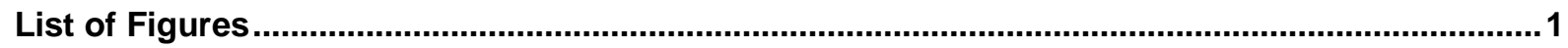

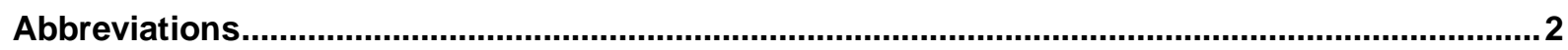

Summary

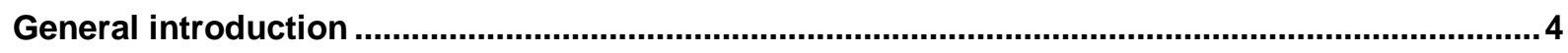

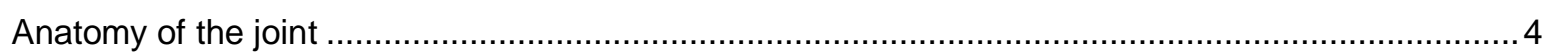

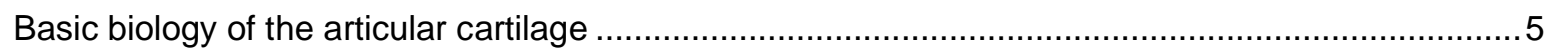

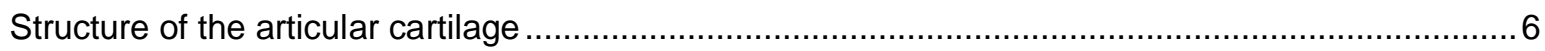

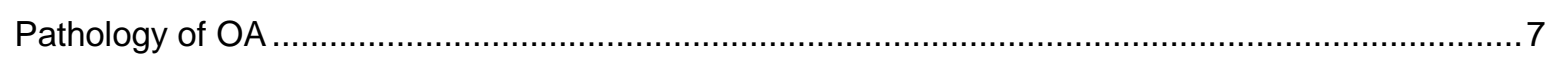

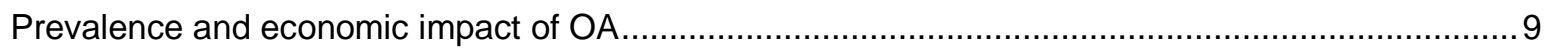

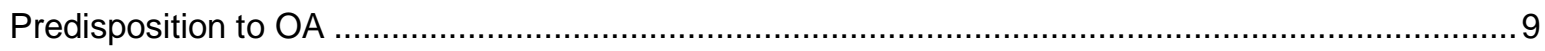

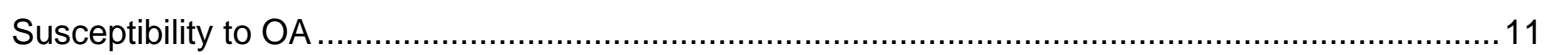

Treatment of $\mathrm{OA}$

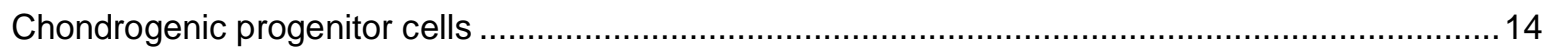

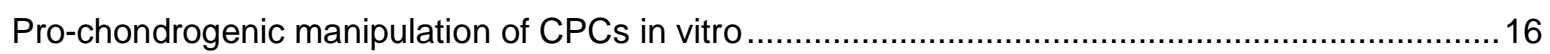

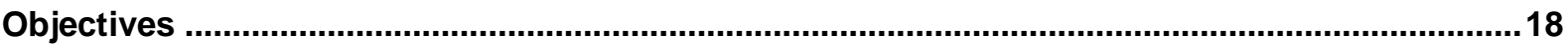

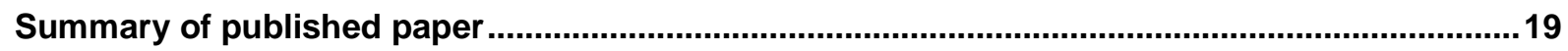

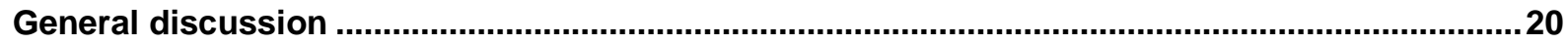

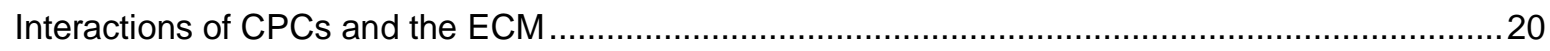

Direct manipulation of CPCs to enhance the chondrogenic potential ............................................22

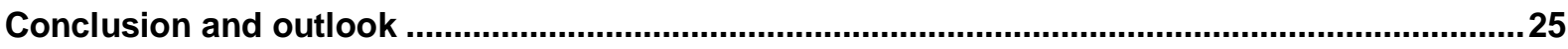

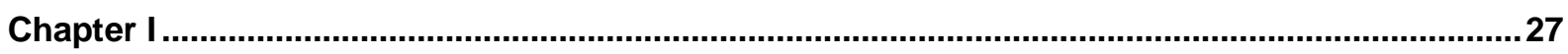

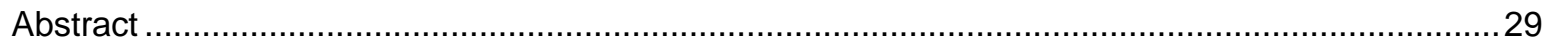

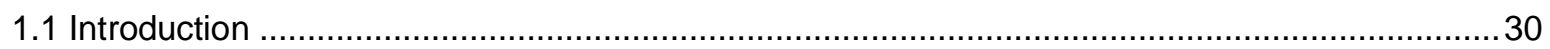

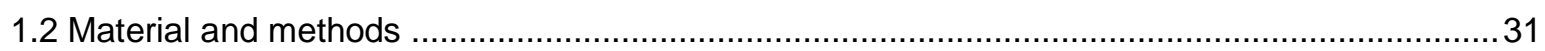

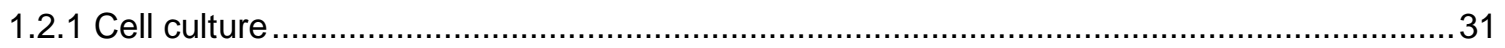

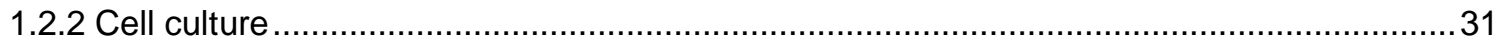

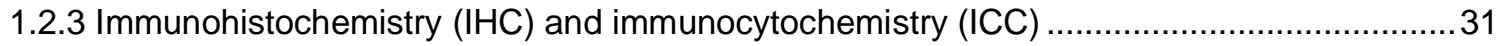

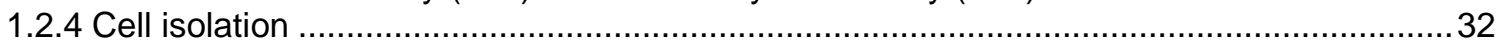

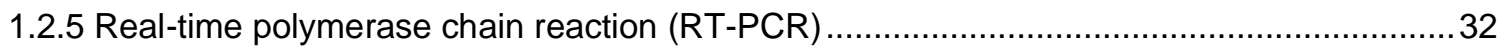

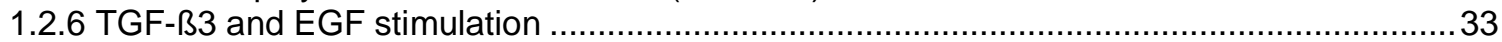

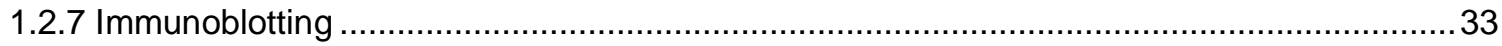

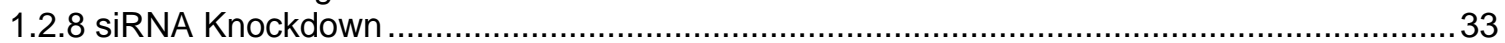

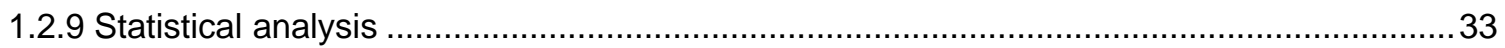

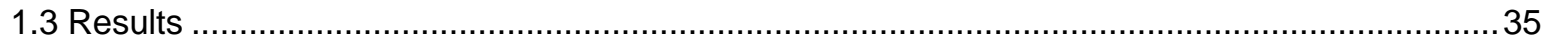

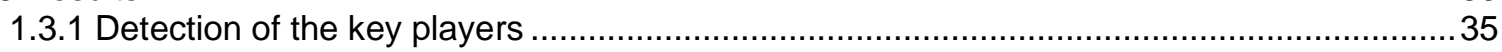

1.3.2 TGF-B3, EGF and BGN affect osteochondrogenic marker expression ...............................35

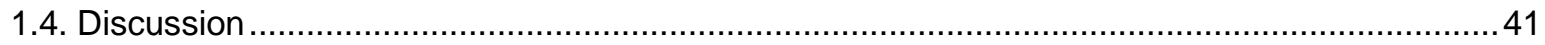

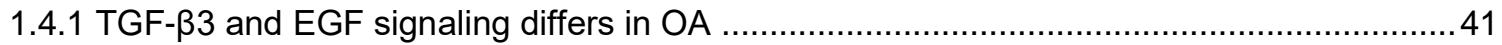

1.4.2 Influence of TGF- $\beta 3$, EGF and BGN manipulation on the chondrogenic potential of CPCs42 


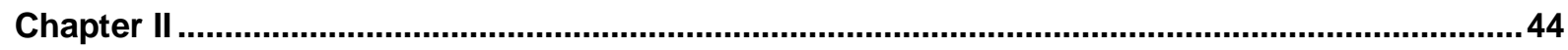

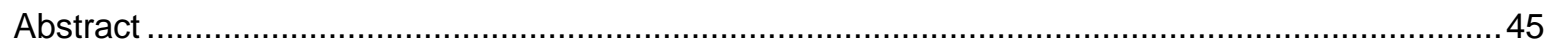

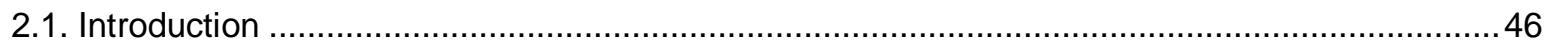

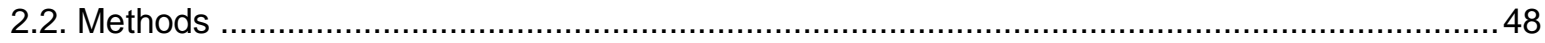

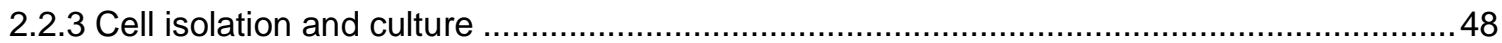

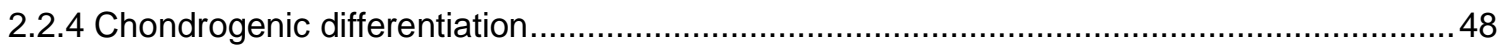

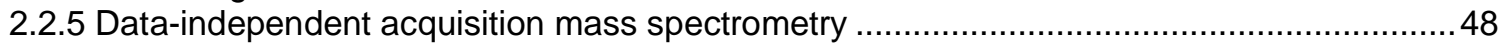

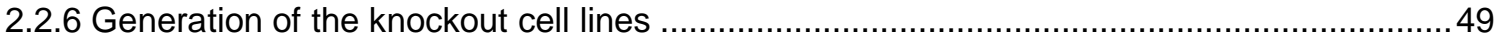

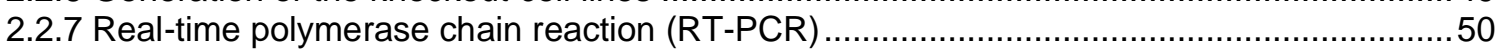

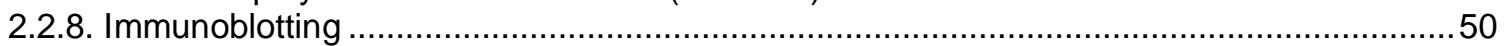

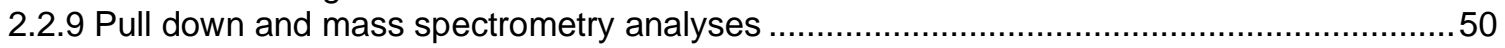

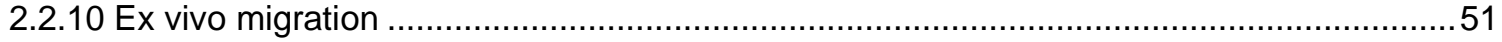

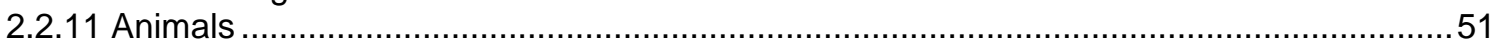

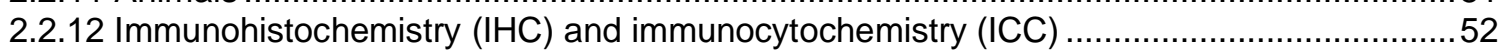

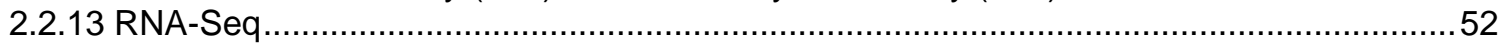

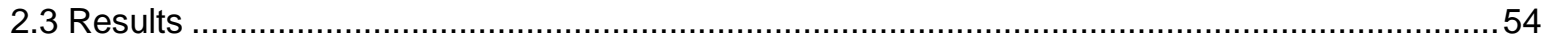

2.3.1 Primary and immortalized CPCs did not exhibit major differences .......................................54

2.3.2 The osteogenic master regulator RUNX2 has a pro-chondrogenic function in CPCs .........54

2.3.3 RAB5C is a co-regulator of SOX9, and its loss increases COL2 synthesis........................56

2.3.4. Loss of RAB5C did not impede proliferation and ECM deposition by CPC in a nude mouse

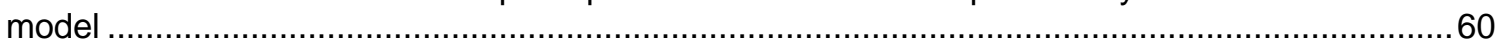

2.3.5. Further characterization of CPC ${ }^{\text {RABSC-- }}$ revealed increased expression of chondrogenic

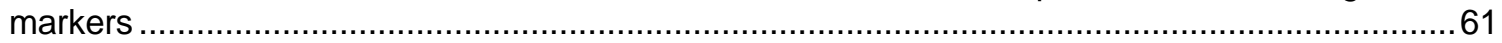

2.3.6 Loss of RAB5C deregulates pathways related to chondrogenesis ....................................64

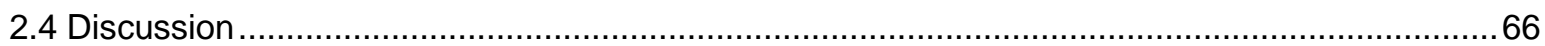

2.4.1 A minimal amount of RUNX2 enhances the chondrogenic differentiation of CPCs ...........66

2.4.2 RAB5C is a potential target that enhances chondrogenesis in CPCs ...............................66

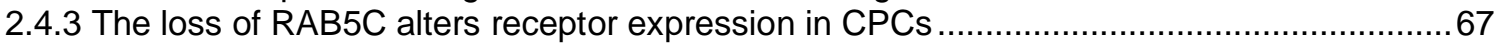

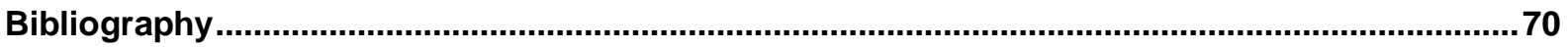

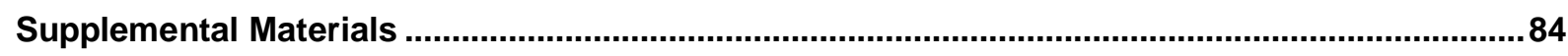

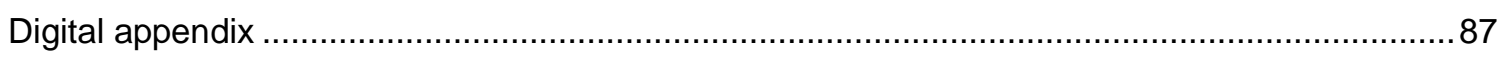

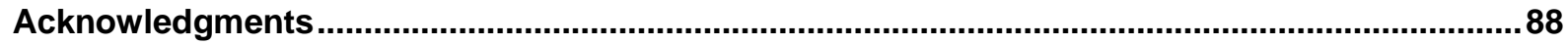

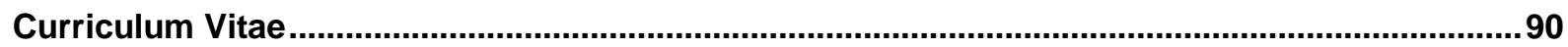




\section{List of Figures}

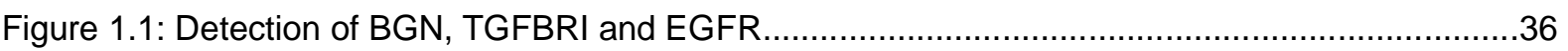

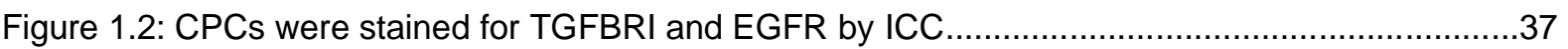

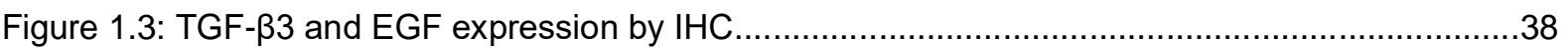

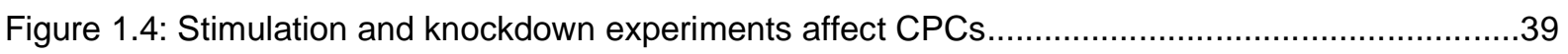

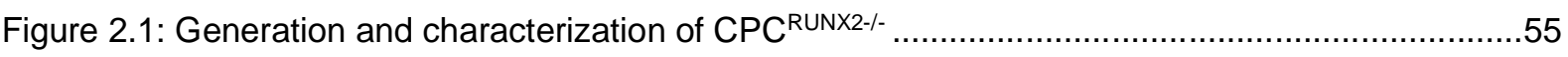

Figure 2.2: Pulldown of SOX9-associated proteins and characterization of $\mathrm{CPC} \mathrm{RABSC}^{\mathrm{R}-1} \ldots \ldots \ldots \ldots \ldots \ldots . . . . . . . . . . .57$

Figure 2.3: Histological examination of alginate beads transplanted into the back of nude mice.........60

Figure 2.4: Broader analysis of CPCRAB5C-/- marker expression during chondrogenic differentiation

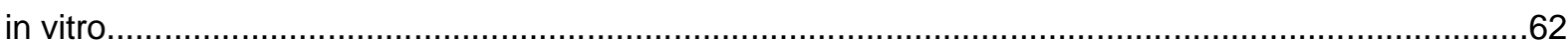

Figure 2.5: Differential expression of mediators involved in chondrogenesis in CPC ${ }^{\text {RAB5C-- }}$.................64 


\section{Abbreviations}

ACAN

AGRN

BGN

BMP

BMPR1B

CC-D

$\mathrm{CC}-\mathrm{H}$

COL

CPCs

DIA-MS

DZ

ECM

EGF

EGFR

FDR

FINC

GO

$\mathrm{His}$

hT

ICC

$\mathrm{IHC}$

$\mathrm{IHH}$

IL

IL4R

KD

$\mathrm{KO}$

LAM

MMP

$M Z$

NID2

OA

PAM

$\mathrm{R}^{2}$

$\mathrm{RAB}$

RNAi

RUNX2

SMAD

SOX

SZ

TGF- $\beta$

TGFBRI

WB
Aggrecan

Agrin

Biglycan

Bone morphogenetic protein

Bone morphogenetic protein receptor type $1 \mathrm{~b}$

Chondrocyte residing in diseased tissue

Chondrocyte residing in healthy tissue

Collagen

Chondrogenic progenitor cells

Data-independent acquisition mass spectrometry

Deep zone

Extra-cellular matrix

Epidermal growth factor

Epidermal growth factor receptor

False discovery rate

Fibronectin

Gene Ontology

Polyhistidine tag

Human telomerase reverse transcriptase

Immunocytochemistry

Immunohistochemistry

Indian hedgehog

Interleukin

Interleukin 4 receptor

Knockdown

Knockout

Laminin

Matrix metallopeptidase

Middle zone

Nidogen 2

Osteoarthritis

PAM, protospacer adjacent motif

Goodness-of-fit

Ras-related protein

RNA interference

Runt-related transcription factor 2

Mothers against decapentaplegic homolog

Sex determining region $Y$-box

Superficial zone

Transforming growth factor $\beta$

Transforming growth factor $\beta$ receptor I

Western Blot 


\section{Summary}

Osteoarthritis $(\mathrm{OA})$ is a degenerative disease of the joint leading to the degradation of the articular cartilage. Current therapies cannot halt or reverse the disease, leading to a severe impact on life quality accompanied by immense health care and society cost. One major characteristic of $O A$ is the replacement of articular cartilage by a fibrocartilaginous repair tissue. Chondrogenic progenitor cells (CPCs) reside in the late-stage $O A$ fibrocartilage and express the fibrotic marker collagen type 1 (COL1). However, these cells can undergo chondrogenic differentiation in vitro and produce the articular cartilage marker collagen type 2 (COL2). The aim of this project is to analyze how the CPCs' chondrogenic potential can be increased to lay the foundation for future therapeutic interventions in OA. The chondrogenic transcription factor SRY (sex determining region Y)-box 9 (SOX9) and the osteogenic transcription factor runt-related transcription factor 2 (RUNX2) are key regulators in CPCs and control their chondrogenic differentiation. Chapter I of this thesis analyzes the effect of the extra-cellular matrix (ECM) protein biglycan (BGN) and of the transforming growth factor $\beta$ (TGF- $\beta$ ) and epidermal growth factor (EGF) signaling pathways on SOX9 and RUNX2 expression. Histological staining confirmed the presence of these molecules in late-stage OA fibrocartilage specimens. Analysis on the RNA and protein level demonstrated that BGN modulates TGF and EGF signaling events and vice versa. TGF and EGF stimulation of CPCs resulted in elevated osteochondrogenic marker expression, including SOX9 and RUNX2. Chapter II deals with a direct manipulation of the osteochondrogenic regulators SOX9 and RUNX2. Despite its osteogenic role in chondrocyte hypertrophy that precedes bone formation, RUNX2 was confirmed to have a pro-chondrogenic effect. Next, the early endosomal marker ras-related protein Rab-5C (RAB5C) was identified as potential interaction partner of SOX9 in CPCs. The deletion of RAB5C using CRISPR/Cas9 increased the chondrogenic potential of CPCs and did not impair their ability to migrate. Finally, our findings suggest that altered bone morphogenetic protein, notch and interleukin signaling mediate this pro-chondrogenic effect.

In summary, this thesis discusses novel strategies to manipulate the chondrogenic potential of CPCs. First, the modulation of chondrogenic signaling events in CPCs by BGN highlights the role of the ECM on the chondrogenic potential. Secondly, RAB5C was identified as potential co-regulator of SOX9 in CPCs and resembles a candidate for future research on therapeutic interventions in OA. 


\section{General introduction}

Osteoarthritis $(\mathrm{OA})$ is the most common form of arthritis and a major cause of pain and disability around the world (Reginster, 2002). OA affects the joints by degenerative processes, leading to the destruction of the articular cartilage and immobilization of the affected joint (Felson, 2006). It has been estimated that $80 \%$ of OA patients have impaired movement and $25 \%$ cannot perform major activities. OA accounts for $2.4 \%$ of all years lived with disability and showed a $75 \%$ increase between 1990 and 2013, making it the third most rapidly rising condition associated with disability after diabetes and dementia (Wittenauer et al., 2013).

\section{Anatomy of the joint}

The musculoskeletal system is composed of muscles, bones, tendons, ligaments, joints and joint capsules. Joints are connections between bones that allow for various types and degrees of movement and thus are essential for the body's articulation. They can be classified based on morphological criteria, e.g., the joint structure. Diarthroidal joints are characterized by the occurrence of a synovial gap that is absent in synarthrodial joints. The synovial gap is located between the two ends of the opposing bones and is filled with synovial fluid that provides lubrication during movement. This fluid is secreted by the synovium, a membrane sealing the synovial gap. Furthermore, a fibrous joint capsule engulfs and supports the underlying synovium. Muscles and ligaments collaborate with the joint capsule to provide stability and limit the joints range of movement (Garnero et al., 2000). Finally, a unique soft tissue, the articular or hyaline cartilage is pivotal for the joint's integrity. Located at the end of each articular bone and bordering the synovial gap, it provides resistance to the intense compression forces that occur during locomotion (Fox et al., 2009).

In summary, the diarthrodial joint is composed of different specialized tissues that allow for movement, while maintaining joint integrity and opposing the intensive and repetitive loading forces. Diseases affecting the joint can lead to destruction of the articular cartilage, destabilizing the joint and thus may result in total joint failure. Therefore, research on the structure and function of articular cartilage aims to preserve this unique and essential tissue. 


\section{Basic biology of the articular cartilage}

Articular cartilage is about $2-4 \mathrm{~mm}$ thick and is only inhabited by chondrocytes that exhibit a limited replication potential. The major task of articular cartilage is to provide a smooth, lubricated surface to allow articulation by facilitating the transmission of loads with a low frictional coefficient (Fox et al., 2009). The limited capacity for regeneration is a result of an absent perichondrium harboring stem cells (Goldring and Goldring, 2010). This highly specialized tissue is characterized by the lack of blood vessels, lymphatics and nerves. The chondrocyte is nurtured by diffusion from the synovial fluid and is depending on anaerobic metabolism. Joint movement and loading displaces the synovial fluid, securing the chondrocytes' nutrition and thus, is essential to prevent cartilage degradation (Buckwalter and Mankin, 1998b). Chondrocytes synthesize the extracellular matrix (ECM) in which they will be trapped. The ECM prevents migration of the chondrocytes, cell-to-cell contacts as well as the associated direct communication between cells. Nevertheless, signal transduction is established via growth factors, piezoelectric forces, hydrostatic pressure and mechanical load. These signals coordinate chondrocytes to develop, maintain and repair the ECM. Natural homeostasis of the ECM involves anabolic processes, such as the increased synthesis of ECM proteins, or catabolic processes such as the expression of ECM turnover enzymes (Fox et al., 2009). Functionally, the ECM not only provides the tissues properties, but also plays a major part in organizing the stem-cell niche by modulating signaling events (Bi et al., 2007).

Structurally, the ECM is composed of water, collagens (COL), proteoglycans, noncollagenous proteins as well as glycoproteins. COLs are comprised of three polypeptide $\alpha$-chains wound into a homo- or heterotrimeric helix. The confirmation, folding and stability of each alpha chain is dictated by a repetitious amino acid motif that mainly contains glycine, proline and hydroxyproline (Brodsky et al., 2008). Other key components of articular cartilage are proteoglycans. Proteoglycans are strongly glycosylated protein monomers and interact with collagens to provide structural support to the ECM. They consist of one protein core with one or more negatively charged linear glycosaminoglycans chains that are composed of more than 100 monosaccharides. In contrast to proteoglycans, glycoproteins are less heavily glycosylated and their oligosaccharide chains are rather short and branched. Glycoproteins are mainly integrated into the cell membrane and involved in cell recognition as well as signal transduction (Fox et al., 2009). Finally, some proteins in 
the ECM do not fit into the aforementioned categories. The research on these proteins includes their interaction with the ECM or their altered abundance during OA (Roughley, 2001).

The most prominent markers of articular cartilage are COL2 and the proteoglycan aggrecan (ACAN). COL2 is a homotrimer and makes up to $90-95 \%$ of all $\mathrm{COL}$ in the cartilage. Moreover, COL2 forms fibrils, provides the tensile strength of the tissue and entraps proteoglycan aggregates. The entrapped aggregates consist of ACAN bound to hyaluronan and thus possess an immense capacity to bind water. Together, COL2 and ACAN aggregates provide the articular cartilage with its osmotic properties and resilience by imbedding water (Fox et al., 2009). Other prominent markers of articular cartilage are COL9 and COL11, as both are required for proper ECM organization (Bruckner and van der Rest, 1994).

\section{Structure of the articular cartilage}

Based on the proximity to the chondrocyte, the ECM in articular cartilage is divided into three regions that display unique features. The pericellular matrix is adjacent to the cell membrane and is important for signal transduction (Poole, 1997). Therefore, it contains proteoglycans such as biglycan (BGN) that can interact with receptors to modulate signaling events (Nastase et al., 2012). The thicker territorial matrix engulfs the pericellular matrix and protects the chondrocytes from substantial loads. Finally, the interterritorial region provides the biomechanical properties of articular cartilage (Poole, 1997). In this region, proteoglycans are abundant and the COLs are oriented according to their location in the respective cartilage zone, which will be described in the following.

Cartilage is divided into four zones, each featuring unique characteristics. The outmost superficial zone contains mainly COL1 and COL9, which are arranged parallel to the cartilage surface. They distribute the compressive load over a vast area and provide protection against sheer forces. The middle zone is located underneath the superficial zone, mainly consisting of oblique arranged COL2 fibers as well as proteoglycans, and provides resistance against compressive forces. The underlying deep zone is characterized by COL2 fibers that are perpendicularly aligned to the joint surface, the highest proteoglycan content and the lowest water concentration; resulting in the greatest resistance to compressive forces. Finally, the 
tidemark segregates the deep zone from the calcified zone that secures the articular cartilage to the subchondral bone (Fox et al., 2009). During joint development, the calcified zone is produced by terminally differentiated chondrocytes, the so called hypertrophic chondrocytes (Goldring and Goldring, 2010). They replace their ECM with hypertrophic markers such as COL10 to induce ossification of the cartilage and eventually deposit calcium (Sandell and Aigner, 2001).

In summary, the different zones of healthy articular cartilage resist and distribute the occurring shear and compressive forces upon load to the subchondral bone. This is achieved by the smooth, lubricated surface that allows for low-friction when the joint is loaded. The electrostatic forces between proteoglycans and water provide a high resistance to the occurring compressing forces (Blalock et al., 2015). Then, the increased interstitial fluid pressure squeezes the interstitial fluid out of the cartilage. Finally, interstitial fluid flows back into the cartilage as the compressive load is removed. Articulation is based on the unique properties of articular cartilage as well as on the other specialized joint tissues. Pathological alterations may affect these tissues and impede proper joint function (Fox et al., 2009).

\section{Pathology of OA}

$\mathrm{OA}$ is a disease that leads to failure of synovial joints as a result of disrupted balance between cartilage breakdown and repair (Eyre, 2004). Moreover, not only does this include the destruction of the articular cartilage, but the whole joint becomes affected as well. $O A$ is characterized by a state of constant low inflammation. Symptoms of $O A$ include pain, stiffness, reduced movement, swelling and crepitus in the absence of systemic features such as fever (Hunter and Felson, 2006). Nevertheless, some patients are asymptomatic despite exhibiting structural changes typical for $O A$ (Hannan et al., 2000). Hitherto, there is no explanation for these cases and in general the rather late occurring diagnosis exacerbates the research on the initial events leading to OA (Heinegard and Saxne, 2011).

On the protein level, OA leads to degradation of the articular cartilage. In healthy individuals, articular cartilage it is an avascular tissue inhabited only by chondrocytes. The chondrocytes keep the equilibrium between anabolic and catabolic processes, by secreting the ECM; and ECM turn over enzymes such as matrix metallopeptidases (MMPs). However, in OA, MMPs are overexpressed leading to an 
increased turnover of the ECM. First, the chondrocytes exhibit an increased ECM synthesis and secret MMP inhibitors to counteract the catabolic MMPs. Eventually, this procedure is insufficient to sustain the ECM, and thus a loss of protein and protein organization with the simultaneous increase of water can be observed. Additionally, the cellular organization is affected by $O A$ and the formation of chondrocyte clusters can be observed (Goldring and Goldring, 2007). The extensive deposition of COL1 leads to the formation of a fibrocartilaginous repair tissue of lesser quality accompanied by severe loss of cartilage elasticity (Miosge et al., 2004, Miosge et al., 1998). Finally, macroscopical fissures and erosion events take place, further impairing the joint function (Hollander et al., 1995).

Pathological alterations affect all other joint tissues, too. The tidemark segregating the articular cartilage from the underlying bone duplicates, which is probably triggered by regional calcification of deep articular cartilage. Furthermore, the sprouting of blood vessels from the subchondral bone into this usually avascular region tissue can be observed (Goldring, 2012). Degeneration is observed in the ligaments and the subchondral bone (Schulze-Tanzil, 2019). Lesions in the bone marrow may form and osteophytes emerge (Cicuttini et al., 1996). Additionally, the occurrence of subchondral microfractures (Burr, 2004) and bone angina (Simkin, 2004 ) is characteristic of OA. During the onset of OA, thickening of the synovial capsule, synovial hyperplasia, activated synoviocytes, fibrosis as well as lymphocytic invasion may occur (Scanzello and Goldring, 2012). Moreover, adjacent to the synovial membrane is the infrapatellar fat pad, resembling a rich reservoir of inflammatory adipokines and chemokines (loan-Facsinay and Kloppenburg, 2013). This fat pad can be activated during $O A$ or by synovitis. Early inflammation events may play a significant role in the development of $O A$, as the released inflammatory mediators could direct chondrocytes from an anabolic to a catabolic phenotype (Heinegard and Saxne, 2011).

In total, OA can affect all tissues of the joint and the pathological changes lead to the loss of normal joint function. In particular, the replacement of healthy articular cartilage containing mainly COL2 by a fibrocartilaginous repair tissue containing mainly COL1 is characteristic for OA. In many patients, the natural occurring repairing processes are insufficient to halt the progress of the disease and total joint failure takes place. 


\section{Prevalence and economic impact of $O A$}

About $10-15 \%$ of adults over 60 are estimated to suffer from OA worldwide, among these are approximately $9.6 \%$ men and $18 \%$ of women. OA affects mainly the weight bearing joints having the highest age-standardized prevalence for men and women in the knee (25.4\% and $15.4 \%)$ and the hip (19.6\% and $4.2 \%)$. Other joints including the hand, ankle, elbows and shoulder can also be affected. Finally, it should be taken into account that the prevalence of $O A$ itself and the specific types varies between different countries (Wittenauer et al., 2013).

As mentioned before, $\mathrm{OA}$ is a disease affecting mainly the elderly. Therefore, the burden of OA will increase in future due to the aging of the world's population. The United Nations calculated that the number of people of the age of 60 will substantially increase and make up to more than $20 \%$ of the world's population by 2050 . A conservative $O A$ prevalence estimation of $15 \%$ implies that in 2050, 130 million people will suffer from OA and 40 million will be severely disabled (Lim and Lau, 2011).

The treatment of OA patients constitutes a massive economic burden that includes direct costs of testing, purchase of adaptive aids and devices, drugs as well as surgical intervention. Further indirect cost exist, as one study reported that $30.7 \%$ of patients surveyed were unable to do chores and $3.6 \%$ had taken time off work in the last 6 months due to their condition (Maetzel et al., 2004). In the US alone, the annual cost for OA has been estimated to be greater than 185 billion USD (Kotlarz et al., 2009). In general, the OA costs for every country lie between $0.25 \%$ and $0.5 \%$ of the country's GDP (Puig-Junoy and Ruiz Zamora, 2015).

In summary, $\mathrm{OA}$ is characterized by mainly affecting the elderly population. This is of particular interest considering the aging of the world's population. The severe economic impact of $O A$ includes the disease's treatment as well as the resulting years lived with disability.

\section{Predisposition to OA}

OA can be classified in two groups, primary and secondary OA. Primary OA or idiopathic $O A$ is related to the aging process as well as the natural occurring wear and tear processes, but nevertheless affects all ages. Secondary OA has the same symptoms and pathology, but results from a known cause most likely after injury. 
Therefore, often younger individuals are diagnosed with secondary OA (Musumeci et al., 2015).

The most important risk factors identified by various studies are listed in the following: First, a strong hereditary component has been noticed, as up to $60 \%$ of OA cases are discussed to be a consequence of genetic factors (Wittenauer et al., 2013). Over 80 gene mutations have been linked to the pathology of OA (Ryder et al., 2008), including mutations in mediators of the transforming growth factor $\beta$ (TGF$\beta$ ) (Reynard and Loughlin, 2012) and epidermal growth factor (EGF) (Qin and Beier, 2019) signaling pathways. TGF- $\beta$ signaling is mediated by the binding of a TGF- $\beta$ ligand to a TGF type II receptor and the subsequent phosphorylation of a TGF type I receptor. The type I receptor phosphorylates mothers against decapentaplegic homologs (SMADs) such as SMAD2, that form heterodimers with SMAD4 and become translocated into the nucleus to regulate downstream gene expression. However, signaling can be blocked by inhibitory SMADs such as SMAD7 (van der Kraan, 2018). The loss of TGF signaling led to a progressive OA phenotype in mice (Shen et al., 2014). Next, mutations in mediators of the EGF signaling pathway were also associated with OA. EGF signaling is triggered by the binding of an epidermal growth factor receptor (EGFR) to an EGF ligand and the subsequent formation of an asymmetric dimer with another ligand bound EGFR family member (Burgess et al., 2003). The subsequently autophosphorylated EGFR activates context dependent downstream genes, either leading to anabolic processes including chondrocyte proliferation and survival, or catabolic processes including SOX9 inhibition and MMP expression (Qin and Beier, 2019). In addition to mutations affecting signaling events, mutations in genes encoding for cartilage proteins, such as COL2 and COL9, are related to OA (Heinegard and Saxne, 2011). However, Musumeci et al. (2015) highlighted that despite the great numbers of genes involved in OA pathology, there is not a single high impact $O A$ locus, but rather interplay of many genetic factors. Finally, epigenetic factors, referring to alterations of the phenotype without changes in the DNA sequence, play a role in joint development, homeostasis and OA pathology (Rice et al., 2020). For example, hyper- and hypomethylation of genes of mediators involved in TGF- $\beta$-, Notch- as well as interleukin (IL) signaling were reported in cartilage samples of mild and severe OA (Moazedi-Fuerst et al., 2014).

The relation between the natural occurring aging processes and $O A$ is still under investigation. First, the avascular nature of cartilage and the limited proliferation 
capacity of chondrocytes influence the tissue's preservation. According to the Hayflick limit (Hayflick, 1984), chondrocytes have 30-40 replications during their lives and furthermore, there is evidence that the senescent chondrocytes lose the ability to repair and maintain the ECM (Mobasheri, 2011). This process starts in the superficial zone of the articular cartilage and proceeds into the underlying tissue over time (Hollander et al., 1995), being accompanied by increased death in chondrocytes. However, it is not clear, whether $O A$ is induced by chondrocyte apoptosis initiated at the end of their replication limit, or OA induces chondrocyte apoptosis as cell matrix interactions are essential for chondrocytes (Zamli and Sharif, 2011).

As mentioned before, gender differences, such as the strong increase of OA after menopause in women exist, indicating that systemic estrogen level (Boyan et al., 2013) as well as altered signaling events (Kinney et al., 2005) play a pivotal role in OA. In addition to total cartilage volume, sex based differences in bone, muscle or tendon properties may impact the progression of OA (Musumeci et al., 2015). Finally, studies on the ethnicity of patients reported racial differences regarding the different types of OA, as well as pain intensity and disability. However, the adjustment for demographic, health-related and medical access factors and inaccuracies of selfreported OA mitigates this finding (Allen, 2010).

In total, OA can be categorized into primary without known idiopathy; and secondary, after trauma. Predisposing factors for OA include genetic mutations, epigenetic alterations, aging, sex and race.

\section{Susceptibility to OA}

Additional susceptibility factors are being investigated for OA pathology. First, the dietary is linked to OA, e.g., one association study stated low intake of vitamin $C$ and vitamin $D$ as a possible risk factor, whereas the consumption of fruits, milk products and meat exhibited a positive effect on OA (Sanghi et al., 2015). In general, bad nutrition is likely a factor predisposing people to obesity that destroys the cartilage as consequence of overloaded joints. The risk to develop OA is three times as high in overweight or obese people (Blagojevic et al., 2010). Interestingly, obesity and OA are also associated in non-weight-bearing joints. Therefore, studies investigate systemic factors, e.g., the altered expression of metabolic factors as consequence of an inflamed adipose tissue (Musumeci et al., 2015). Investigation of the adipokine 
leptin demonstrated its expression to be proportional to TGF- $\beta$ expression as well as to the level of cartilage destruction. In addition, the accumulation of advanced glycation end products and the increase of their receptors in chondrocytes are linked to OA and aging (Loeser et al., 2005, DeGroot et al., 1999). This eventually leads to increased cross-linking and stiffness of the cartilage (Verzijl et al., 2002), as well as increased MMP production and ECM turnover in chondrocytes (Yammani et al., 2006).

Sport has a protective effect towards $O A$, as it strengthens the tendons, the cartilage and the muscles protecting the joint. However, high impact sports resemble a risk for cartilage injury and the excessive exercise with an injured joint was linked to $O A$ (Musumeci et al., 2015). Local mechanical risk factors such as the adduction moment, malalignment, meniscal damage, bone marrow lesions, and altered quadriceps strength intensify the onset of OA (Felson, 2004). Sport injuries and injuries in general play a major role in the development of OA. Among knee injuries alone, $23 \%$ involve the meniscus and $25 \%$ involve the anterior cruciate ligament (Thomas et al., 2017), both structures providing support of the joint. Thus, the resulting destabilization is an immense burden for the joint and the articular cartilage. A possible biomechanical explanation for the higher OA risk in anterior cruciate ligament reconstructed or deficient individuals include abnormal weight distribution as well as quadriceps weakness. Furthermore, meniscus destabilization is a method to induce $O A$ in animal models and is used as a routine procedure for secondary $O A$ studies (McCoy, 2015). In total, not only injuries of the articular cartilage, but of the adjacent tissue alike can increase the risk to develop $O A$, which highlights the systemic character of OA. Finally, a survey reported that agricultural workers, housekeepers, truck drivers and other occupations with high physical demands display a high risk for $O A$ that may result from specific ergonomic stresses, e.g., squatting, kneeling and knee bending (Rossignol et al., 2003).

In summary, the most prominent susceptibility factors of $O A$ include diet, being overweight, injuries, sport and occupation. $O A$ can be induced by trauma in animal models and is used for research on secondary OA. Treatment options of OA amongst others counter act these factors. 


\section{Treatment of OA}

Hitherto treatment of OA primarily focuses on pain relief as well as delaying total loss of joint function. Currently, no cure exists to halt or reverse the onset of OA. The OARSI (Osteoarthritis Research Society International) developed evidence-based guidelines to manage knee and hip $O A$ which include reducing joint pain and stiffness, maintaining and improving joint mobility, reducing physical disability and handicap, improving health-related quality of life, limiting the progression of joint damage and educating patients about the nature of the disorder and its management. Treatment of $\mathrm{OA}$ should combine non-pharmacological with pharmacological methods. The most important modalities proposed by Zhang et al. (2008) are listed in the following: Non-pharmacological interventions include the loss of weight to relieve pressure on joints and reduce the systemic factors involved in OA. Furthermore, physiotherapy and regular exercise will help to strengthen the joint. Pharmacological intervention includes primarily the prescription of analgesics, e.g., acetaminophen, which can be toxic to the liver (Black, 1984). Non-steroidal antiinflammatory drugs are commonly used to treat OA, but approximately over $30 \%$ in people taking non-steroidal anti-inflammatory drugs are estimated to experience adverse effects (Pirmohamed et al., 2004). For patients with severe pain the intra articular injection of corticosteroids or hyaluronate is recommended. However, the efficiency of HA injections vary between studies, e.g., Miller et al. (2020) did not report clinical important improvements. Consistent with this are ambivalent results about alternative medical products to treat $O A$ including supplemental glucosamine and chondroitin sulphate, two natural occurring constituents of cartilage proteins (Vasiliadis and Tsikopoulos, 2017). Finally, the use of opioids is limited to extraordinary circumstances due to their adverse side effects. Developers of novel pharmaceutical treatment options strive for therapies with less side effects and a better outcome. The drugs that are currently under investigation can be categorized among others into chondrogenesis inducers, matrix degradation inhibitors, apoptosis inhibitors, and anti-inflammatory cytokines (Zhang et al., 2016).

Another OA intervention strategy is the autologous chondrocyte transplantation to treat cartilage defects. Primarily, a small piece of healthy articular cartilage is collected from the patient. The cartilage is then digested, the chondrocytes isolated and expanded until a sufficient number for reimplantation has been reached. A high number of chondrocytes can be directly injected into the joint or attached to a 
scaffold before implantation. Unfortunately, chondrocytes transplanted into late-stage $O A$ tissue are affected by the degenerative microenvironment resulting in dedifferentiation or apoptosis (Zhang et al., 2016). Furthermore, any surgical intervention that lays open the sterile joint environment increases the risk of infection. Finally, joint replacement is the ultimate means if no function improvement and pain relief could be obtained with the aforementioned interventions. However, hypersensitivities to the prosthesis may occur and moreover, index joint replacement increases the risk for contralateral joint replacement after 5-8 years (Lamplot et al., 2018). Furthermore, periprosthetic joint infection significantly increases the mortality of patients (Zmistowski et al., 2013).

In total, the current treatment options for OA can help to reduce pain and slow down the progress of OA. However, the burden of this disease still severely affects the life quality of patients and finally, for most patients, total joint replacement must take place. Therefore, there is great need for new therapeutic intervention strategies.

\section{Chondrogenic progenitor cells}

One hallmark of $O A$ is the replacement of articular cartilage by the fibrocartilaginous repair tissue of lower quality. Koelling et al. (2009) identified a migrating cell population of fibroblastic phenotype that is distinct from chondrocytes and inhabits late-stage OA cartilage tissue. Furthermore, these cells were reported to be positive for the expression of $\mathrm{COL} 1$ suggesting a role in the formation of the fibrocartilaginous repair tissue. Subsequent characterization of these cells revealed a strong expression of stem cell markers including STRO-1, CD13, CD29, CD44, CD73, CD90, and CD105. However, these cells were not positive for bone marrow-derived stromal cell markers CD271, CD18, or CD31. They can be distinguished from chondrocytes by their fast proliferation activity and increased replication limit, exhibiting senescence only at high passages. Further analysis elaborated their stem cell character, as this cell population successfully differentiated into the chondrogenic, osteogenic and adipogenic lineage. Therefore, these multipotent cells were named chondrogenic progenitor cells (CPCs) and other groups adopted this terminology (Wang et al., 2020, Seol et al., 2012, Matta et al., 2019, Joos et al., 2013). 
The successful in vitro chondrogenic differentiation of the in late-stage OA naturally occurring CPCs resembles a major step in the search of new intrinsic therapeutic interventions. Like in chondrocytes, the major chondrogenic transcription factor SOX9 and the major osteogenic transcription factor RUNX2, play a pivotal role in determining the chondrogenic potential of CPCs (Koelling et al., 2009). SOX9 has broad functions in various cell types, but is primarily known for its essential role in inducing chondrogenesis, including chondrogenic proliferation, maturation and ECM formation (Amano et al., 2009). In humans, heterozygous mutations of SOX9 leads to the skeletal dysmorphology syndrome (Wagner et al., 1994) whereas heterozygous mice SOX9 mutants die prenatally due to skeletal abnormalities (Bi et al., 1999). In addition to the activation of major cartilage markers such as COL2 and ACAN, the expression of two other SOX proteins is triggered by SOX9. SOX5 and SOX6 are needed for chondrocyte development (Smits et al., 2004) and the SOX trio, consisting of SOX5, SOX6 and SOX9, is sufficient to induce chondrogenic differentiation in even non-chondrogenic cells (Ikeda et al., 2004).

The other major regulator of CPC chondrogenesis is the human Drosophila RUNT homolog RUNX2. The expression of RUNX2 is upregulated in osteoblasts, as well as in hypertrophic chondrocytes of the calcified zone. In hypertrophic chondrocytes, RUNX2 induces MMP13 that degrades the cartilaginous markers such as COL2, and upregulates the fibrocartilage marker $\mathrm{COL} 1$ as well as the hypertrophic marker COL10, eventually inducing ossification (Bruderer et al., 2014). The deletion of RUNX2 results in absent or delayed chondrocyte hypertrophy (Kim et al., 1999, Inada et al., 1999), whereas the targeted expression of RUNX2 in non-hypertrophic chondrocytes accelerates their differentiation (Takeda et al., 2001). Mutations of RUNX2 are associated with the cleidocranial dysplasia in humans and mice nullizygous for RUNX2 lack mineralized bone in the skeleton. Furthermore, the distinct mutations associated with the different severity of cleidocranial dysplasia, suggest a strict genetic control of RUNX2 (Zhou et al., 1999).

In summary, CPCs are a unique, multipotent and migratory cell population residing in late-stage $\mathrm{OA}$ tissue. While synthesizing COL1 in situ, they are capable to differentiate into chondrocytes and produce COL2 in vitro. Their chondrogenic potential is determined by the chondrogenic transcription factor SOX9 and the osteogenic transcription factor RUNX2. In order to enhance the CPCs' chondrogenic 
potential, manipulation of these regulators may resemble a crucial step for future therapeutic interventions in OA.

\section{Pro-chondrogenic manipulation of CPCs in vitro}

CPCs are viable as cells of the chondrogenic lineage if they are simply placed in a 3D alginate environment without further chondrogenesis inducing supplementation. Furthermore, CPCs cultured on Matrigel sustained expression of stem cell markers CD29 and CD73. This highlights the role of the ECM on CPCs (Koelling et al., 2009) and in stem cell biology (Fuchs et al., 2004, Bi et al., 2007). The importance of the ECM explains the finding that disturbed cell-matrix interactions is a hallmark of $O A$ (Sandell and Aigner, 2001, Poole et al., 1991, Goldring and Goldring, 2007). Schminke et al. (2016a) reported that the mice lacking the ECM molecule nidogen 2 (NID2) exhibited substantially reduced cartilage proteoglycan content, as well as an increased calcified zone. Furthermore, CPCs cultured with supplemental ECM components NID2 and laminin (LAM) increased the expression of chondrogenic markers such as COL2 while downregulating $C O L 1$ expression. In case of NID2, this pro-chondrogenic effect was linked to TGF- $\beta$ signaling, more specifically, via SMAD2 phosphorylation. Additionally, growth factors were used for direct stimulations of CPCs. TGF- $\beta 3$ in combination with bone morphogenetic protein 6 (BMP6) did not upregulate SOX9 expression, but nevertheless reduced RUNX2 expression. This was accompanied by the upregulation of COL2 as well as the downregulation of MMP13 and COL1 (Koelling et al., 2009).

The prevalence and pathogenesis of $O A$ is influenced by the patient's sex, therefore CPCs were stimulated with sex steroids. Subsequently, an altered expression of SOX9 and RUNX2 as well as their downstream targets was reported. This is of particular interest, as the estrogen and testosterone levels vary according to age and sex (Koelling and Miosge, 2010). Finally, direct manipulation of SOX9 and RUNX2 using RNAi was demonstrated to alter the expression of ECM markers. The knockdown (KD) of RUNX2 increased the chondrogenic potential by elevating the expression of SOX9, COL2 and ACAN. Contrary, the KD of SOX9 reduced RUNX2 and $A C A N$ expression (Koelling et al., 2009). 
In total, the chondrogenic potential of CPCs can be increased by ECM components, growths factors or direct manipulation of the transcription factors SOX9 and RUNX2, and could resemble attractive targets for small molecules in future OA therapies. 


\section{Objectives}

The previous research on CPCs reported their regenerative potential and highlighted the role of CPCs in future OA therapeutic studies. CPCs are usually involved in the formation of the fibrocartilaginous repair tissue in situ, but $3 \mathrm{D}$ in vitro culture induces their chondrogenic differentiation accompanied by the synthesis of articular cartilage proteins. Therefore, we focused on investigating means to activate their intrinsic potential also in situ. The studies conducted in this thesis elucidated how an increase of the chondrogenic potential of CPCs can be achieved that is primarily characterized by the upregulation of SOX9 and its downstream targets, e.g., COL2 and ACAN. The downregulation of RUNX2 is aspired to reduce expression of fibrocartilage marker such as COL1. In theory, this may improve the quality of the repair tissue occurring in OA. Previous research reported that ECM molecules or growth factors influence SOX9 and RUNX2 expression, resulting in altered expression of articular cartilage markers. Furthermore, direct manipulation of SOX9 and RUNX2 influences the expression of ECM molecules related to articular cartilage and its turnover.

The objectives of Chapter I were to histologically localize the ECM molecules BGN, the growths factors TGF- $\beta 3$ and EGF, as well as their receptors in healthy and latestage OA cartilage specimens. Furthermore, if these molecules are present in the cartilage, a potential interaction of BGN with these receptors can be investigated by co-localization and KD experiments in vitro. Finally, the influence of these growth factors on the chondrogenic potential of CPCs must be elucidated by stimulation experiments to determine whether EGF or TGF $\beta 3$ signaling positively affects the expression of chondrogenic markers.

In Chapter II, we aimed to investigate if a KO of RUNX2 via CRISPR/Cas9 further increases the pro-chondrogenic effect observed after KD of RUNX2 in CPCs. Furthermore, we aimed to identify potential co-regulators of SOX9 by pull down and target potential candidates for KO mediated via CRISPR/Cas9 in order to increase the chondrogenic potential of CPCs. Analysis of a potential candidate KO cell line includes chondrogenic marker expression on mRNA and protein level in vitro and in vivo. Moreover, impairing effects of the KO must be excluded by in vivo and in situ studies of the KO cell line's proliferation and migration abilities. This study was designed to investigate the immediate regulatory network of SOX9 and therefore, working around the many modulators in signaling cascades complicating research on signaling events. 


\section{Summary of published papers}

\section{Chapter I}

Chapter I analyzed how the ECM proteoglycan BGN as well as the growth factors TGF and EGF influence the chondrogenic potential of CPCs. The expression of BGN, TGF- $\beta 3$, and EGF as well as of transforming growth factor $\beta$ receptor I (TGFBRI) and EGFR was histologically localized in healthy and articular cartilage, elaborating the relevance of these molecules in OA. Subsequently, first evidence was gathered for different TGF and EGF signaling events in CPCs and chondrocytes. Furthermore, the co-localization of BGN with TGFBRI or EGFR in CPCs was demonstrated, indicating that BGN modulates the signaling of the respective receptor, which was further elaborated performing KD of BGN. Finally, the stimulation of TGF- $\beta 3$ and EGF led to upregulation of both, SOX9 and RUNX2 as well as of chondrogenic, fibrogenic and hypertrophic markers. Although final analysis of ECM protein levels was not specified, the broad stimulation of CPCs using TGF and EGF may be too unspecific for further therapeutic research in CPCs, and a more finetuned modulation is required to upregulate the chondrogenic potential of CPCs.

\section{Chapter II}

Chapter II investigated how the chondrogenic potential of CPCs can be manipulated with the help of co-regulators of SOX9. In the first experiments, a pro-chondrogenic function of RUNX2 was determined, shifting our focus on reducing RUNX2 but not depleting it. Next, the early endosomal marker RAB5C was identified as a potential interaction partner of SOX9 by pull down. The deletion of RAB5C positively enhanced the chondrogenic potential of CPCs, by increasing the COL2 protein level. Furthermore, increased expression of the SOX trio, COLs related to cartilage and ACAN, were observed after the loss of RAB5C. CPCs carrying a KO of RAB5C did not lose the essential abilities of proliferation and ECM synthesis in vivo. Additionally, this cell line invaded late-stage OA cartilage specimen in situ. Finally, our data suggest that the pro-chondrogenic effect after the deletion of RAB5C in CPCs is likely mediated by altered BMP, NOTCH and IL signaling events. 


\section{General discussion}

Osteoarthritis affects all tissues of the joint, but the limited capacity for selfregeneration of articular cartilage is a particular challenge in the search for new therapeutic interventions. The current studies on CPCs reported that this unique cell population possesses the intrinsic potential to differentiate into chondrocytes and produce articular cartilage markers, despite their in situ fibroblastic phenotype. Chapter I and II investigated approaches to increase the chondrogenic potential of CPCs in order to identify targets for future pharmaceutical intervention.

\section{Interactions of CPCs and the ECM}

Chapter I highlighted the role of ECM composition and major signaling pathways on CPCs as reported by Schminke et al. (2016a). This is of particular interest in OA, as the ECM undergoes major alteration by replacing the articular cartilage with fibrocartilage resulting in different modulation of signaling pathways. The expression of the proteins BGN (Embree et al., 2010, lacob and Cs-Szabo, 2010), TGF- $\beta 3$ (Dahlin et al., 2014) and EGF (Nonaka et al., 1999) was previously linked to chondrogenesis. In CPCs, the KD of BGN, a singular ECM molecule, severely affected EGFR abundance, demonstrating the connection of the ECM and cellular receptors. Furthermore, lacob and Cs-Szabo (2010) reported that the incubation with BGN, mimicking the overexpression of BGN observed in OA (Bock et al., 2001), upregulates EGFR expression. Finally, the loss of BGN induces OA in mice (Ameye et al., 2002), which is probably not just due to BGNs involvement in COL fibril organization but also due to altered signaling events. In addition to BGN, a large number of ECM components such as decorin, fibronectin (FINC) and matrilins exist that are linked to signaling events and being differentially expressed in OA cartilage (Sofat, 2009). Considering their function as signaling hubs (Gubbiotti et al., 2017), proteoglycan abundance must be a critical point for the evaluation of repair tissue quality in future therapeutic interventions. The increased proteoglycan synthesis observed in early stages of OA has been interpreted as an insufficient remedy for the general loss of protein content (Goldring and Goldring, 2007, Bock et al., 2001), demonstrating that simple upregulation of cartilage markers cannot stop the progress of $O A$. 
Chapter I depicted the significance of controlled signaling events by highlighting the effects of growth factor stimulation on CPCs. TGF- $\beta 3$ and EGF stimulation increased SOX9, RUNX2, COL1, COL2, COL10 and ACAN, thus chondrogenic and osteogenic marker expression were affected by these growth factors. Contrary, Koelling et al. (2009) reported that stimulation of CPCs using TGF- $\beta 3$ in combination with BMP6 increased COL2 but decreased RUNX2, COL1 and MMP13, despite BMP6 stimulation alone led to severe deposition of COL1 in chondrogenic differentiated adipose-derived stem cells (Diekman et al., 2010). This indicates that specific effects are mediated by the cooperation of different growth factors. The ECM would take major part in this as, e.g., BGN competes with both proteoglycans decorin and fibromodulin for binding of TGF- $\beta$ isoforms (Hildebrand et al., 1994). Thus, a modulation of TGF- $\beta$ signaling occurs by differences in its sequestration into the ECM that functions as a reservoir for growths factors (Macri et al., 2007). During OA the degradation of the ECM floods the joint with TGF- $\beta$ and activates cells that are usually not intensively exposed to these mediators (van der Kraan, 2018).

The ECM and its function are affected by a constant natural remodeling process regulated by MMPs. However, during OA occurs an increased degradation of the ECM. Therapeutic interventions using proteases inhibitors face the problem of selective inhibition to not further unbalance ECM turnover (Goldring and Goldring, 2007). The cleavage of proteoglycans results in neo-epitopes recognized by innate immune system receptors, as seen for BGN. Thus, the increased degradation of the ECM does not just affect the aforementioned signaling events, but eventually leads to an inflammatory response (Nastase et al., 2012). Subsequent degradation events occur, e.g., the inflammatory cytokine IL-1 $\beta$ induced degradation of COL9 that further destabilizes the ECM (Danfelter et al., 2007). This environment resembles an immense challenge for repair attempts and it has to be taken into account that the activation of the intrinsic repair potential of CPCs must overcome the impairing influence of the pathological altered ECM in OA. As seen in autologous chondrocyte transplantation, phenotypic normal chondrocytes undergo apoptosis or dedifferentiate if being placed adjacent to diseased cartilage (Zhang et al., 2016). In addition to pro-apoptotic cytokines and inflammatory mediators released by the surrounding tissue, cell surface molecules such as integrins are involved in chondrocyte apoptosis by binding the pericellular $\mathrm{COL}$ network and providing the 
chondrocyte with pro-survival signals (Zemmyo et al., 2003). Therefore, the expression of these molecules must be investigated.

Taken together, the function of the ECM in articular cartilage is not just limited to providing the tissues properties, but it also represents a signaling network. Therapeutic interventions counteracting OA should upregulate cartilage markers in a controlled manner to avoid adverse effects. Furthermore, the OA cartilage itself has impairing functions on the residing cells that must be overcome.

\section{Direct manipulation of CPCs to enhance the chondrogenic potential}

Chapter I demonstrates the complex network of proteoglycans, growth factors and their mediators. Therefore, simple stimulation with mediators of chondrogenic signaling pathways or utilizing blocking antibodies for their receptors may not be a feasible approach for improving OA. Thus Chapter II was designed to further elucidate ways to increase the chondrogenic potential of CPCs in a simpler manner. As reported by Koelling et al. (2009), direct manipulation of the regulators SOX9 and RUNX2 using RNA interference (RNAi) altered the expression of ECM markers and turnover enzymes. The CRISPR/Cas9 mediated knockout (KO) of RUNX2 in CPCs was indented to boost the chondrogenic effect observed after KD of RUNX2. The decreased deposition of COL1 and COL2 in CPCRUNX2-/ was independent of the SOX9 level, indicating that a minimal amount of RUNX2 is important for COL2 deposition. Interestingly, RUNX2 is an upstream activator of MMP13 that degrades both COL1 and COL2. However, the loss of RUNX2 has been accompanied by reduction of MMP13 rather than an increased expression level. Previously, the reduced expression of MMP13, COL2 and ACAN in mice after the loss of RUNX2 was linked to altered Indian hedgehog $(\mathrm{IHH})$ signaling (Liao et al., 2019a), a signaling pathway that connects chondrogenesis with osteogenesis (Chung et al., 2001). Therefore, one can assume that the minimal amount of RUNX2 is necessary to sustain pro-chondrogenic $\mathrm{IHH}$ signaling, while simultaneously pro-osteogenic traits become suppressed as reported by Koelling et al. (2009). Pro-chondrogenic $\mathrm{IHH}$ signaling was also impaired in a RAB23 KD (Yang et al., 2008). In Chapter II, we identified RAB23 as well as RAB5C and RAB2A as potential co-regulators of SOX9 by performing SOX9-His pull down. Moreover, ECM molecules linked to chondrogenesis including FINC (Kalkreuth et al., 2014), agrin (AGRN) (Eldridge et 
al., 2016) and LAMs (Schminke et al., 2016a) were detected using this approach. To our knowledge, no literature is available describing a direct interaction of these proteins with SOX9 under physiological conditions. Aiming to identify potential targets for a pharmaceutical OA intervention, RAB5C was chosen for further investigation because it was previously linked to EGF signaling (Miaczynska et al., 2004). RAB proteins are involved in vesicular trafficking and were previously targeted in treatment of diseases including osteoporosis (Russell, 2007, Coxon et al., 2005). RAB5C might be involved in the transport of SOX9 leading to its degradation or nuclear localization under physiological conditions. However, no additional literature is available that confirms this hypothesis and SOX9 staining using ICC did not reveal altered cellular

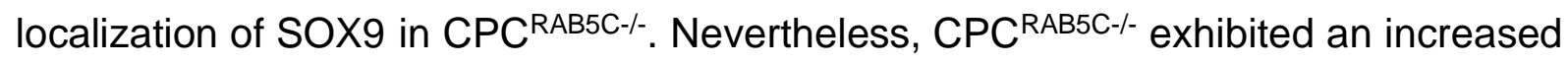
chondrogenic potential, characterized by increased SOX9 expression and COL2 deposition despite no significant reduction of RUNX2 protein level. The observed upregulation of COL9A2, COL11A1 and ACAN during in vitro chondrogenic differentiation is essential to antagonize their increased degradation in OA. In the next step, future research needs to confirm the protein level in vitro and in vivo. Chapter II investigated how the in CPC ${ }^{\text {RABSC-- }}$ observed pro-chondrogenic effect may be mediated and demonstrated that bone morphogenetic protein receptor type $1 B$ (BMPR1B), SMAD7, NOTCH3 and interleukin 4 receptor (IL4R) were downregulated after the loss of RAB5C. These candidates discussed in Chapter II, but it should be considered that their simultaneous downregulation might affect the chondrogenic potential of CPCs differently than the single deregulation of each candidate alone.

The final questions to address are the quality of the secreted ECM and how the inflammatory OA environment affects the CPCs, in order to confirm RAB5C as a potential target for future $O A$ therapies. As stated before, in addition to crude synthesis, the fibrillation, organization and turnover of COLs is essential for an increased repair tissue quality and regulated amongst others by proteoglycans and

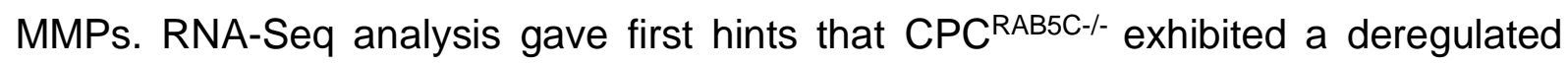
expression of, e.g., MMP13 that may influence $\mathrm{COL}$ organization. Also the deposition of COL1 remained unchanged after the loss of RAB5C, what is likely to influence the organization of other COLs and signaling events, e.g., mediated by integrins (Boraschi-Diaz et al., 2017) and discoidin domain receptor tyrosine kinases (Schminke et al., 2014). Furthermore, the downregulation of several $I L(R) s$ in CPCRAB5C- - may alter the response of CPCRAB5C- - towards inflammatory and 
apoptotic signals. If CPC ${ }^{\text {RAB5C-I- }}$ exhibits signs of an increased resistance against the OA environment, complementary anti-inflammatory drugs and apoptosis inhibitors may still be indicated. The hitherto gathered evidence from the in vivo and ex vivo experiments indicates that despite the deregulation of numerous genes involved in vital processes, neither proliferation nor ECM synthesis was deteriorated in $\mathrm{CPC}^{\mathrm{RAB5C}-}-$. In addition, in vivo migration was not altered in $\mathrm{CPC}^{\mathrm{RAB5C}-{ }^{-} \text {, which may }}$ be important, as the origin of CPCs remains unknown. One theory proposes that CPCs derive from bone marrow stromal cells and migrate into the cartilage via blood vessels through breaks of the tidemark occurring in late-stage OA. CPCs are positive for bone marrow stromal cell markers CD44, CD73, CD90 and CD105 but exhibit only a low level of STRO-1 and were negative for CD18, CD31 and CD271 (Koelling et al., 2009). On the other hand, CPCs could derive from dedifferentiated chondrocytes of chondrocyte clusters occurring in OA (Schminke et al., 2016a). In both cases, CPCs need to migrate from their place of origin into the OA cartilage to reach and improve the quality of the entire tissue.

In summary, chondrogenic differentiated CPC ${ }^{\text {RABSC-I- }}$ displayed an increased deposition of COL2 and an increased expression of numerous chondrogenic markers. Under consideration of the essential role of the ECM, further research must investigate the protein level of these markers and the resulting repair tissue quality. Finally, the performance of CPC RABSC-- in the impairing $O A$ environment will be a crucial step to evaluate RAB5C as target for research on future therapeutic $O A$ interventions. 


\section{Conclusion and outlook}

This thesis contributed to the scientific field of OA research by further investigating how the chondrogenic potential of CPCs can be manipulated in hindsight of future OA therapies. The ECM does not only provide the tissue with its properties, but also plays a pivotal role in cell signaling events, and regulates differentiation. Consistent with this is the complex crosstalk between CPCs, which synthesize the ECM, and the ECM that modulates signaling events influencing the CPCs. Comparing CPCs and chondrocytes, differences in expression of major osteochondrogenic pathway receptors TGFRI and EGFR were confirmed and probably contribute to the CPCs differentiation potential. CPCs reacted to stimulation of these receptors' main ligands TGF- $\beta 3$ and EGF, further corroborating the evidence that TGF and EGF signaling plays a significant role in CPCs during OA. Furthermore, a fibrocartilaginous repair tissue replaces the articular cartilage in late-stage $O A$. As reported by previous research and in this work, the ECM composition affects, among others, the investigated signaling pathways. In total, the complex connection between the ECM and major signaling pathways, as well as the ECM remodeling process during the progression of $\mathrm{OA}$, argue against a simple intervention by targeting a single receptor or its ligand. Chapter I analyzed how the manipulation of a single molecule of this complex regulatory network eventually results in substantial changes of the CPCs' differentiation potential. Targeting potential co-regulators of the major chondrogenic transcription factor SOX9 proved to be a more attractive approach as demonstrated by the analysis of the CPC RAB5C-/ cell line in the Chapter II. The increased COL2 deposition and upregulation of additional chondrogenic markers resembled the first hallmark of our in vitro studies. Subsequent in vivo experiments confirmed RAB5C as a candidate for future research. Limitations of Chapter II are the missing analyses of the protein levels and a full investigation on the underlying mechanism of the prochondrogenic effect resulting from the deletion of RAB5C. Furthermore, it must be

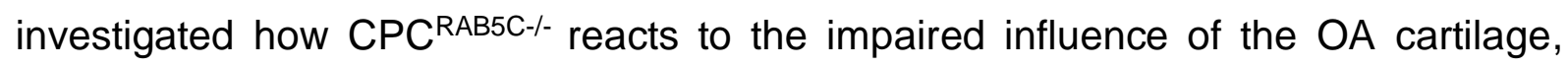
e.g., the inflammation load, and if this affects the ability to secrete a repair tissue of higher quality.

The total effect of a therapeutic activation of CPCs is hard to estimate, as OA is a systemic disease of the joint, and next to the fibrocartilage, other tissues are involved in OA pathology. Therefore, the activation of repair processes by CPCs must be accompanied using other non-pharmacological and pharmacological interventions. 
The observed decrease of cytokine related genes after deletion of RAB5C could affect the CPCs inflammatory response. A possible therapeutic intervention targeting RAB5C in CPCs could lead to a reduction of inflammatory cytokines secreted by CPCs and subsequently, this may reduce or retard the activation of the synovium, resulting in an overall reduction of systemic inflammation. The increased synthesis of articular cartilage markers and the organization of the ECM will finally determine whether this repair tissue is more capable to resist to the compressive stress than the naturally occurring fibrotic repair tissue. As no alteration was observed in COL1 deposition after the loss of RAB5C, it seems unlikely that this improved repair tissue will not exhibit signs of fibrosis. Nevertheless, an improved repair tissue may have a severe personal and socioeconomical impact, by slowing down the progression of $\mathrm{OA}$ and reducing the years lived with disability. 


\section{Chapter I}

The influence of TGF-B3, EGF and BGN on SOX9 and RUNX2 expression in human chondrogenic progenitor cells

The following chapter was published in the Journal of Histochemistry \& Cytochemistry.

J Histochem Cytochem. 2019 Feb; 67(2): 117-127.

Published online 2018 Nov 15. doi: 10.1369/0022155418811645

\section{Authors}

Jerome Nicolas Janssen ${ }^{a *}$, Sarah Batschkus ${ }^{b *}$, Stefan Schimmel ${ }^{a}$, Christa Bode ${ }^{a}$, Boris Schminke ${ }^{c}$, Nicolai Miosge $e^{a, d}$

aUniversity Medical Center, Tissue Regeneration Work Group, Department of Prosthodontics, Robert-Koch-Straße 40, 37075 Goettingen, Germany

bUniversity Medical Center, Department of Orthodontics, Robert-Koch-Straße 40, 37075 Goettingen, Germany

'University Medical Center, Department of Oral and Maxillofacial Surgery, RobertKoch-Straße 40, 37075 Goettingen, Germany

dCorresponding author: nmiosge@gwdg.de, +495513933927

* equal contribution

\section{Autor contributions}

Jerome Nicolas Janssen: Study conception, study design, analyses and interpretation of data, figure preparation, manuscript preparation, and statistical analyses; Sarah Batschkus: Study design, analyses and interpretation of data, figure preparation, manuscript preparation, and statistical analyses; Boris Schminke: Manuscript preparation; Stefan Schimmel: Acquisition of data, analyses and interpretation of data; Christa Bode: Acquisition of data; Nicolai Miosge: Study conception, study design, interpretation of data, and manuscript preparation. 


\section{Co-Author release form}

For the publication entitled "The Influence of TGF- $\beta 3$, EGF, and BGN on SOX9 and RUNX2 Expression in Human Chondrogenic Progenitor Cells".

Jerome Janssen has my permission to include material, which was accepted for publication, of which I was co-author, in his doctoral dissertation.

Jerome Nicolas Janssen*, Sarah Batschkus*, Stefan Schimmel, Christa Bode, Boris Schminke, and Nicolai Miosge

"The Influence of TGF- $\beta 3$, EGF, and BGN on SOX9 and RUNX2 Expression in Human Chondrogenic Progenitor Cells"

* These authors contributed equally

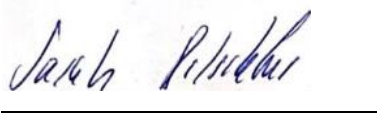

Sarah Batschkus 


\begin{abstract}
Osteoarthritis $(\mathrm{OA})$ is the most common chronic joint disease and leads to the degradation of the extracellular matrix by an imbalance between anabolic and catabolic processes. TGF- $\beta 3$ and EGF influence the osteochondrogenic potential of chondrocytes. In this study, we compared the expression of mediators and receptors in the TGF- $\beta 3$ and EGF pathways, as well as biglycan (BGN), in healthy and diseased chondrocytes. Furthermore, we used chondrogenic progenitor cells (CPCs) for in vitro stimulation and knockdown experiments to elucidate the effects of TGF- $\beta 3$ and EGF on the chondrogenic potential. Our results demonstrate that the expression of TGFBRI and EGFR is altered in diseased chondrocytes as well as in CPCs. Moreover, TGF- $\beta 3$ and EGF stimulation influenced the expression levels of BGN, SOX9 and RUNX2 in CPCs. Therefore, changes in TGFBRI and EGFR expression likely contribute to the degenerative and regenerative effects seen in late stages of OA.
\end{abstract}




\subsection{Introduction}

Arthritis is projected to affect 78.4 million US adults by 2040 (Hootman et al., 2016). The most common type is osteoarthritis (OA), and its prevalence rises with age, thus affecting a majority of individuals over the age of 65 (Dahaghin et al., 2005). OA is characterized by cartilage breakdown and results in joint failure (Buckwalter and Mankin, 1998a, Horton et al., 2006). To date, therapeutic interventions can alleviate symptoms but cannot cure the disease (Buckwalter and Mankin, 1998a).

One novel strategy is the activation of intrinsic reparative cells (Schminke and Miosge, 2014). A migratory population of chondrogenic progenitor cells (CPCs), which exhibit pluripotent capacities, was identified in the late-stage of OA (Koelling et al., 2009). Like chondrocytes, CPCs are embedded in an extracellular matrix (ECM) containing collagens, proteoglycans and glycoproteins (Bock et al., 2001, Koelling et al., 2009, Miosge et al., 1998). The pericellular matrix, the innermost part, is important for signal transduction (Eggli et al., 1985). Investigations suggest that altered cell-matrix interactions lead to the upregulation of the MMP-13 in chondrocytes (Xu et al., 2005). Furthermore, pericellular matrix proteins, such as agrin, laminin and nidogen, were found to enhance chondrogenesis by upregulating SOX9 (Schminke et al., 2016a, Eldridge et al., 2016). Biglycan (BGN) is a small leucine-rich proteoglycan that interacts with members of the transforming frowth factor $\beta 3$ (TGF- $\beta 3$ ) pathway (Embree et al., 2010, Hara et al., 2017), as well as with members of the epidermal growth factor (EGF) pathway (lacob and Cs-Szabo, 2010), and binds to mediators and receptors to increase its activity (Nastase et al., 2012). The TGF- $\beta 3$ and EGF signaling pathways are both known to influence the differentiation of chondrocytes (Nonaka et al., 1999, Dahlin et al., 2014). Furthermore, BGN-deficient mice exhibit an OA phenotype and increased cartilage degradation (lacob and Cs-Szabo, 2010). Additionally, BGN was upregulated in latestage OA tissues, where it might compensate for the general loss of proteoglycans (Bock et al., 2001).

In this study, we investigated if the ECM molecule BGN, as well as the TGF- $\beta 3$ and EGF signaling pathways, affect the chondrogenic differentiation of CPCs. 


\subsection{Material and methods}

\subsubsection{Cell culture}

CPCs cartilage samples were histopathological classified according to the Osteoarthritis Research Society International (OARSI) standards (Pritzker et al., 2006) and prepared as described elsewhere (Koelling et al., 2009). Briefly, we utilized samples from the lateral condyle of knee joints that were collected from a region directly adjacent to the main defect with grade 4.0 to 4.5 (Pritzker et al., 2006). The respective area is depicted in the Supplemental Figure S1 of Koelling et al. (2009). The samples derived from the deep and middle zones exhibiting chondrocyte clusters and deep surface fissures (Mankin grade IV). The patients [ $\mathrm{n}=15$ (7 males and 8 females)] with a mean age of 67.1 (range, 44 to 85 ) years met the American College of Rheumatology classification for OA (Altman et al., 1986) and gave their written informed consent, consistent with the ethical regulations of our institution. Healthy specimens from three accident victims revealed macroscopically and histologically intact hyaline cartilage with a smooth surface, and all of the layers were visible and corresponded to an ORSI grade of 0 to 1 . These healthy specimens were also taken from the lateral condyle of knee joints to match the OA samples.

\subsubsection{Cell culture}

CPCs (241ht cell line) were cultured (Koelling et al., 2009) and cultivated under standard conditions at $37^{\circ} \mathrm{C}$ and $5 \% \mathrm{CO}_{2}$. Three-dimensional culture was performed as described elsewhere (Koelling et al., 2009).

\subsubsection{Immunohistochemistry (IHC) and immunocytochemistry (ICC)}

Primary antibodies were applied in the following concentrations: BGN, 1:100, polyclonal rabbit H-150, sc-33788 (IHC); BGN, 1:100, monoclonal mouse 3E2, sc100857 (ICC); EGF, 1:100, polyclonal rabbit Z-12:sc-275; EGFR, 1:100, polyclonal rabbit 1005:sc-03; TGFBRI, 1:100, polyclonal rabbit (V-22):sc-398; TGF-ß3, 1:100, polyclonal rabbit V:sc-82; all from Santa Cruz (Heidelberg, Germany). For IHC, a HiDef Detection ${ }^{\text {TM }}$ Alk Phos Polymer System (962D, Cell Marque, Rocklin, California) with PermaRed/AP-Auto (K049-Auto, Cell Marque) was applied. Polyclonal donkey anti-rabbit Alexa Fluor 555, ab150074, 1:500 (Abcam, Cambridge, UK) and polyclonal goat anti-mouse DyLight 488, 072-03-18-06, 1:500 (KPL) secondary antibodies were applied for ICC. 


\subsubsection{Cell isolation}

To obtain chondrocytes from healthy (CC-H) and diseased cartilage (CC-D), tissue samples from the deep zones of $5-10 \mathrm{~mm}^{3}$ were treated with $10 \mathrm{mg}$ of collagenase type I (17100-017, Gibco, Karlsruhe, Germany) and $10 \mathrm{mg}$ of collagenase type II (C6885-1G, Sigma-Aldrich, Steinheim, Germany) in $10 \mathrm{~mL}$ of medium for $6 \mathrm{~h}$ at $37^{\circ} \mathrm{C}$. The suspension was filtered, and the cells were distributed into cell culture flasks. In the case of CPCs, a standard explant protocol was performed (Koelling et al., 2009).

\subsubsection{Real-time polymerase chain reaction (RT-PCR)}

RNA was isolated using the QIAshredder (79654, Qiagen, Hilden, Germany) and RNeasy Plus Mini Kit (74134, Qiagen) following the manufacturer's instructions, and the QuantiTect Reverse Transcription Kit (205313, Qiagen) was used to synthesize cDNA. Primers were designed with Primer3web 4.0.0 (Untergasser et al., 2012) and ordered from Eurofins MWG Operon. PCR was performed by an Eppendorf RealPlex ${ }^{2}$ system in a total volume of $10 \mu \mathrm{L}$ with $5 \mu \mathrm{L}$ of SYBR Green qPCRSuperMix-UDG (KK4600, Invitrogen, Darmstadt, Germany). Determination of the relative mRNA ratio was performed (Pfaffl, 2001) using $\beta_{2}$ microglobulin for normalization. The products were sequenced (SeqLab, Goettingen, Germany) and verified using the NCBI library. Primers were ordered from Eurofin Genomics (Ebersberg, Germany). The primers used were as follows: ACAN fw, 5' ACAGCTGGGGACAT; ACAN rev, 5' GTGGAATGCAGAGG; BGN fw, 5' AATGAACTCCACCTAGACCACAA; BGN rev, 5' GATGTTGTTGGAGTG CAGATAGAC; COL1 fw, 5' TTCCCCCAGCCACAAAGAGTC; COL1 rev, 5' CGTCA TCGCACAACACCT; COL2 fw, 5' CTCCTGGAGCATCTGGAGAC, COL2 rev, 5' ACCACGATCACCCTTGACTC; COL10 fw，5' GCTAAGGGTGAAAGGGGTTC; COL10 rev, 5' CTCCAGGATCACCTTTTGGA; EGFR fw, 5' CGACAGCTATGAGATG GAGGA; EGFR rev, 5' GATCCAGAGGAGGAGTATGTGTG; RUNX2 fw, 5' TTCCAGACCAGCAGCACTC; RUNX2 rev, 5' CAGCGTCAACACCATCATT; SOX9 fw, 5' CAGGCTTTGCGATTTAAGGA; SOX9 rev, 5' CCGTTTTAAGGCTCAAGGTG; TGFBRI fw, 5' AACCTGCTCTCCTGCTTGCT; TGFBRI rev, 5' CTCCCTTCCACCT CTAATGACTGA. 


\subsubsection{TGF-B3 and EGF stimulation}

CPCs were cultured in $3 D$ alginate for $3 \mathrm{~d}$ before stimulation with $2 \mathrm{ng} / \mathrm{mL}$ of TGF- $\beta 3$ (T5425, Sigma-Aldrich) or using 10, 20 or $40 \mathrm{ng} / \mathrm{mL}$ of hrEGF (354052, BD Science, Heidelberg, Germany) for $24 \mathrm{~h}$. Costimulation was performed with $2 \mathrm{ng} / \mathrm{mL}$ of TGF$\beta 3$ and $10 \mathrm{ng} / \mathrm{mL}$ of hrEGF. For the detection of SOX9 protein, cells were stimulated with $10 \mathrm{ng} / \mathrm{mL}$ of hrEGF and additional $10 \mathrm{ng} / \mathrm{mL} \mathrm{hrEGF}$ for $4 \mathrm{~h}$ before harvesting.

\subsubsection{Immunoblotting}

Protein amounts were determined by SDS-PAGE and Western blotting (WB) using PVDF membranes. TBS-T was used for washing and $5 \%$ milk powder in TBS-T for blocking. Primary antibodies were diluted [BGN: 1:1000, polyclonal rabbit $\mathrm{H}-150$, sc33788 (Santa Cruz); EGFR: 1:1000, polyclonal rabbit 1005:sc-03 (Santa Cruz); pSMAD2: 1:500, polyclonal rabbit \#3101 (Cell Signaling, Leiden, Netherlands); RUNX2: 1:2000, polyclonal rabbit ab23981 (Abcam); SOX9: 1:2000, monoclonal mouse H00006662-M02 (Abnova, Heidelberg, Germany)] and incubated overnight. Secondary antibodies were diluted [Polyclonal goat anti-mouse A 9917, 1:40000 (Sigma-Aldrich) and Polyclonal goat anti-rabbit, A 0545, 1:100000 (Sigma-Aldrich)] and incubated for $1 \mathrm{~h}$. WesternBright ${ }^{\mathrm{TM}}$ Sirius (K-12043-D20, Biozym, Hess. Oldendorf, Germany) and WesternBright ${ }^{\mathrm{TM}}$ ECL (K-12045-D20, Biozym) were used for detection, and evaluation was performed with ImageJ Software (Version 1.07) with a-tubulin (T6199, 1:10000, Sigma-Aldrich) for normalization (Gassmann et al., 2009).

\subsection{8 siRNA Knockdown}

Cells $\left(5 \times 10^{5}\right)$ were transfected with $10 \mu \mathrm{mol} / \mathrm{mL}$ BGN siRNA (SR300431; OriGENE Technologies, Herford, Germany) via the Human MSC Nucleofector Kit (VAPE-1001, Lonza, Basel, Switzerland) using program U-23 of Nucleofector ${ }^{\mathrm{TM} I I}$ (Lonza). Scrambled AllStars-negative siRNA (102784, Qiagen) was used as a negative control. Cells were cultured in $2 \mathrm{D}$ for $3 \mathrm{~d}$.

\subsubsection{Statistical analysis}

SPSS version 13.0 was used (IBM, Ehningen, Germany). qPCR was performed with at least $n=6$ and WB with $n=3$ samples. The Shapiro-Wilk test was used to test for normality of distribution, and two-tailed one-sample t-tests were used for significance. 
Bars show the mean \pm SD change compared to the untreated control (set as 1$)$. ${ }^{*} \mathrm{p}<$ 0.05 . 


\subsection{Results}

\subsubsection{Detection of the key players}

Initially, we localized BGN, which influences TGF- $\beta 3$ and EGF signaling by interacting with cell surface receptors. Changes in BGN expression during $O A$ might play a role in disease progression due to altered interactions with these signaling pathways. Occurrence of BGN was confirmed by $I H C$ in healthy (Fig. 1.1A) and diseased (Fig. 1.1B) cartilage samples. In the next step, we localized TGFBRI and EGFR by IHC. The diseased tissue sample lacks the superficial zone (SZ), thus we localized TGFBRI (Fig. 1.1C-E) and EGFR (Fig. 1.1F-H) staining of chondrocytes residing in the diseased tissue (CC-D) only in the middle (MZ) and deep zones (DZ). We found that TGFBRI expression in the CPCs was significantly increased (Fig. 1.11). Contrary to this, EGFR expression was reduced in CC-D and was even less in the CPCs (Fig. 1.1J).

To further investigate a possible interaction between BGN and both receptors, we performed an ICC double staining in vitro. In both cases, we observed BGN together with either TGFBRI (Fig. 1.2A-D) or EGFR (Fig. 1.2E-H), which might indicate a colocalization of $B G N$ with these receptors.

After detecting the altered receptor expression in $O A$, we investigated the distribution of TGF- $\beta 3$ and EGF in healthy and diseased cartilage (Fig. 1.3). TGF- $\beta 3$ was expressed in healthy (Fig. 1.3A) and OA cartilage specimens (Fig. 1.3B), including the middle (Fig. 1.3C) and deep (Fig. 1.3D) zones. Also, EGF was expressed in healthy (Fig. 1.3E) and diseased cartilage (Fig. 1.3F). Representative IHC images of the middle zone and deep zone in diseased cartilage are shown in Fig. 1.3G and Fig. $1.3 \mathrm{H}$, respectively.

\subsubsection{TGF-B3, EGF and BGN affect osteochondrogenic marker expression}

TGF-B3, a mediator of one of the major signaling cascades for chondrogenic differentiation, has been recently described as having a pro-chondrogenic effect in developing cartilage but turns into a major pathological effector in OA (van der Kraan, 2017). Furthermore, the influence of the EGF signaling cascade exhibits positive (Shepard et al., 2013) and negative effects (Nonaka et al., 1999) on chondrogenesis. In the following experiments, we investigated the role of TGF-B3, EGF and BGN on CPCs. We considered $2 \mathrm{ng} / \mathrm{mL}$ TGF-B3 and $10 \mathrm{ng} / \mathrm{mL}$. High concentrations of EGF may inhibit cell growth (Kaplan et al., 1990) and EGFR signaling is linked to terminal 
A

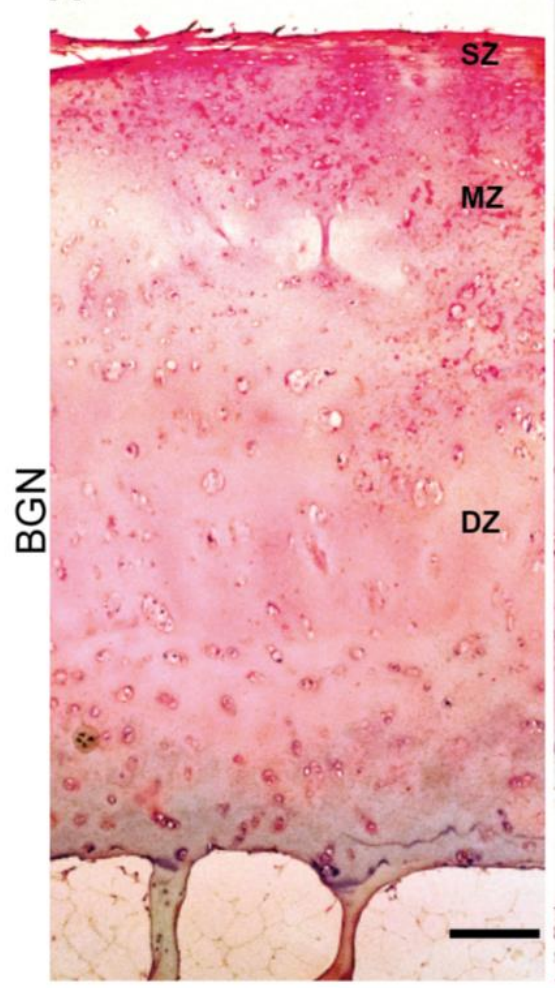

$M Z$

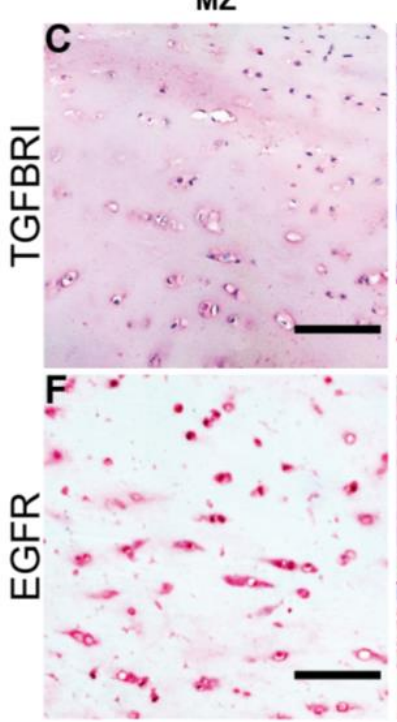

B

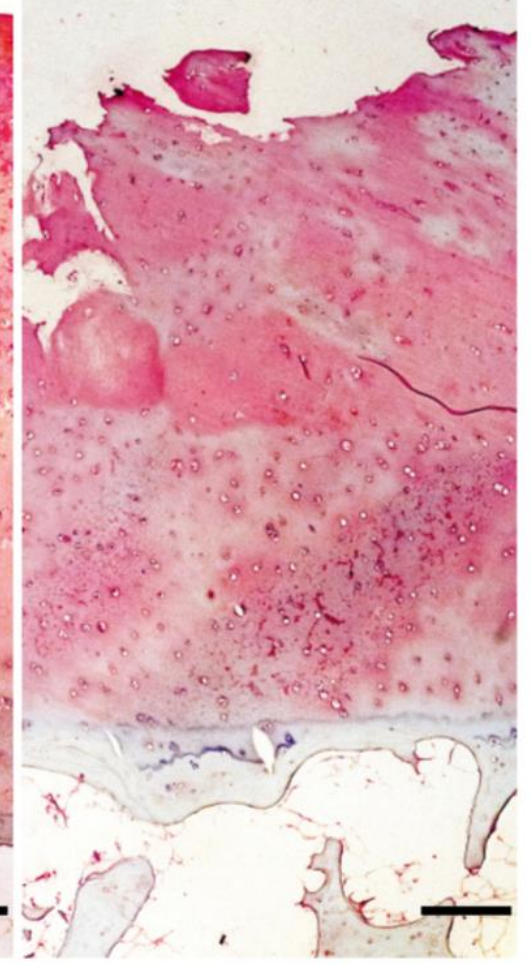

DZ

E
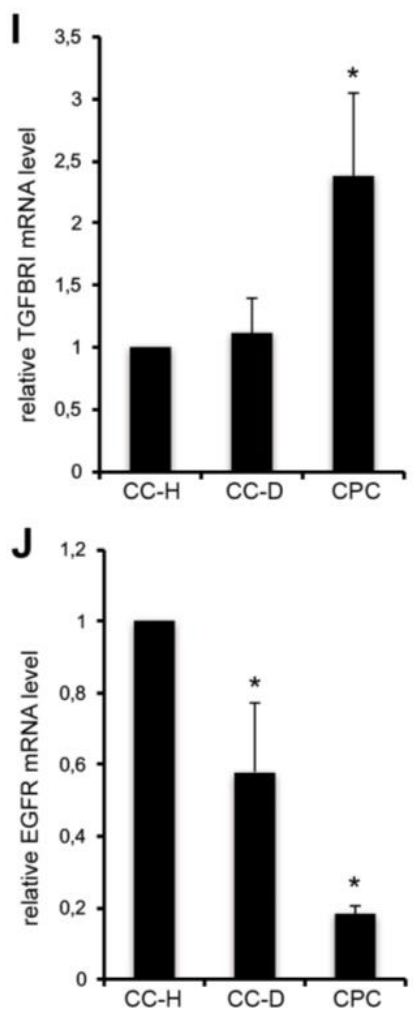

Figure 1.1: Detection of BGN, TGFBRI and EGFR. Staining of BGN in (A) healthy tissue and (B) latestage OA tissue. CC-D exhibited positive IHC staining of TGFBRI in the (C) middle and (D) deep zones. (E) Membranous staining of TGFBRI in CC-D. EGFR staining of CC-D residing in the middle $(F)$ and deep (G) zones. (H) Membranous staining of EGFR in CC-D. Relative expression levels of (I) TGFBRI and (J) EGFR mRNA in CC-D and CPCs compared to in CC-H. Abbreviations: $\mathrm{SZ}=$ superficial zone; $M Z$ = middle zone; $D Z$ = deep zone; $C C-D=$ chondrocytes residing in diseased tissue; $\mathrm{CC}-\mathrm{H}$ chondrocytes residing in healthy tissue. Arrows indicate duplication of the tidemark. Scale bar in A and B: $750 \mu \mathrm{m}$. Scale bar in C, D, F and G: $150 \mu \mathrm{m}$. Scale bar in E and H: $75 \mu \mathrm{m}$.

differentiation and apoptosis in chondrocytes (Zhang et al., 2013).

Stimulation with TGF- $\beta 3$, EGF or the combination of both increased TGFBRI, SMAD2, EGFR and BGN expression (Fig. 1.4A). Next to the upregulation of SMAD2, 


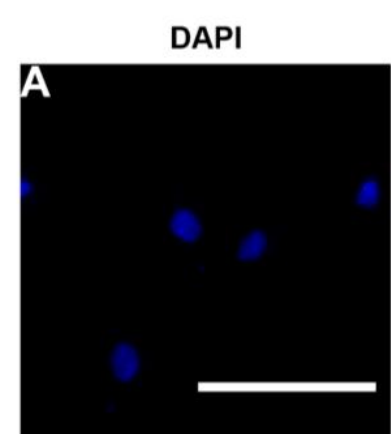

DAPI

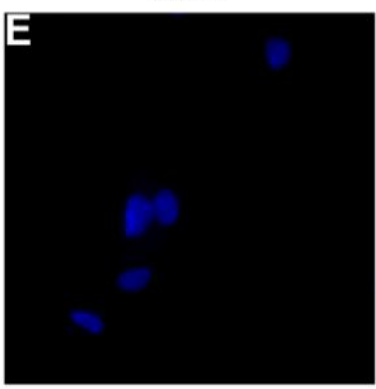

BGN

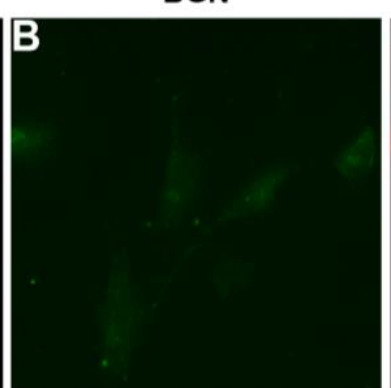

BGN

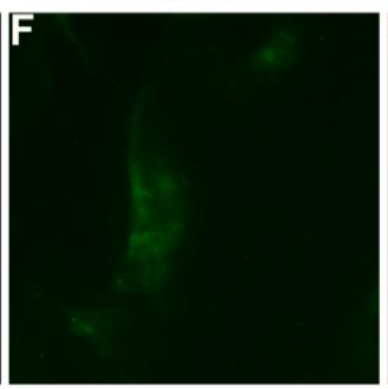

TGFBRI

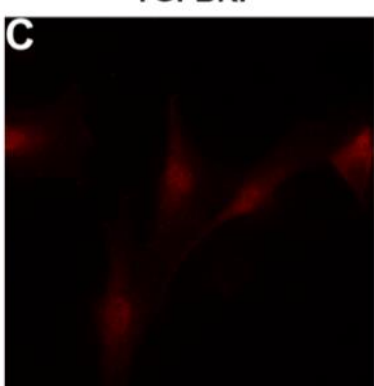

EGFR

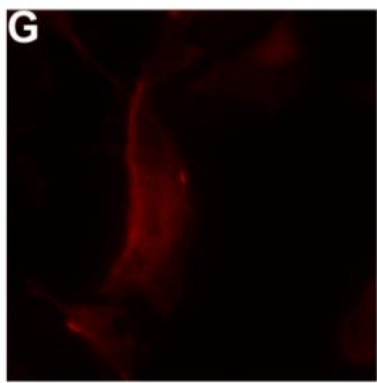

Merge

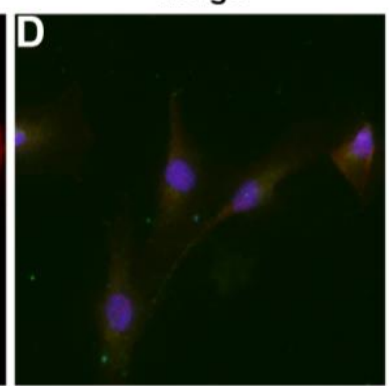

Merge

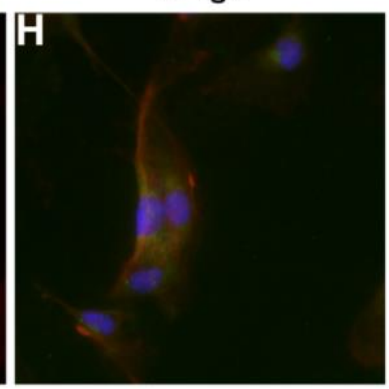

Figure 1.2: CPCs were stained for TGFBRI and EGFR by ICC. (A and E) Nuclei were stained with DAPI. (B and F) Staining of BGN. (C) TGFBRI signal. (D) Colocalization of BGN and TGFBRI. (G) EGFR signal. (H) Colocalization of BGN and EGFR. Scale bar: $75 \mu \mathrm{m}$

we detected that TGF- $\beta 3$ stimulation led to SMAD2 phosphorylation (Fig. 1.4B) that also has been described for chondrocytes (van der Kraan, 2017). The upregulation of $B G N$ is in strong agreement with BGN upregulation of Mg-63 cells after TGF- $\beta 3$ treatment (Heegaard et al., 2004). Furthermore, we demonstrated that BGN knockdown decreased the amount of EGFR (Fig. 1.4C and Fig. 1.4D). SOX9 and RUNX2 are the master regulators of CPC osteochondrogenesis (Koelling et al., 2009). Therefore, we investigated the effect of TGF- $\beta 3$ and EGF stimulation on their expression level. As the previous stimulation with $10 \mathrm{ng} / \mathrm{mL}$ EGF resulted in only a minor increase of BGN, we also varied the stimulation dose up to $40 \mathrm{ng} / \mathrm{mL} E G F$. We found that both TGF- $\beta 3$ and EGF strongly enhanced SOX9 expression (Fig. 1.4E). Furthermore, RUNX2 was also increased, except that stimulation via $40 \mathrm{ng} / \mathrm{mL}$ of EGF left RUNX2 unchanged. This may be due to cell toxicity of the increasing EGF concentration. Furthermore, the combined stimulation of TGF- $\beta 3$ and EGF strongly increased RUNX2 expression. The expression of SOX9 is the strongest indicator for chondrogenesis, therefore we wanted to investigate if the increased mRNA level of SOX9 is capable to increase the protein level. We chose to stimulate cells with only $10 \mathrm{ng} / \mathrm{mL}$ EGF, as we have shown that RUNX2 expression was only slightly upregulated under this concentration of EGF. Moreover, to avoid any cytotoxic effects, but to obtain a strong pro-chondrogenic affect, after 24 hrs of EGF stimulation, 

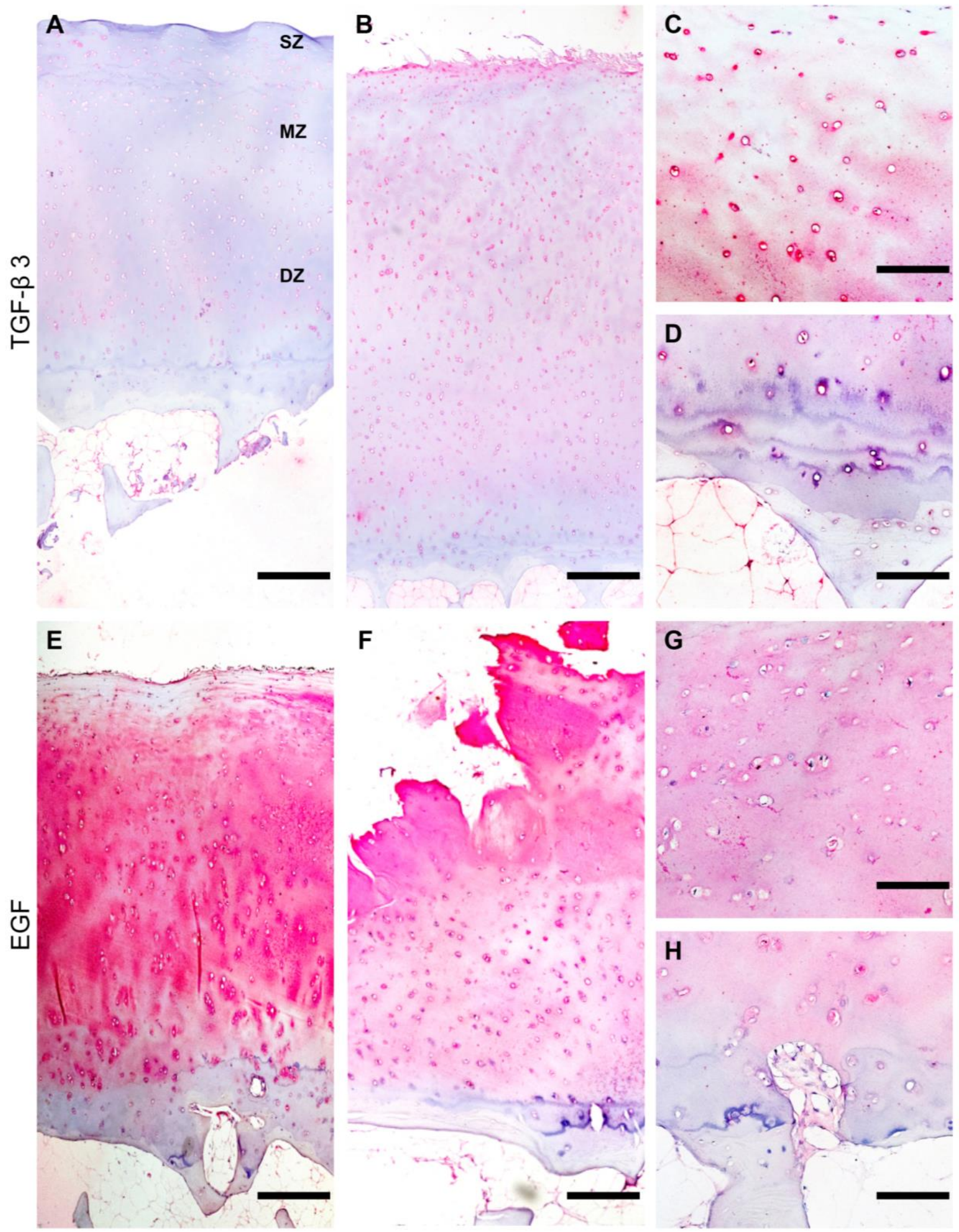

Figure 1.3: TGF- $\beta 3$ and EGF expression by IHC. Staining of TGF- $\beta 3$ in (A) healthy and (B) diseased cartilage. Higher magnification of the $M Z(C)$ and $D Z(D)$ of diseased cartilage. EGF was found in healthy $(E)$ and diseased $(F)$ cartilage. EGF immunohistology of diseased cartilage $M Z(G)$ and $D Z$ $(H)$. Abbreviations: $S Z$ = superficial zone; $M Z$ = middle zone; $D Z$ = deep zone. Scale bar in $A, B, E, F$ : $750 \mu \mathrm{m}$. Scale bar in C, D, G and H: $150 \mu \mathrm{m}$. 
A

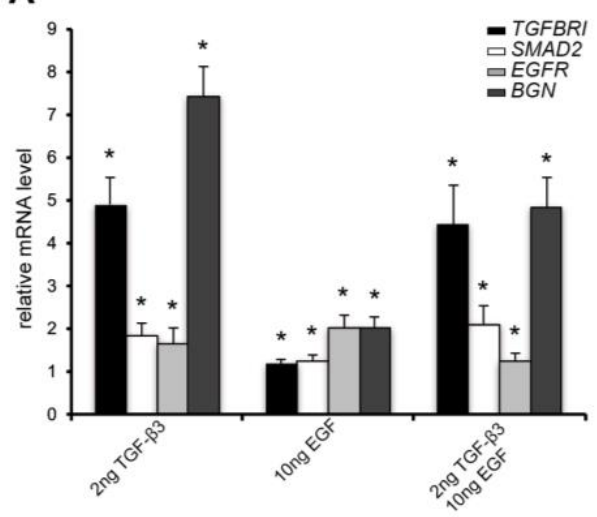

$\mathbf{E}$

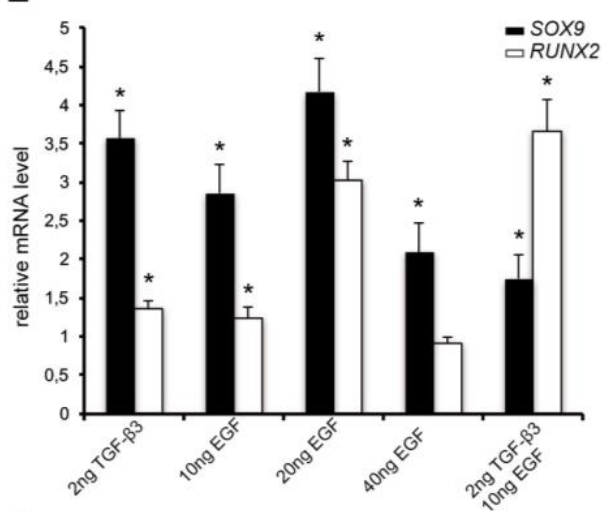

$\mathbf{H}$

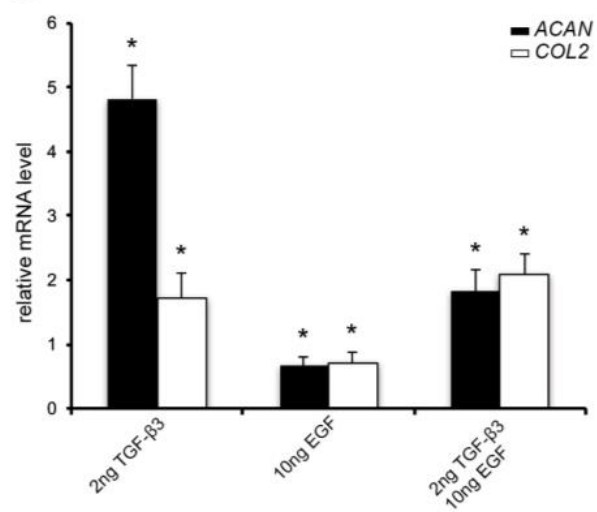

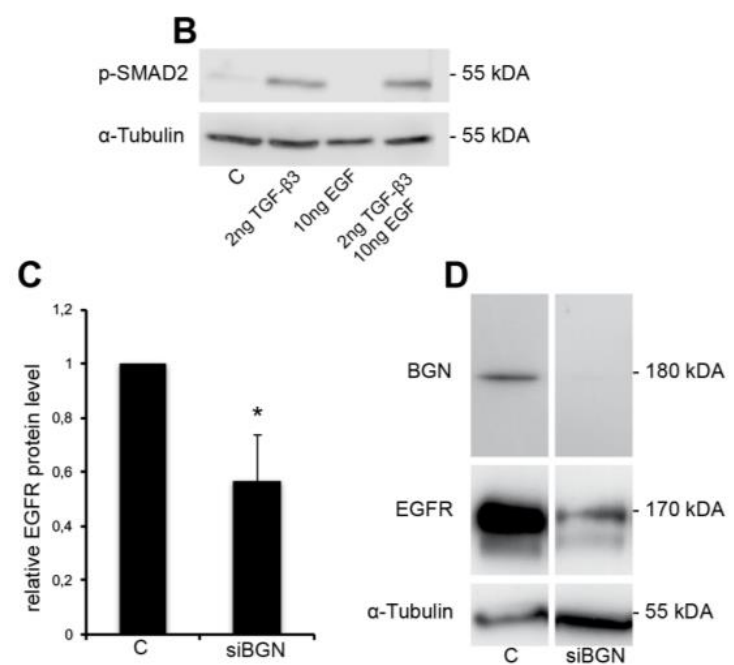

$\mathbf{F}$

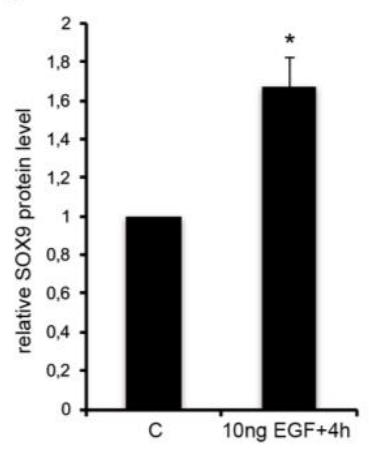

$\mathbf{G}$

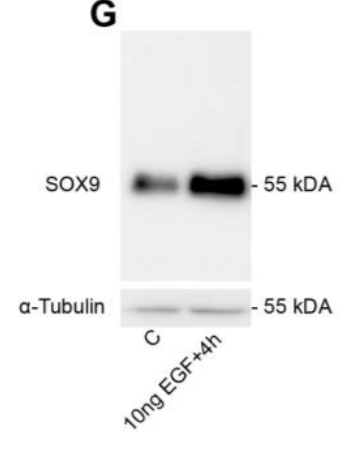

I

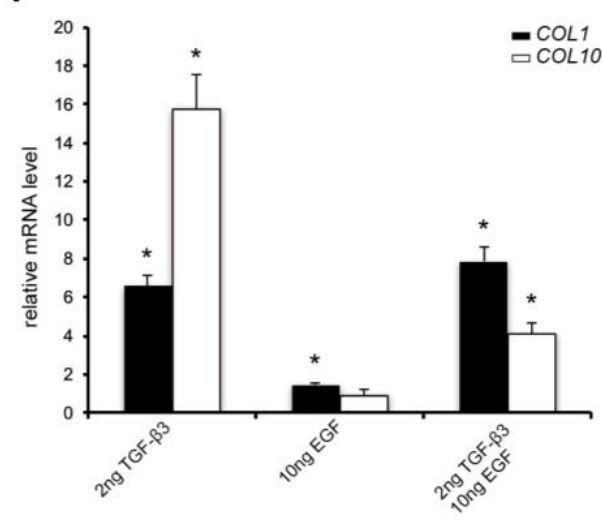

Figure 1.4: Stimulation and knockdown experiments affect CPCs. (A) Effect of TGF- $\beta 3$ and EGF stimulation on the TGFBRI, SMAD2, EGFR and BGN mRNA level. (B). Representative WB of $p$ SMAD2 after TGF- $\beta 3$ and EGF stimulation. (C) Effect of BGN knockdown on EGFR protein level. (D) Representative WB of BGN knockdown. (E) Stimulation of CPCs by TGF- $\beta 3$ and EGF altered SOX9 and RUNX2 mRNA expression. (F) Analysis of SOX9 protein level after stimulation with EGF. (G) Representative WB of SOX9 after EGF stimulation. (H) Chondrogenic and (I) osteogenic (COL1) as well as hypertrophy (COL10) marker expression after TGF- $\beta 3$ and EGF stimulation.

we additionally stimulated for $4 \mathrm{hrs}$ with fresh EGF. Indeed, we observed an increased SOX9 protein level (Fig. 1.4F and Fig. 1.4G). Finally, we investigated the expression levels of ECM markers, as the increased SOX9 and RUNX2 expression levels influence the chondrogenic or the osteogenic potential. TGF- $\beta 3$ and the 
combined stimulation with EGF increased both ACAN and COL2 mRNA levels, whereas exclusive EGF stimulation decreased both markers' expression (Fig. 1.4H). Furthermore, osteogenic and hypertrophy markers like, COL1 and COL10 respectively, were not decreased by any of the stimulations (Fig. 1.4I), thus neither TGF- 33 nor EGF stimulation displayed only the desired pro-chondrogenic effect but also increased at least one of the osteogenic and hypertrophy markers. 


\subsection{Discussion}

We investigated the influence of TGF- $\beta 3$ and EGF and how they are linked to the ECM component BGN with regard to SOX9 and RUNX2, which are accredited as major regulators of osteochondrogenesis.

CPCs build a fibrocartilaginous repair tissue, its fiber network, mainly containing collagen type I and not collagen II, is insufficient to regenerate a healthy hyaline cartilage (Miosge et al., 1998). However, the chondrogenic potential of CPCs can be enhanced by upregulation of SOX9, thus improving their regeneration attempts (Koelling et al., 2009, Schminke and Miosge, 2014). The manipulation of signaling cascades is one way to influence SOX9 expression, e.g., the TGF- $\beta 3$ pathway is known to enhance chondrogenesis in chondrocytes as well as in meniscus cells (Muhammad et al., 2014). Also the EGF pathway has been linked to osteochondrogenesis (Shepard et al., 2013), and further evidence of an EGFR-SOX9 signaling cascade was found in another developmental context (Grimont et al., 2015).

\subsubsection{TGF- $\beta 3$ and EGF signaling differs in $O A$}

After we localized BGN, TGFBRI and EGFR to confirm that these molecules could also be involved in human articular cartilage physiology, we further investigated the role of these players. Firstly, we focused on the differences in TGFBRI expression between $\mathrm{CC}-\mathrm{H}$ and CC-D as reduced expression of TGFBRI has been linked to OA in a mouse model (Blaney Davidson et al., 2005). Since we did not observe a significant difference, we conclude that either the cells investigated here reacted to the artificial culturing conditions or that other factors including post-translational modifications of TGFBRI, as well as their ligand concentration, play a role. However, CPCs exhibited an increased expression of TGFBRI, which implies that this receptor takes part in the OA disease phenotype. This multipotent cell population resides in late-stage OA tissues and is capable of differentiating into chondrocytes and other cell lineages; therefore, the decrease in receptor expression may be related to their differentiation potential (Ischenko et al., 2014, Droguett et al., 2010). EGF signaling is strongly involved in chondrogenesis by elevating the level of SOX9 (Ling et al., 2011, Chen et al., 2015). The downregulation of EGFR expression in CC-D is likely an indicator of the catabolic changes that the cartilage undergoes in $O A$, and the lack of EGFR promotes chondrocyte maturation (Sibilia et al., 2003). In earlier studies, we 
demonstrated that CPCs are regulated by the antagonists RUNX2 and SOX9 and take part in the formation of the fibrocartilaginous repair tissue in late-stage OA. Reduced pro-chondrogenic EGFR signaling is in strong agreement with the RUNX2controlled, fibroblastic phenotype of CPCs in vivo and in vitro.

\subsubsection{Influence of TGF- $\beta 3$, EGF and BGN manipulation on the chondrogenic potential of CPCs}

In articular cartilage, altered ECM homeostasis is a major factor contributing to OA. The ECM component BGN interferes with members of the TGF- $\beta 3$ family (Embree et al., 2010, Hara et al., 2017) and EGF (lacob and Cs-Szabo, 2010) signaling pathways. We detected TGF- $\beta 3$ and EGF in human articular cartilage and found evidence that in vitro stimulation with these players also upregulates BGN in CPCs. The upregulation of BGN after TGF- $\beta 1$, TGF- $\beta 2$ and TGF- $\beta 3$ treatment has been shown in various cell types, including osteosarcoma cells and VSMCs (Heegaard et al., 2004, Burch et al., 2010). Both cell types are strongly regulated by RUNX2 and SOX9 (Lucero et al., 2013, Liu et al., 2014, Lin et al., 2015, Briot et al., 2014), as are CPCs (Koelling et al., 2009). Furthermore, we observed that BGN influences the EGFR protein level as it has been stated before in a mouse model (lacob and CsSzabo, 2010) and thus, one can speculate about a complex regulation chain in which BGN mediates the TGF- $\beta 3$ and EGF pathways. This is supported by the colocalization of BGN and the respective receptors as shown here. Recent reviews have focused on the diverse functions of the ECM molecule perlecan (Douglass et al., 2015), suggesting that proteoglycans act as central signaling hubs through interactions with other ECM molecules and cell receptors (Gubbiotti et al., 2017). Loss of such a hub may lead to dysbalanced signaling resulting in the initially increased anabolic and finally catabolic processes that have been observed after BGN loss in mandibular condylar chondrocytes (Embree et al., 2010). Also the results of previous studies concerning TGF- $\beta 3$ and EGF signaling (Zhang et al., 2014, Sibilia et al., 2003, Pombo-Suarez et al., 2009, Bush and Beier, 2013, Blaney Davidson et al., 2005) indicate a highly regulated network of various players at various developmental timepoints necessary to determine the final osteochondrogenic effects. We showed that TGF- $\beta 3$ and EGF stimulation increased expression of BGN, EGFR and TGFBRI and seems to upregulate the osteochondrogenic potential in general, considering the rise of SOX9 and RUNX2 expression. In accordance with this, TGF- $\beta 3$ stimulation upregulated chondrogenic, 
osteogenic and hypertrophic markers, which we could not observe after exclusive EGF stimulation. EGF stimulation upregulated SOX9, however also decreased ACAN and COL2 and increased COL1 expression. Thus, TGF- $\beta 3$ and EGF signaling have a potential for anabolic and catabolic processes, but their specificity is determined in a more complex manner, including further mediators activating alternative signaling cascades, e.g., the proposed transition from pro-chondrogenic SMAD2/3 signaling to hypertrophic SMAD1/5/8 signaling (van der Kraan, 2017, Bush and Beier, 2013) as shown for TGF- $\beta 3$. In late-stage OA, dysregulation of this network may promote disease progression. BGN has been linked to angiogenesis during fracture repair by altering the expression and function of endostatin (Myren et al., 2016). Altered TGF and EGF signaling may influence BGN expression and its regulatory functions in the deep zone, resulting in the vascularization of the calcified zone.

Taken together TGF, EGF and BGN were found to be expressed in articular cartilage and bear the capacity to influence each other, as well as the expression of the osteochondrogenic regulators SOX9 and RUNX2. The direct stimulation of CPCs in vitro with TGF- $\beta 3$ and EGF increased the chondrogenic master regulator SOX9 but also increased osteogenic and hypertrophy markers. Further research is needed to determine exclusively chondrogenic mediators in these signaling cascades, which would help to identify attractive targets for future OA therapy. 


\section{Chapter II}

\section{Enhancing the chondrogenic potential of chondrogenic progenitor cells by deleting RAB5C}

The following chapter was submitted to Cell Stem Cell.

\section{Authors}

Jerome Nicolas Janssenª, Valerio Izzi ${ }^{b}$, Elvira Henze ${ }^{a}$, Gökhan Cingöz ${ }^{a}$, Florian Lowen ${ }^{a}$, David Küttner ${ }^{\mathrm{a}}$, Ruth Neumann ${ }^{\mathrm{a}}$, Christof Lenz ${ }^{\mathrm{c}, \mathrm{d}}$, Vicki Rosen ${ }^{\mathrm{e}}$, Nicolai Miosge ${ }^{a, d}$

aUniversity Medical Center, Tissue Regeneration Work Group, Department of Prosthodontics, 37075 Goettingen, Germany

${ }^{\text {b} F a c u l t y ~ o f ~ B i o c h e m i s t r y ~ a n d ~ M o l e c u l a r ~ M e d i c i n e, ~ U n i v e r s i t y ~ o f ~ O u l u, ~ F I-90014 ~ O u l u, ~}$ Finland

'Bioanalytical Mass Spectrometry Group, Max Planck Institute for Biophysical Chemistry, 37077 Göttingen, Germany

IInstitute of Clinical Chemistry, Medical Faculty, Georg-August-University, 37075 Göttingen, Germany

eDevelopmental Biology, Harvard School of Dental Medicine, Boston, MA 02115, USA.

Corresponding author: nmiosge@gwdg.de, +495513933927

\section{Autor contributions}

Jerome Nicolas Janssen: Study conception, study design, analyses and interpretation of data, figure preparation, manuscript preparation, and statistical analyses; Elvira Henze, Gökhan Cingöz, Florian Lowen, David Küttner and Ruth Neumann: Assisted with the experiments; Valerio Izzi: Computational and statistical analyses; Cristof Lenz: Designed and assisted with the experiments. Vicki Rosen: Study conception, experimental design and interpretation of data; Nicolai Miosge: Study conception, study design, interpretation of data, and manuscript preparation. 


\section{Abstract}

Osteoarthritis $(\mathrm{OA})$ is the most prevalent chronic joint disease that affects a large proportion of the elderly population. Chondrogenic progenitor cells (CPCs) reside in late-stage $O A$ cartilage tissue, producing a fibrocartilaginous extra-cellular matrix; these cells can be manipulated in vitro to deposit proteins of healthy articular cartilage.

CPCs are under the control of SOX9 and RUNX2. In our earlier studies, we identified a pivotal role for RUNX2 in enhancing the chondrogenic potential of CPCs. Here we demonstrate that CPCs carrying a knockout of RAB5C, a protein involved in endosomal trafficking, exhibited elevated expression of multiple chondrogenic markers, including the SOX trio, and displayed increased COL2 deposition, whereas no changes in COL1 deposition were observed.

We report RAB5C as an attractive target for future therapeutic approaches designed to increase the COL2 content in the diseased joint. 


\subsection{Introduction}

Osteoarthritis $(\mathrm{OA})$ is the most common musculoskeletal disease in the elderly (Reginster, 2002). According to the WHO, by 2050, 130 million people will suffer from OA and 40 million people will be severely disabled by OA (WHO, 2013). The disease is characterized by the degradation of the articular cartilage, which results in impaired joint functionality (Felson, 2006). Current therapies provide symptomatic relief but are unable to cure the disease, and patients eventually require total joint replacement (Lohmander and Roos, 2007). The search for new OA treatment options focuses on regenerative cell therapies, among others modalities (Brittberg et al., 1994, Schminke and Miosge, 2014).

In the joint, chondrocytes populate the healthy articular cartilage, secreting extracellular matrix (ECM) components such as collagen type II (COL2) and other characteristic proteins that are responsible for the unique properties of the tissue (Buckwalter and Mankin, 1998a, Oldberg et al., 1990). During OA, disturbed cellmatrix interactions lead to the degradation of the healthy articular cartilage (Sandell and Aigner, 2001, Poole, 1997, Goldring and Goldring, 2007, Heinegard and Saxne, 2011), resulting in fibrillation processes and the formation of a fibrocartilaginous repair tissue (Miosge et al., 1998, Miosge et al., 2004, Horton et al., 2006) that is mainly composed of collagen type I (COL1). This repair tissue lacks the mechanical properties of healthy cartilage (Setton et al., 1999).

Previous studies by our group reported that fibrocartilage repair tissue is derived from a unique cell population of migratory, clonogenic and multipotent chondrogenic progenitor cells (CPCs) (Koelling et al., 2009, Seol et al., 2012). In vitro experiments have revealed the capacity of CPCs to differentiate into chondrocytes in vitro (Joos et al., 2013, Jenei-Lanzl et al., 2014, Embree et al., 2016, Janssen et al., 2019, Wang et al., 2019). Based on these findings, our approach is to increase the chondrogenic potential of CPCs in vivo. The differentiation of CPCs is mainly determined by the chondrogenic transcription factor SOX9 and by the osteogenic factor RUNX2 (Koelling et al., 2009). SOX9 is an essential factor expressed throughout the chondrocyte lineage, from mesenchymal chondroprogenitor condensation until hypertrophic differentiation ( $\mathrm{Bi}$ et al., 1999, $\mathrm{Bi}$ et al., 2001), and it regulates the expression of chondrogenic markers such as COL2 (Lefebvre et al., 1997). RUNX2, the master regulator of osteogenesis (Otto et al., 1997), also plays a crucial role in early chondrogenesis. Nullizygous RUNX2 mice exhibit delayed or absent 
chondrocyte hypertrophy (Kim et al., 1999, Inada et al., 1999). Knockdown of RUNX2 in CPCs increases the expression of SOX9, ACAN and COL2, but decreases the expression of catabolic markers such as MMP13 and ADAMTS5 (Koelling et al., 2009). Due to the critical and versatile functions of SOX9 (Jo et al., 2014) and RUNX2 (Pratap et al., 2011), we strove for a subtler manipulation of the chondrogenic potential than the direct targeting of these master regulators.

In our study, we identified a pivotal role for RUNX2 in determining the chondrogenic potential of CPCs, and we identify RAB5C as a potential interacting partner of SOX9. By knocking out (KO) RAB5C, we increased the chondrogenic potential of CPCs in vitro and transplanted these manipulated cells into a nude mice model to analyze its effect in vivo. Additionally, we provide the first insights into the possible underlying cell biological mechanism. 


\subsection{Methods}

\subsubsection{Cell isolation and culture}

A standard explant protocol was applied (Koelling et al., 2009) using histopathologically confirmed late-stage OA tissue (Pritzker et al., 2006) and 4 CPC lines (CPC241, CPC674, CPC677, and CPC678) from patients (2 males and 2 females, age 61-82 years, height $156-185 \mathrm{~cm}$, weight $60-110 \mathrm{~kg}$ ) cultivated under standard conditions at $37^{\circ} \mathrm{C}$ with $5 \% \mathrm{CO}_{2}$ in DMEM + GlutaMax ${ }^{\mathrm{TM}}$ supplemented with $10 \%$ FCS and $50 \mu \mathrm{g} / \mathrm{mL}$ gentamycin (Janssen et al., 2019, Koelling et al., 2009). A lentivirus expressing hTERT was produced as described in a previous study (Docheva et al., 2010). The pLenti6/v5-hTERT plasmid was cotransfected with pLP1, pLP2, and pLP/VSVG helper plasmids (ViraPower lentiviral expression system, Invitrogen) in 293FT cells, and the supernatant was collected after $48 \mathrm{hrs}$. CPCs were infected with the hTERT lentivirus (moi of $5 \times 10^{4}$ ) and selected with $10 \mu \mathrm{g} / \mathrm{mL}$ blasticidin for 1 week.

\subsubsection{Chondrogenic differentiation}

First, $7 \times 10^{5}$ cells were embedded in sterile 1.2\% FMC Biopolymer alginate (Häuselmann et al., 1994, Koelling et al., 2009) and cultured with standard DMEM supplemented with $3.9 \mu \mathrm{M} / 100 \mathrm{~mL}$ dexamethasone, $10 \mathrm{mg} / \mathrm{mL}$ Na-pyruvate, 4 $\mathrm{mg} / 100 \mathrm{~mL}$ L-proline, $5 \mathrm{mg} / 100 \mathrm{~mL}$ ascorbate and $5 \mu \mathrm{L} / \mathrm{mL}$ ITS for up to 28 days. Cells were retrieved from beads using HEPES-EDTA.

\subsubsection{Data-independent acquisition mass spectrometry}

CPCs from patients were differentiated towards the chondrogenic lineage. On day 27, the medium was changed to FCS-free chondrogenic medium. SDS-PAGE, in-gel trypsin digestion, extraction and MS were performed using the methods described in a previous study (Batschkus et al., 2017). For the generation of a peptide library, equal amount aliquots from each sample were pooled to a total amount of $150 \mu \mathrm{g}$, dried in a vacuum concentrator and resuspended in $0.1 \%$ TFA. The pool was then separated into 14 fractions using reverse-phase chromatography $(1.0 \mathrm{~mm} I \mathrm{ID} \times 150$ $\mathrm{mm}$, Hypersil Gold C18 aq, $5 \mu \mathrm{m}$, Thermo Fisher Scientific) with 5-40 \% acetonitrile/0.01 M ammonium hydroxide $\left(\mathrm{pH} \mathrm{8.0)}\right.$ at a rate of $200 \mu \mathrm{min}^{-1}$ and a staggered pooling scheme $(1+15+29)$. 
For mass spectrometry, peptide samples were reconstituted in $2 \%$ acetonitrile/ $0.1 \%$ formic acid (v:v) and spiked with a synthetic peptide standard used for retention time alignment (iRT Standard, Schlieren, Schweiz). Samples were analyzed using a nanoflow chromatography system coupled to a hybrid triple quadrupole-TOF mass spectrometer using the method described in a previous study (Erdmann et al., 2019). Proteins were identified using ProteinPilot Software version 5.0 build 4769 (AB Sciex) and "thorough" settings. The combined qualitative analyses were searched against the UniProtKB human reference proteome (revision 04-2018, 93,609 entries) augmented with a set of 52 known common laboratory contaminants to identify proteins at a False Discovery Rate (FDR) of $1 \%$.

Spectral library generation and peak extraction were achieved with PeakView Software version 2.1 build 11041 (AB Sciex) using the SWATH quantitation microApp version 2.0 build 2003. Following the retention time correction using the iRT standard, peak areas were extracted using information from the MS/MS library at an FDR of 1\% (Lambert et al., 2013). The resulting peak areas were then summed to peptide and finally protein area values per injection, which were used for further statistical analysis. Cell lines were grouped together (CPC677 and CPC241hT, CPC674 and CPC674hT, and CPC678 and CPC678hT), and proteins were compared using the Mann-Whitney $U$ test with the FDR correction. Significant proteins were selected by thresholding at a $p$ value $<0.05$, divided into up- and down-regulated by fold change (primary or immortalized).

\subsubsection{Generation of the knockout cell lines}

For this experiment, $1 \times 10^{6}$ cells were transfected with $2 \mu \mathrm{g}$ each of pSp-Cas9(BB)2A-GFP (Addgene) vector pairs (inserts: RAB5C: 5' GAAGAGAGAAGGAGCGTCCAT, 5' GgGTTAAGCGGCCTGAAATC; RUNX2: 5' GCCGGCCACTTCGCTAACTTG, 5' GAGGTCTTGGAGGACGTCCG) in $100 \mu \mathrm{l}$ of the Human Nucleofector Solution using nucleofector program C17 (Amaxa). Immediately afterwards, the cells were cultured under standard conditions. Transfected cells were sorted by FACS to achieve one cell per well, gDNA was isolated (Kappa mouse genotyping kit KK7103) and loci were sequenced using the following primers: RAB5C: 5' CCCTAGCTGCTGGTCTGTTC, 5' TCAAGTGATCCTCCCACTCC; and RUNX2: 5' TCAGACAGAGGTGGGGGTAG, 5' AGACCTGAGGAGAGGCGTTT. 


\subsubsection{Real-time polymerase chain reaction (RT-PCR)}

RT-qPCR was performed as previously described (Koelling et al., 2009), using the $\Delta \Delta C T$ method (Livak and Schmittgen, 2001). The primers are listed in Tab. S2.4. At least 3 replicates were analyzed using Student's t-test or ANOVA followed by Tukey's post hoc test, ${ }^{*} p<0.05$.

\subsubsection{Immunoblotting}

Protein levels were determined using SDS-PAGE and Western blotting with PVDF membranes. TBS-T was used for washing and $5 \%$ milk powder in TBS-T was used for blocking (Janssen et al., 2019, Koelling et al., 2009). Primary antibodies were diluted as follows and incubated with the membrane overnight: RUNX2: 1:2000, polyclonal rabbit ab23981 (Abcam); SOX9: 1:2000, monoclonal mouse H00006662M02 (Abnova); COL1: 1:500, polyclonal rabbit R1038 (Acris); COL2A1: 1:300, monoclonal mouse sc-51801 (Santa Cruz); RAB5C: 1:500, monoclonal mouse sc365667 (Santa Cruz); Anti-6X His tag ${ }^{\circledR}$ : 1:2000, ab18184 (Abcam). Secondary antibodies were diluted as follows and incubated with the membrane for $1 \mathrm{~h}$ : polyclonal goat anti-mouse A 9917, 1:40000 (Sigma-Aldrich) and polyclonal goat anti-rabbit, A 0545, 1:100000 (Sigma-Aldrich). WesternBright ${ }^{\text {TM }}$ Sirius (K-12043-D20, Biozym) and WesternBright ${ }^{\mathrm{TM}}$ ECL (K-12045-D20, Biozym) were used for detection with a C-DiGit Blot Scanner. Protein levels were evaluated with Image Studio Digits Version 5.2 and normalized to the levels of $\alpha$-tubulin (T6199, 1:10000 Sigma-Aldrich) or GAPDH (ab9848, 1:5000, Abcam) (Gassmann et al., 2009). At least 3 replicates were analyzed using Student's t-test, ${ }^{*} p<0.05$.

\subsubsection{Pull down and mass spectrometry analyses}

HEK293T cells were transfected with pPM-hSOX9-His (PV132789, ABM) using PolyFect ${ }^{\boxplus}$. After 48 hrs, cells were lysed and the released His-tagged protein was purified and incubated with HisPurTM Ni-NTA Magnetic beads in equilibrium buffer. Subsequently, the beads were washed and incubated with the lysate of CPCsiRUNX2 (Koelling et al., 2009) $\mathrm{O} / \mathrm{N}$ at $4^{\circ} \mathrm{C}$ while rotating. Finally, the beads were washed and the protein complexes were eluted and precipitated with ethanol. SDS-PAGE, in-gel trypsin digestion and extraction and MS were performed using the methods described by Batschkus et al. (2017) with slight alterations. Each lane was cut into 11 equidistant slices. Peptides were separated using a 37 min linear gradient (5-35\%) and analyzed using a Top 10 data-dependent acquisition method. Three biological 
and two technical replicates were combined. Peak lists were extracted from the raw data with Raw2MSM (version v1.10) and analyzed using Mascot (version 2.4.1) by searching against the SwissProt database version 2014_08 and validated with Scaffold 4.3.4. Spectral counting was used to determine relative protein abundances between samples (Lundgren et al., 2010). Spectral counts were normalized between the different samples using the DESeq method (Anders et al., 2013, Anders and Huber, 2010). Interacting proteins were identified using a two-stage Poisson model that was specifically adapted for spectral count data and included a biological and variance filter (Fischer et al., 2014). Differential binding between treatment and control groups was quantified by determining the log fold change using a FDR of $5 \%$. All mass spectrometry proteomics data have been deposited into the ProteomeXchange Consortium via the PRIDE partner repository (Perez-Riverol et al., 2018) with the dataset identifier PXD021785.

\subsubsection{Ex vivo migration}

For this experiment, $1 \times 10^{6}$ cells were transfected with $4 \mu \mathrm{g}$ of pmaxGFP TM (Lonza) as described above. Osteoarthritic cartilage without signs of rheumatoid involvement were obtained from the knee joints of adult patients ( 1 male and 3 females, age 6279 years, height $156-176 \mathrm{~cm}$, weight $55-92 \mathrm{~kg}$ ) suffering from late-stage $\mathrm{OA}$ after total knee replacement. The patients met the American College of Rheumatology classification criteria (Altman et al., 1986) and provided written informed consent, consistent with relevant ethical regulations (25/12/10). The histopathological classification of OA cartilage confirmed the presence of late-stage OA (Pritzker et al., 2006).

\subsubsection{Animals}

In vivo experiments using mice were performed in accordance with the Guide for the Care and Use of Laboratory Animals and were approved by the Harvard Medical Area Institutional Animal Care and Use Committee. Mice were maintained in a virusand parasite-free barrier facility, housed on a 12-hour light/dark cycle and fed a standard diet with food and water available ad libitum. Female homozygous Foxn1nu mice were ordered from Jackson Lab (strain $002019-\mathrm{NJ} / \mathrm{J}$ ) and housed under sterile conditions. Cells used for implantation were embedded in 1.2\% PRONOVA SLG100 alginate and 4 beads were transplanted into the back of nude mice $(7$ mice for $\mathrm{CPC}^{\text {Control }}, 4$ mice for $\mathrm{CPC}^{\mathrm{RABSC}-1}$, and 3 mice for empty alginate beads). Mice were 
sacrificed after 28 days, the beads were retrieved and fixed for histology, or CPCs were retrieved using HEPES-EDTA.

\subsubsection{Immunohistochemistry (IHC) and immunocytochemistry (ICC)}

IHC and ICC were performed as previously described (Schminke et al., 2016b, Janssen et al., 2019). For $\mathrm{IHC}$, tissue samples were fixed at $55^{\circ} \mathrm{C}$ for $2 \mathrm{~h}$. Primary antibodies were applied at the following dilutions for IHC: ACAN: 1:100, monoclonal mouse AHP0012 (Thermo Fisher); COL1: 1:50, polyclonal rabbit R1038 (Acris); COL2: 1:50, polyclonal rabbit NB100-91715 (Novus Biologicals); and KI-67: 1:50, monoclonal mouse M7240 (Dako Cytomation). For detection, a HiDef Detection ${ }^{\mathrm{TM}}$ Alk Phos Polymer System (962D, Cell Marque) with PermaRed/AP-Auto (K049-Auto, Cell Marque) was applied. The following primary antibodies were applied for ICC: RAB5C: 1:50, monoclonal mouse sc-365667 (Santa Cruz); RUNX2: 1:20 polyclonal rabbit sc-10758 (Santa Cruz); and SOX9: 1:50, polyclonal rabbit sc-20095 (Santa Cruz). Alexa Fluor 555-conjugated polyclonal donkey anti-rabbit (ab150074, 1:500, Abcam) and DyLight 488-conjugated polyclonal goat anti-mouse (072-03-18-06, 1:500, KPL) secondary antibodies and a 1:1000 dilution of DAPI were applied for ICC.

\subsubsection{RNA-Seq}

Gene expression in CPC Control and CPC RAB5C-- was measured on days 0,3 and 28. Total RNA was isolated with an RNeasy kit (Qiagen). RNA-Seq libraries were prepared using TruSeq kits (Illumina). Samples were assessed for sequencing quality using FastQC (version 0.11.5) (Andrews, 2010). All experiments were performed in triplicate, and three biological replicates were sequenced per condition. Datasets are available at GEO (GSE158463). SortMeRNA (version 2.1) (Kopylova et al., 2012) was used to determine the proportion of rRNAs in the samples. Human RNA-Seq data were aligned to the human genome assembly hg38 using STAR (version 2.5.2a) (Dobin et al., 2013) with the default options. The number of reads in each gene in the human genome version 89 was quantified for every sample using FeatureCounts (version 1.5.0-p1) (Liao et al., 2014). All analyses were performed using R v4.0.1. Normalized gene-level RNA-Seq count tables were first averaged for duplicated genes, then divided into groups by genetic (RAB5C status) and time (0, 3 or 28 days) factors and analyzed. For linear gene expression modeling of time and group ordered data, linear regression equations were fit for each gene in both 
groups. The goodness-of-fit $\left(R^{2}\right)$ and $p$ value for each gene were compared between groups, and, depending whether a stringent or less stringent model was used, regressor lists were established at cut-off values of $R^{2}=0.8$ and $p<0.05$. Gene expression was considered altered in CPC ${ }^{\text {RABSC- }-~}$ if the genes were present in the CPC Control list but absent in the CPCRAB5C-- list. Genes were further selected and compared using the Mann-Whitney $U$ test with the FDR correction. The cartilage morphogenesis signature was downloaded from the MSigDB and the relative enrichment values were inferred for each sample using the "singScore" package in $R$. Differential enrichment was evaluated using the Mann-Whitney $U$ test with the FDR correction. For GSEA, the differential expression analysis was performed between each set of CPC Control and CPC ${ }^{\text {RAB5C-- }}$ samples using DESeq2 (version 1.18.1)(Love et al., 2014). The web service WebGestalt (version 0.4.3)(Liao et al., 2019b) was applied to identify enriched GO categories and KEGG pathway terms (adjusted $p<$ 0.05). 


\subsection{Results}

\subsubsection{Primary and immortalized CPCs did not exhibit major differences}

CPCs have been a useful model to study the molecular mechanisms related to the pathology of OA (Seol et al., 2012, Joos et al., 2013, Wang et al., 2020, Matta et al., 2019). First, we wanted to determine whether the immortalized CPCs utilized in our previous studies (Janssen et al., 2019, Wagner et al., 2019) and used here differ from primary CPCs after chondrogenic differentiation. Therefore, we performed proteome profiling using data-independent acquisition mass spectrometry (DIA-MS) to elucidate the differences between the two corresponding CPC cell lines before and after immortalization. Additionally, we included one primary cell line and one immortalized cell line from a different patient to consider the effects related to different patient origins. After the chondrogenic differentiation of these cell lines, the DIA-MS analysis detected 2449 proteins (Fig. S2.1). Only $43(1.76 \%)$ proteins in the two corresponding cell lines and $20(0.82 \%)$ proteins in the non-matching cell lines were downregulated after immortalization (Tab. S2.1). Only $16(0.65 \%)$ proteins were upregulated in both corresponding cell lines after immortalization, while only 33 (1.35\%) proteins were upregulated in the non-matching cell lines (Tab. S2.1).

Therefore, we concluded that immortalization did not substantially deregulate the proteome, thus confirming that our immortalized cell lines, one of which was used in the following experiments, represent a suitable model to investigate the mechanisms of $\mathrm{OA}$ and the role of CPCs in chondrogenic regeneration.

\subsubsection{The osteogenic master regulator RUNX2 has a pro-chondrogenic function in CPCs}

As described in previous studies, CPCs reside in the fibrocartilaginous repair tissue of patients with late-stage OA (Miosge et al., 1998) and can be manipulated in vitro to produce hyaline cartilage proteins (Koelling et al., 2009, Dai et al., 2020). Because CPCs are controlled by the osteogenic regulator RUNX2 and the chondrogenic regulator SOX9, diminished RUNX2 expression induced by RNA interference led to upregulation of the articular cartilage marker COL2 and downregulation of the fibrocartilaginous marker COL1 (Koelling et al., 2009). Thus, we were interested in determining whether we would be able to further enhance this effect by knocking out RUNX2 using a CRISPR/Cas9 approach targeting exon 2 (Fig. 2.1A). First, the CPCRUNX2- cell line was examined in 2D culture, and the successful deletion of this expression exon was confirmed using PCR (Fig. 2.1B). Decreased SOX9 and 
A

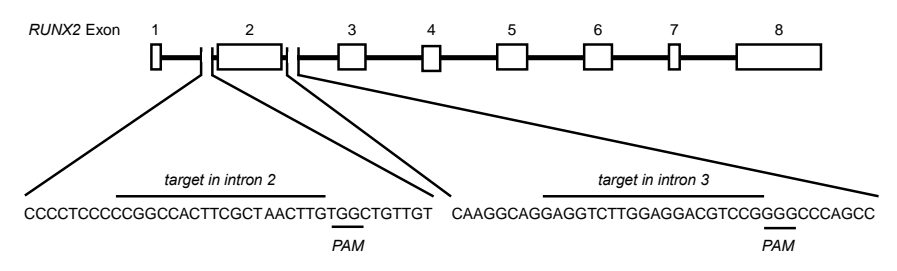

B

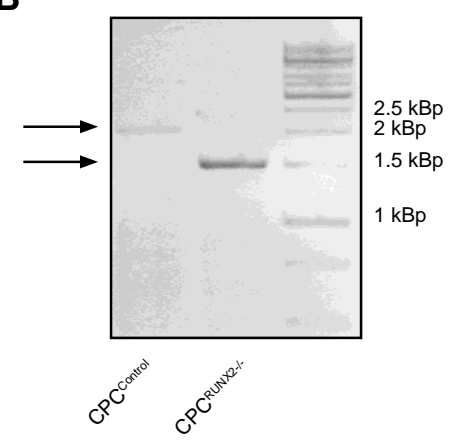

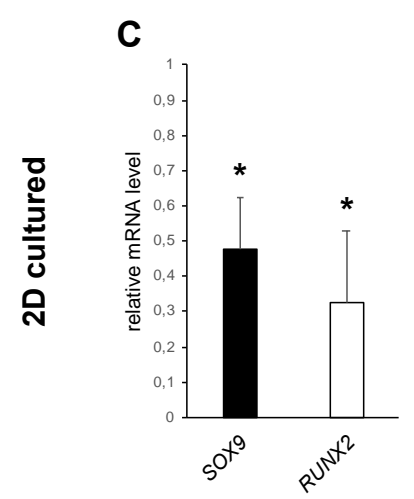

D
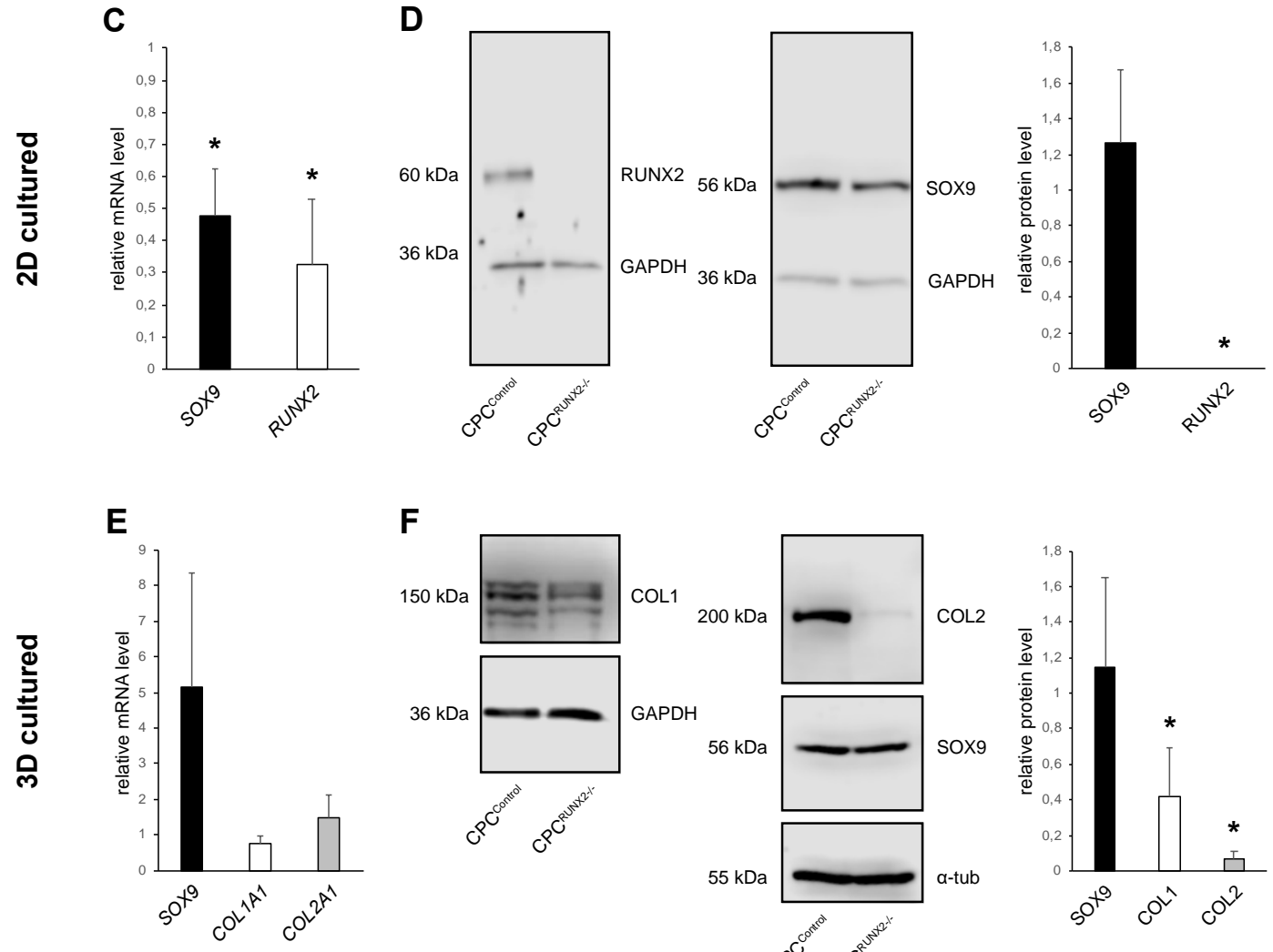

$\mathbf{F}$
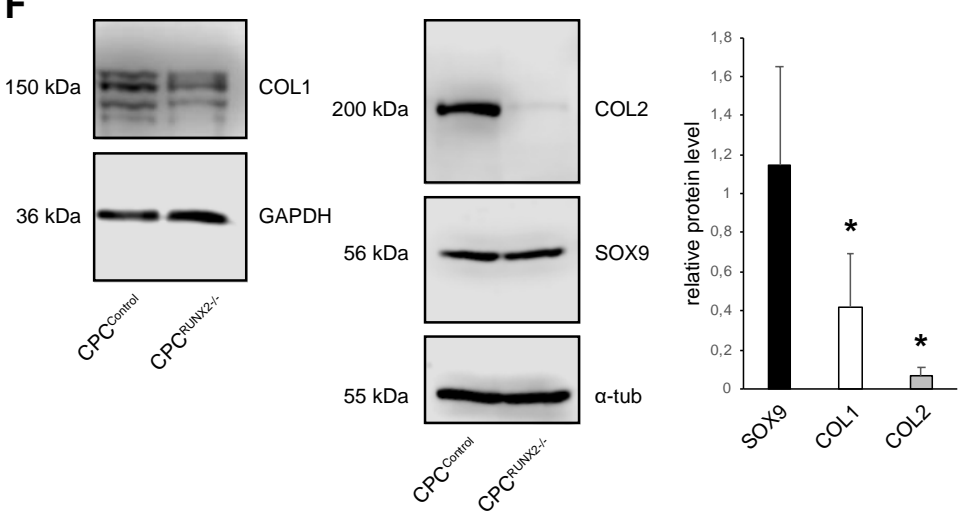

Figure 2.1: Generation and characterization of CPC RUNX2--.$(A)$ Schematic of the RUNX2 locus. Exon lengths are scaled, while intron sizes are reduced for better visualization. (B) PCR analysis of the RUNX2 exon 2 locus showing the deletion of 500bp in CPCRUNX2-/- by CRISPR/Cas9. (C) qPCR and (D) Western Blot analyses of SOX9 and RUNX2 levels in 2D cultured CPC RUNX2-- . After 28 days of 3D alginate culture, CPC RUNX2-/- were subjected to $(E)$ qPCR and $(F)$ Western Blot analyses of SOX9, RUNX2, COL1 (all bands were measured) and COL2 levels. Abbreviations: PAM, protospacer adjacent motif.

RUNX2 (Fig. 2.1C) expression levels were detected using qPCR. Subsequently, an unchanged level of the SOX9 protein and the complete absence of the RUNX2 protein were demonstrated by Western Blot (Fig. 2.1D).

In the next step, CPC Control and CPC RUNX2-- were seeded in 3D alginate for 28 days to induce chondrogenic differentiation. No significant changes in SOX9, COL1A1 and COL2A1 expression were detected (Fig. 2.1E). Regarding the protein level, we did 
not observe a change in the SOX9 level, whereas the levels of COL1 and particularly COL2 were substantially decreased (Fig. 2.1F). We propose that a minimal amount of RUNX2 is required to enhance the chondrogenic potential of CPCs, and therefore we anticipated decreased but not abolished RUNX2 levels in subsequent experiments.

In consideration of future therapeutic approaches, strategies directly targeting RUNX2 or SOX9 might have severe consequences due to their numerous upstream function in various cell types (Valenti et al., 2016, Pritchett et al., 2011, Izzi et al., 2019, Hanley et al., 2008). Furthermore, testing of CPC Control carrying a KO of candidate genes reported in the literature and known to be involved in the pathogenesis of OA, namely, MFGE8 (Albus et al., 2016) and YWHAE (Nefla et al., 2015), did not improve chondrogenic differentiation in vitro (data not shown). Therefore, we aimed to identify potential co-regulators of SOX9 whose manipulation might enhance the chondrogenic potential of CPCs.

\subsubsection{RAB5C is a co-regulator of SOX9, and its loss increases COL2 synthesis} For the next approach, we assumed that possible co-regulators directly or indirectly interact with SOX9 in CPCs and thus would be identified by a SOX9-His pull down. First, the SOX9 bait protein was produced in HEK293T cells transfected with pPMhSOX9His (Fig. 2.2A). The lysate of untransfected HEK293T cells was used to assess the binding of non-specific proteins to the column (Fig. 2.2B, left lane). We assumed that an increased SOX9 level promotes the expression of co-regulators involved in chondrogenesis in CPCs. Therefore, we used CPC ${ }^{\text {siRuNX2 }}$ overexpressing SOX9 (Koelling et al., 2009) to increase the efficiency of the pull down. For control, aliquots of the lysate were run on a SDS gel and used for Western Blot to detect SOX9 and the His-tag (Fig. 2.2B, right lane). The mass spectrometry analysis revealed 3448 identified protein clusters with 393 protein clusters identified exclusively in the control, while 344 clusters were exclusively related to CPCsiRUNX2 (Fig. 2.2C). The statistical analysis revealed a number of significantly enriched proteins (Fig. 2.2D). SOX9, which has been described to form homodimers (Huang et al., 2015), was among the 50 most enriched proteins (Tab. 2.1). Furthermore, three different ras-related proteins (RABs) involved in vesicular trafficking were detected. One of these proteins, RAB23 was investigated in the mouse ATDC5 cell line, and the manipulation of this protein decreases SOX9 levels (Yang et al., 2008). This finding supported our experimental design and our assumption that co-regulators of 

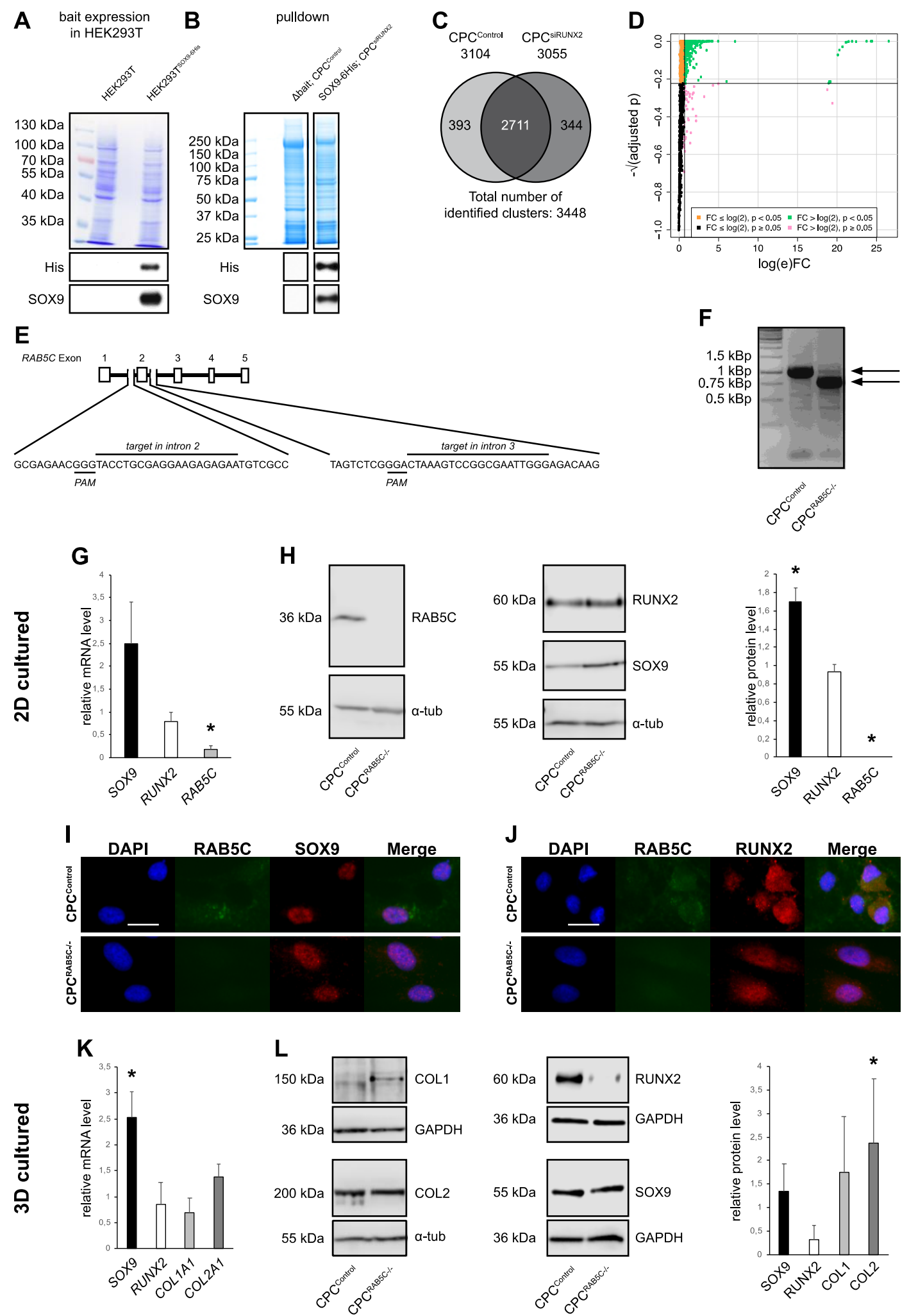

Figure 2.2: Pulldown of SOX9-associated proteins and characterization of CPC ${ }^{\text {RAB5C-- }}$. (A) Coomassie staining of the lysates of control or SOX9-6His-transfected HEK293T cells. The His tag and SOX9 were detected using Western blotting. (B) Coomassie-stained SDS gel of control and CPCsiRUNX2 eluates after $\triangle$ bait or SOX9-His pulldown. The His tag and SOX9 were detected using Western blotting. (C) Overview of proteins detected in CPC Control and CPC siRUNX2 using mass spectrometry. (D) Volcano plot of the identified relevant proteins in $\mathrm{CPC}^{\text {siRUNX2 }}{ }^{\text {compared to }} \mathrm{CPC}{ }^{\text {Control }}$. (E) Schematic of 
the RAB5C locus with scaled exons and reduced intron sizes for better visualization. (F) CRISPR/Cas9-mediated deletion of 250 bp of $R A B 5 C$ exon 2 was confirmed by PCR. SOX9, RUNX2

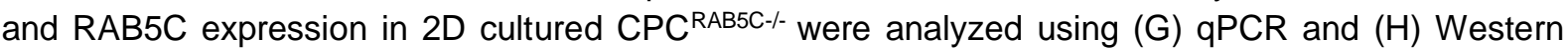
blotting. ICC staining of CPC ${ }^{\text {Control }}$ and CPC RAB5C-- for DAPI, RAB5C and (I) SOX9 or (J) RUNX2. Scale bar: $20 \mu \mathrm{m}$. CPCs ${ }^{\mathrm{RABSC}--}$ were cultured in 3D alginate for 28 days and SOX9, RUNX2, COL1 (all bands were measured) and COL2 levels were assessed using (K) qPCR and (L) Western blotting. Abbreviations: His, polyhistidine tag; PAM, protospacer adjacent motif.

Table 2.1: Top50 proteins identified by SOX9-His pulldown

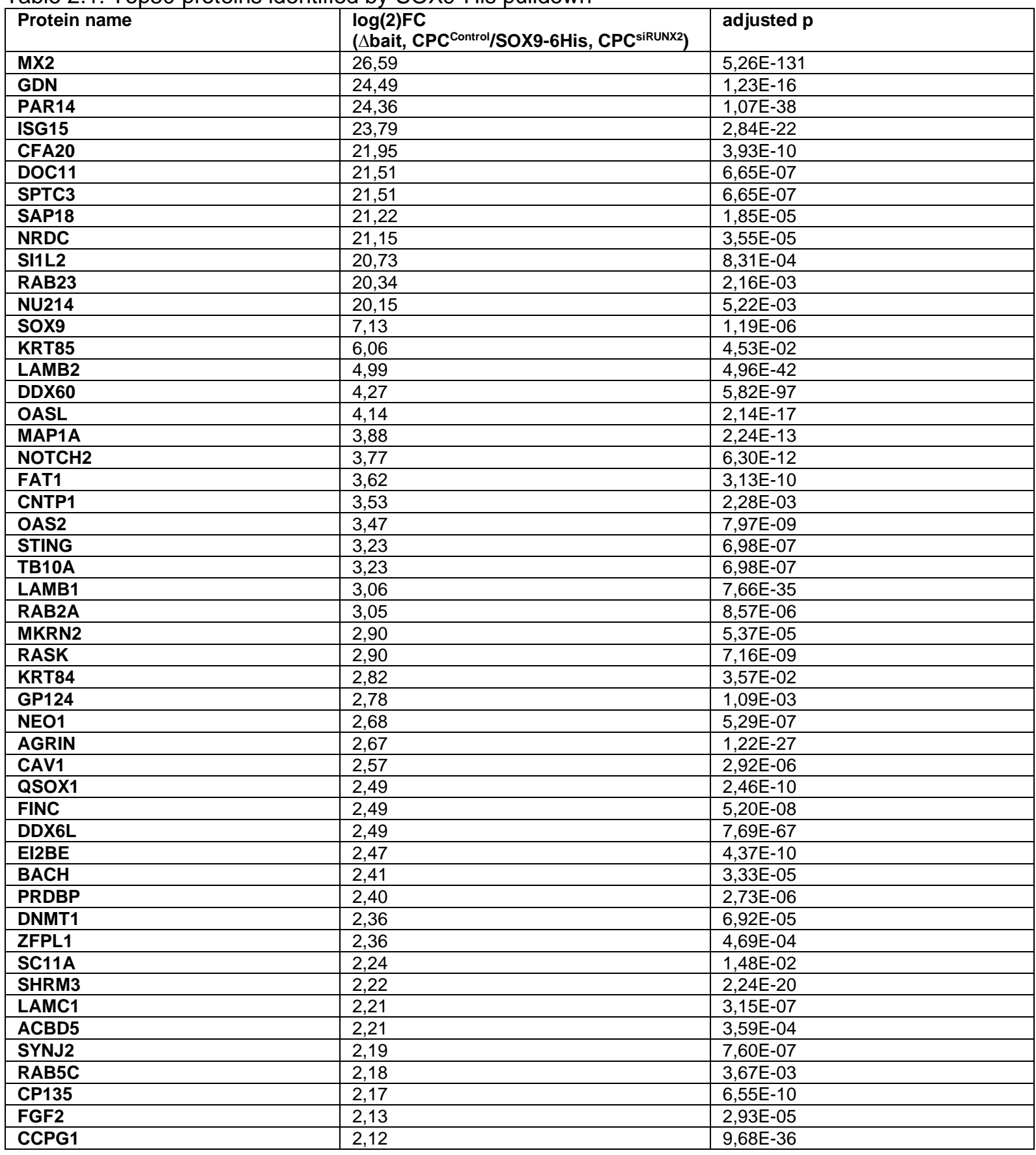


SOX9 would be identified using this approach. Subsequently, we decided not to investigate RAB2A, but instead analyzed RAB5C, an early endosomal marker that already has been linked to EGF signaling (Miaczynska et al., 2004), which participates in the chondrogenesis of CPCs (Janssen et al., 2019).

First, we generated a CPC ${ }^{\text {RABSC-I }}$ line, by targeting the flanking introns of $R A B 5 C$ exon 2 using CRISPR/CAS9 (Fig. 2.2E), as confirmed using PCR (Fig. 2.2F). An analysis of 2D cultured CPC ${ }^{\text {RABSC-- }}$, did not reveal significant changes in SOX9 and RUNX2 expression, but RAB5C expression was reduced (Fig. 2.2G). Subsequently, successful depletion of the RAB5C protein and an increased level of the SOX9 protein were observed using Western Blot (Fig. 2.2H). As RAB5C was identified using the SOX9-His pull down, in vitro co-localization of SOX9 and RAB5C was investigated using ICC. SOX9-RAB5C co-localization was not observed in the control, as SOX9 staining was mainly detected in the nucleus, as marked by DAPI (Fig. 2.2I). Furthermore, the deletion of RAB5C did not alter the nuclear localization of SOX9. The lysosomal degradation of RUNX2 is promoted by SOX9 (Cheng and Genever, 2010); therefore, we assessed the co-localization of RUNX2 with the early endosomal marker RAB5C (Fig. 2.2J). Co-localization was observed in the cytoplasm of CPCControl, but the deletion of RAB5C did not alter the localization of RUNX2. Subsequently, we performed an ex vivo migration experiment to determine whether the loss of RAB5C prevents CPCs from migrating into late-stage OA cartilage tissue, a key feature of manipulated CPCs in future therapeutic interventions. Therefore, $\mathrm{CPC}^{\text {Control }}$ and $\mathrm{CPC}^{\mathrm{RAB} 5 \mathrm{C}-\mathrm{-}-}$ were transfected with GFP and placed on the surface of the OA repair tissue. After 4 days, GFP-positive CPC ${ }^{\text {Control }}$ and CPC ${ }^{\text {RAB5C- }- \text { were }}$ observed at a depth of approximately $1800 \mu \mathrm{m}$ in the $\mathrm{OA}$ tissue specimens, indicating that the loss of RAB5C did not affect the migratory potential of CPCs (Fig. S2.2). In order to elucidate changes in the chondrogenic potential, $\triangle P C^{C o n t r o l}$ and

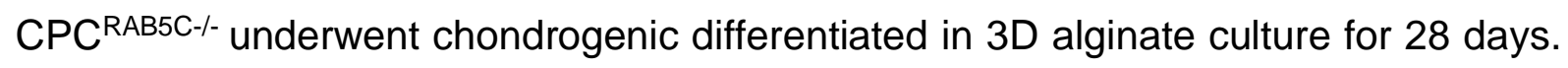
We confirmed a significant increase in SOX9 expression, but the expression of COL1A1 and COL2A1 remained unchanged (Fig. 2.2K). Moreover, the level of the RUNX2 protein was substantially but not significantly $(p=0.08)$ decreased (Fig. 2.2L). Finally, because the level of the COL2 protein increased, CPC ${ }^{\text {RABSC-I- }}$ passed the first hallmark of our screen for candidates for potential therapeutic interventions to ameliorate OA pathogenesis in the future. 

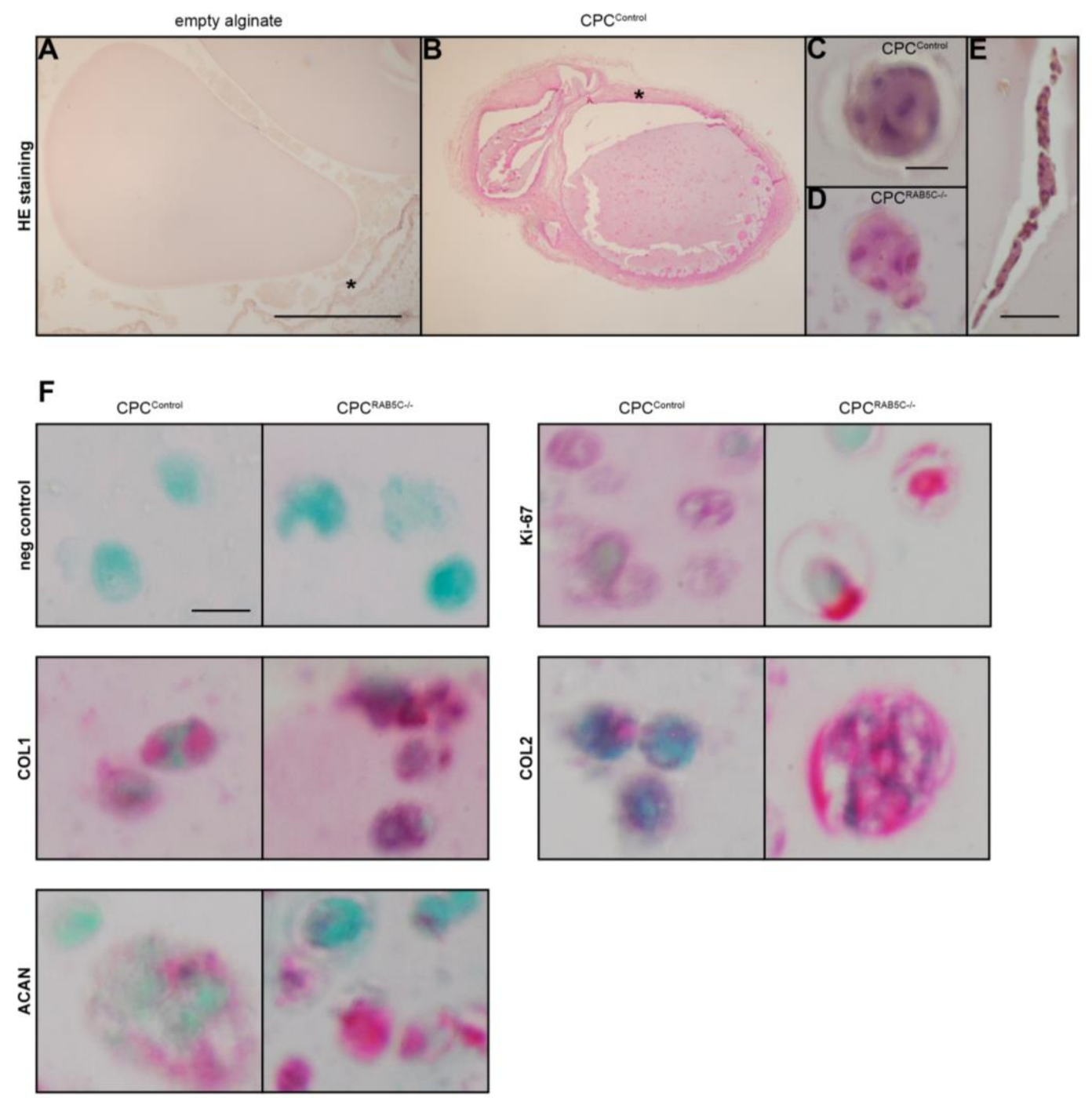

Figure 2.3: Histological examination of alginate beads transplanted into the back of nude mice. (A) HE staining of implanted beads did not reveal migration of mouse cells into the beads, as evidenced by the empty alginate control and $\left({ }^{*}\right)$ encapsulation of beads. (B) Representative images of HE staining of alginate beads carrying CPC Control. (Scale bar: $1 \mathrm{~mm}$ ). Chondrocyte clusters were observed in animals injected with (C) $\mathrm{CPC}^{\text {Control }}$ and (D) $\mathrm{CPC}^{\mathrm{RAB5C}}$-/- (scale bar: $12.5 \mu \mathrm{m}$ ), as along with (E) blood vessel formation into the beads (scale bar: $50 \mu \mathrm{m}$ ). (F) Negative control staining and Ki-67, COL1,

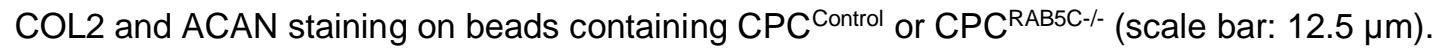

\subsubsection{Loss of RAB5C did not impede proliferation and ECM deposition by CPC in a nude mouse model}

We were interested if CPC ${ }^{\text {RABSC-I }}$ exhibited signs of impaired vitality under conditions resembling the in situ environment to evaluate RAB5C as a potential target. Alginate

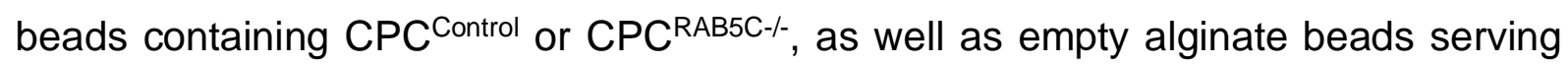
as a negative control, were transplanted into skin pockets of nude mice. After 28 days of nourishment by the tissue fluid instead of chondrogenic medium, the beads were retrieved from the mice for further analysis. The histological examination revealed the formation of fibrotic capsules enclosing all implanted beads (Fig. 2.3A 
and Fig. 2.3B, asterisk). The empty alginate control showed no migration of mouse cells into the scaffold after 28 days (Fig. 2.3A). Living and dead cells were observed using HE staining in the alginate beads (Fig. 2.3B). Furthermore, the emerging formation of chondrocyte clusters was observed in CPC Control (Fig. 2.3C) and CPC ${ }^{\text {RAB5C-- }}$ (Fig. 2.3D), as along with blood vessel formation into the beads (Fig. 2.3E). Subsequently, we examined the cells with IHC (Fig. 2.3F). First, proliferation was assessed using $\mathrm{KI}-67$ staining and revealed proliferating cells, particularly in cell clusters. When the ECM composition was analyzed, CPC ${ }^{\text {RABSC-I- }}$ deposited COL1 and COL2, consistent with the findings from our in vitro experiments. Furthermore, we detected positive staining for aggrecan (ACAN), which has a key function in hyaline cartilage (Heinegard and Saxne, 2011).

In conclusion, CPCs were still able to proliferate, despite the deletion of RAB5C. Additionally, qualitative IHC staining revealed the deposition of COL2 and ACAN, both of which are abundant in articular cartilage. This finding allowed us to continue with a deeper analysis of the $\mathrm{CPC}^{\mathrm{RAB5C}-\mathrm{I}}$, including additional markers for a possibly positive effect for chondrogenesis of CPCs.

\subsubsection{Further characterization of $\mathrm{CPC}^{\mathrm{RABSC}-/-}$-revealed increased expression of chondrogenic markers}

In the next step, we investigated the expression of additional chondrogenic markers using RNA-Seq. CPC Control and CPC ${ }^{\text {RAB5C-- }}$ samples were collected on days 0,3 , and 28 of chondrogenic differentiation in vitro. First, we determined the expression profile of all cartilage-related genes during the onset of the chondrogenic differentiation of CPC Control and CPC ${ }^{\text {RABSC- }-~}$ by performing an enrichment analysis of genes related to the term cartilage morphogenesis using MSigDB (Fig. 2.4A). The initiation of differentiation led to increased enrichment of this signature from day 0 to day 3 in both cell lines (CPC Control and CPC ${ }^{\text {RABSC-- }}$, $p<0.001$ ). CPC ${ }^{\text {RABSC-- }}$ displayed a decreased enrichment of signature genes compared to CPC Control on day 3 , although no difference was observed between $\mathrm{CPC}^{\text {Control }}$ and $\mathrm{CPC}^{\text {RAB5C-l- }}$ on day 28.

Next, we focused on the most important cartilage markers. Fig. 2.4B-D lists all genes that displayed a significant difference in expression between $\mathrm{CPC}^{\text {Control }}$ and CPC ${ }^{\text {RABSC- }-~}$ at least at one time point. The increased expression of chondrogenic transcription factors and markers (Fig. 2.4B and Fig. 2.4D), as well as the decrease 
A

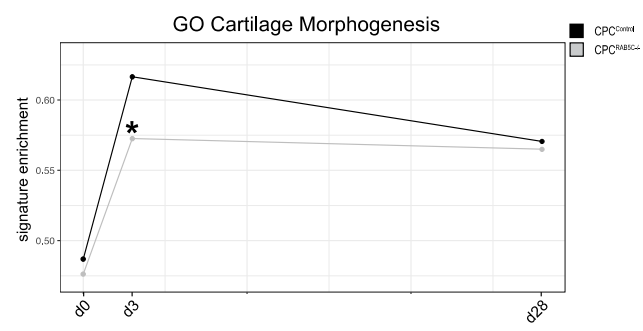

B

Transcription factors
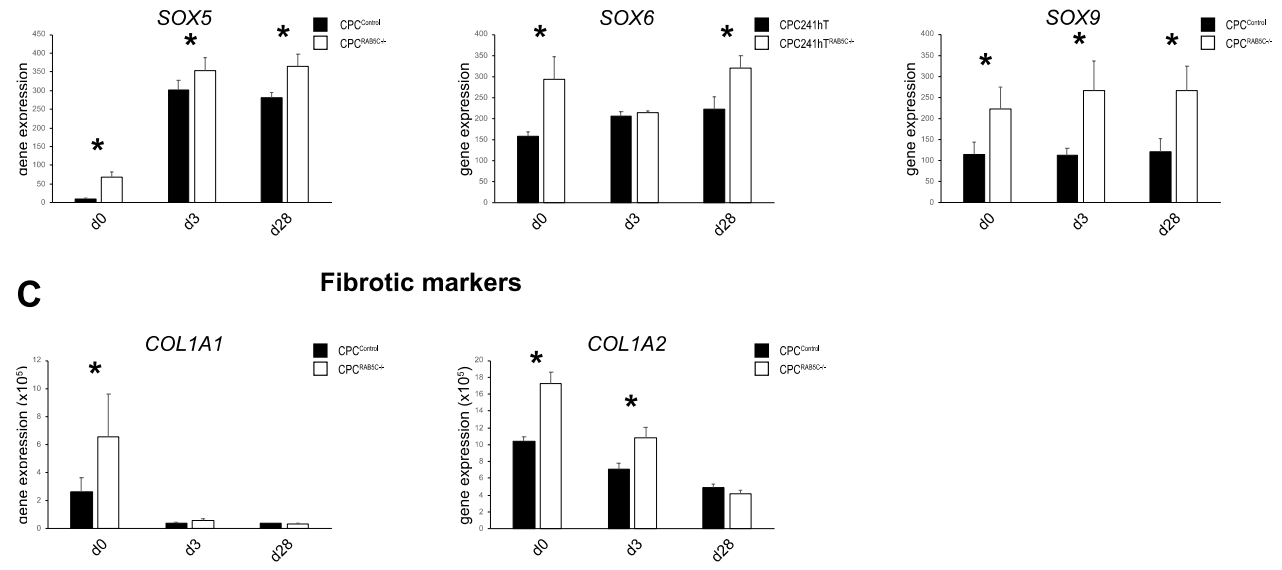

D
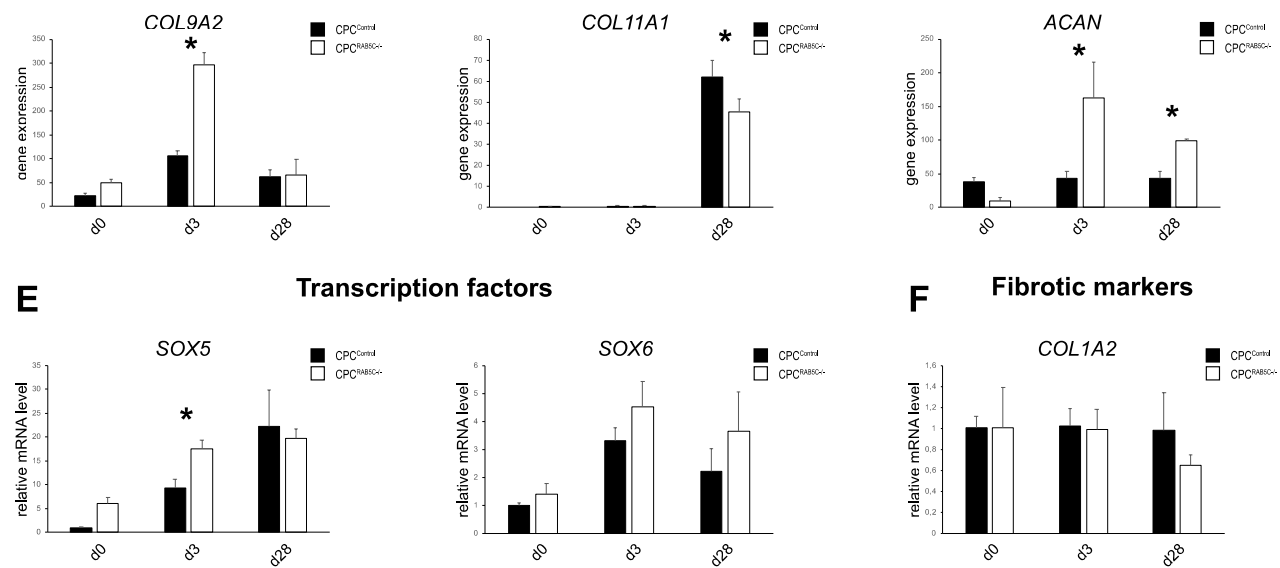

$\mathbf{F}$

Fibrotic markers
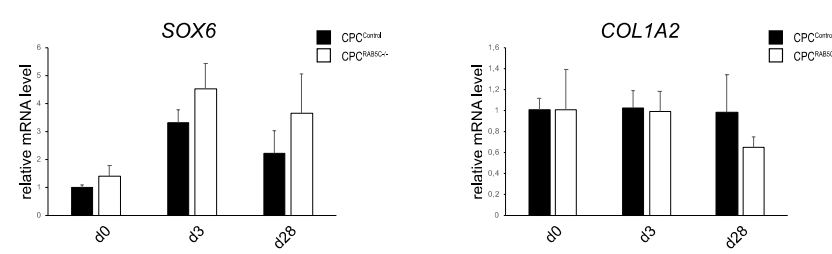

G

Cartilage markers
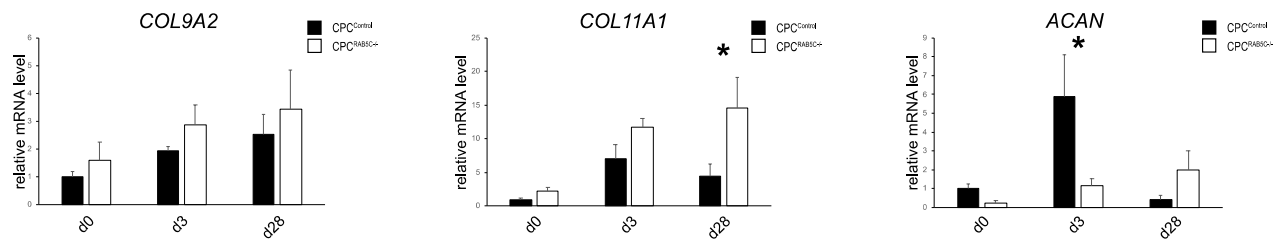

Figure 2.4: Broader analysis of $\mathrm{CPC}^{\mathrm{RABSC}-/}$ marker expression during chondrogenic differentiation in vitro. (A) Differential enrichment of genes that are annotated within the category Cartilage Morphogenesis in MSigDB. RNA-Seq analysis of the expression of (B) the transcription factors SOX5, SOX6, SOX9 and RUNX2, (C) fibrotic markers COL1A1 and COL1A2, and (D) cartilage markers ACAN, COL9A2 and COL11A1 in CPC Control and CPC ${ }^{\text {RAB5C-- }-~}$ on days 0,3 and 28 of chondrogenic differentiation. qPCR analysis of (E) SOX5, SOX6, (F) COL1A2, (G) ACAN, COL9A2 and COL11A1 expression. 
in the expression of fibrotic markers (Fig. 2.4C) in $\mathrm{CPC}^{\text {Control }}$ is consistent with previous studies of 3D alginate cultures (Kumar and Lassar, 2009).

A detailed analysis of the SOX trio (Fig. 2.4B), which plays a major role in chondrogenesis (de Crombrugghe et al., 2001), allowed us to observe higher expression of SOX5 in CPC RAB5C-/ than in CPC Control at every time point. Next, higher SOX6 expression was detected in CPC ${ }^{\text {AAB5C-- }}$ on days 0 and 28 than in $\mathrm{CPC}^{\text {Control. }}$. Finally, the SOX9 expression level was elevated in CPCRAB5C- - on every day compared to the respective control, consistent with the results shown in Fig. $2 \mathrm{~K}$.

Subsequently, we analyzed the fibrocartilage marker COL1A1 (Fig. 2.4C) and observed higher expression in CPC RAB5C-/ compared to CPC ${ }^{\text {Control }}$ on day 0 , but its

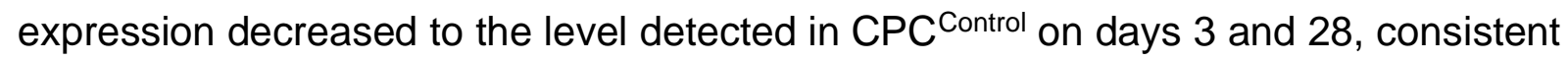
with the results of the qPCR analysis of COL1A1 on day 28 shown in Fig. 2K. Additionally, higher COL1A2 expression was observed on day 0 and day 3 in $\mathrm{CPC}^{\text {RAB5C-/- }}$, which then decreased on day 28 to the level observed in CPC Control. Finally, we investigated markers of hyaline cartilage (Fig. 2.4D). Unfortunately, COL2A1 expression was not detected using RNA-Seq. Nevertheless, COL9A2 and COL11A1 were examined, as both collagens are related to COL2 regulation and organization through crosslinking (Eyre, 1991, Mendler et al., 1989). COL9A2 expression was increased on day 3 in CPC ${ }^{\text {RABSC-l- }}$ and COL11A1 expression was decreased on day 28 in CPC ${ }^{\text {RABSC-- }}$ compared to the respective control. Finally, we observed increased ACAN expression in CPC ${ }^{\text {RABSC-- }}$ on days 3 and 28 compared to the respective control.

We confirmed the results of the RNA-Seq analysis using complementary qPCR (Fig. 2.4E-G) to further corroborate the higher chondrogenic potential observed after the loss of RAB5C. Consistent with the results presented in Fig. 2.4B and Fig. 2.4D, significantly increased SOX5 (Fig. 2.4E) and COL11A1 expression (Fig. 2.4G) were detected at least at one time point in CPC ${ }^{\text {RABSC- }-~}$ compared to CPC Control. However, SOX6 (Fig. 2.4E) and COL9A2 (Fig. 2.4G) expression were increased in CPC RAB5C-at every time point investigated, but the differences were not significant. Finally, differences in COL1A2 expression were not noticed (Fig. 2.4F), while ACAN expression was increased in CPC ${ }^{\text {Control }}$ only on day 3 compared to CPC ${ }^{\text {RAB5C-F- }}$ (Fig. $2.4 G)$. 
A

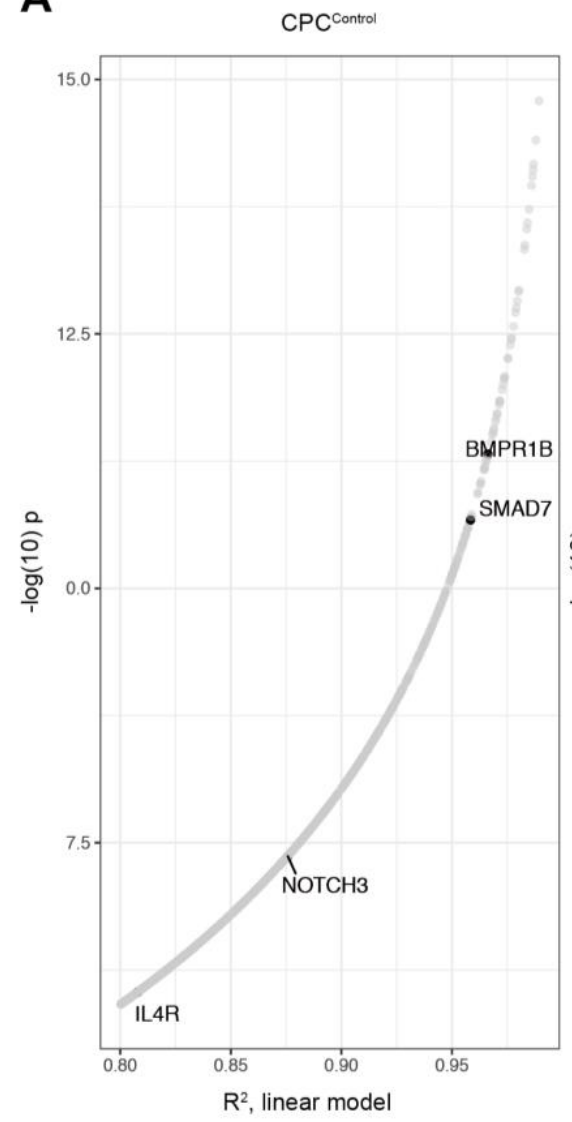

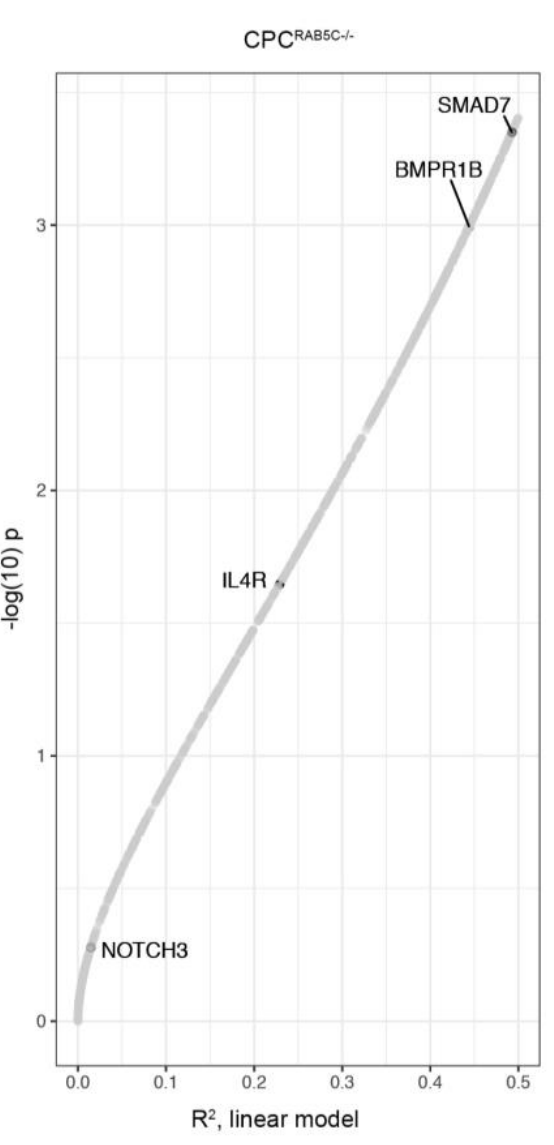

B
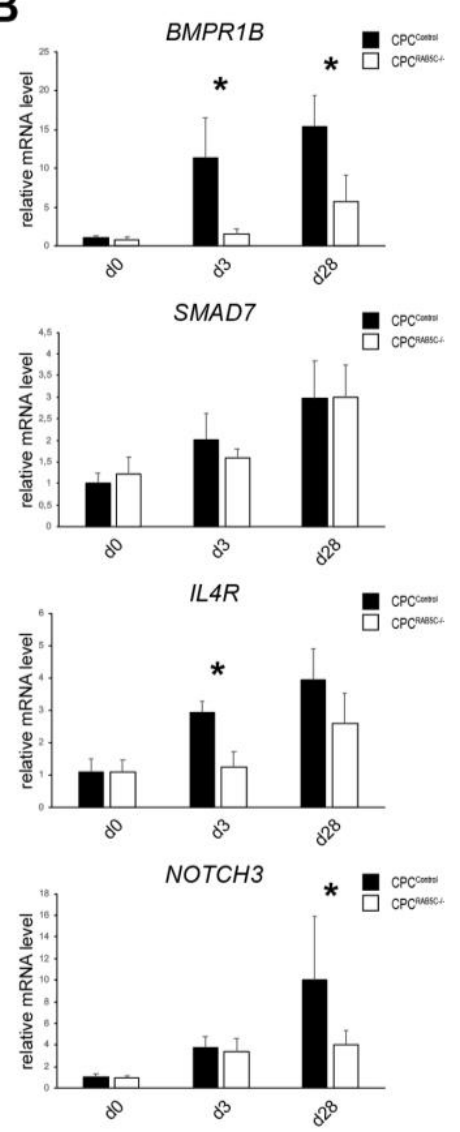

Figure 2.5: Differential expression of mediators involved in chondrogenesis in CPC ${ }^{\text {RAB5C-- }}$. (A) Analysis of genes identified by RNA-Seq fitting a linear model of expression during chondrogenic differentiation $\left(R^{2}=0.8\right.$ and $p$ value $\left.<0.05\right)$ in CPC ${ }^{\text {Control }}$, but not in $C P^{\text {RAB5C-l- }}$. (B) $q P C R$ analysis of BMPR1B, IL4R, NOTCH3 and SMAD7 expression in CPC ${ }^{\text {Control }}$ and CPC ${ }^{\text {RABSC-- }-}$ on days 0,3 and 28.

Based on these findings, we concluded that the deletion of RAB5C did not lead to severe alterations in the expression of all genes related to chondrogenesis, but it positively affected the expression of the most important chondrogenic markers. Therefore, we were interested in elucidating the mechanism underlying this effect.

\subsubsection{Loss of RAB5C deregulates pathways related to chondrogenesis} Next, we searched for other deregulated genes in CPC RAB5C-- to find candidates that mediate the observed increase in the chondrogenic potential. Thus, we applied a statistical model based on the hypothesis that the expression of genes related to chondrogenesis will be linear during the course of chondrogenesis. Subsequently, we matched those genes with linear expression in CPC Control, but not in CPC RAB5C-- , to identify genes with a possible activating or inhibitory effect on chondrogenesis that are deregulated after the loss of RAB5C (Fig. 2.5A and Tab. S2.2). Two members of the BMP signaling pathway, BMPR1B and SMAD7, fit the model in CPC ${ }^{\text {Control }}$, but not in $\mathrm{CPC}^{\mathrm{RABSC}-\mathrm{r}}$. Furthermore, NOTCH3 and IL4R were deregulated in $\mathrm{CPC}^{\mathrm{RAB5C}-{ }^{-}}$. The 
qPCR analysis confirmed the lower expression levels of BMPR1B on days 3 and 28, IL4R on day 3 and NOTCH3 on day 28 , but we did not corroborate our finding for SMAD7 using qPCR (Fig. 2.5B).

In addition, regarding our IL4R results, we performed a GSEA of all deregulated genes in CPC ${ }^{\text {RABSC- }-~}$. The analysis of Gene Ontology (GO) and KEGG pathway terms revealed a substantial downregulation of genes related to the chemokine signaling pathway, response to chemokine and cytokine-cytokine receptor interaction (Fig. S2.3 and Tab. S2.3) including other $I L(R)$ s expressed in CPC RAB5C- - on days 3 and 28 of chondrogenic differentiation.

In summary, we identified mediators of pathways involved in chondrogenesis that were deregulated at least at one of the time points, and the roles of these proteins should be investigated in future studies to further elucidate the pro-chondrogenic effect observed on CPC RAB5C- - .

In conclusion, an increase of the chondrogenic potential of CPCs is not achieved by the complete deletion of RUNX2. We identified RAB5C as a co-regulator of SOX9. RAB5C-deficient CPCs exhibited an increased chondrogenic potential in vitro and were capable of producing cartilage markers in vivo. Furthermore, an abolishment of COL1 synthesis in CPCs to promote COL2 synthesis is not achieved by the simple upregulation of chondrogenic transcription factors. Finally, the effects of the deletion of RAB5C are likely based on altered BMP, NOTCH and IL signaling events, rather than direct interactions between SOX9 and RAB5C. 


\subsection{Discussion}

\subsubsection{A minimal amount of RUNX2 enhances the chondrogenic differentiation of CPCs}

Several studies elucidated the essential roles of SOX9 in chondrogenic differentiation and cartilage development ( $\mathrm{Bi}$ et al., 1999), while studies on the chondrogenic function of RUNX2 have mainly focused on its role in endochondral ossification by inducing chondrocyte hypertrophy (Inada et al., 1999). Our previous study reported the enhanced chondrogenic potential of CPCsiRUNX2-- (Koelling et al., 2009), but here, we observed that the total absence of RUNX2 negatively affects COL2 synthesis, while the level of SOX9, a strong activator of COL2, remained unchanged. The assumption that RUNX2 positively modulates pre-hypertrophic chondrogenesis independent from SOX9 is further corroborated by the findings of Chen et al. (2014), who reported that RUNX2 already plays an important role in earlier stages. The COL2a-Cre driven expression of a truncated RUNX2 protein resulted in distorted growth plate architecture, including decreased chondrocyte numbers in resting, proliferating and pre-hypertrophic regions of mice. However, they did not observe differences in the SOX9 level between wildtype and mutant limbs, again indicating that RUNX2 modulates chondrogenesis independent of the SOX9 level. Nevertheless, neither Chen et al. (2014) nor we investigated whether the RUNX2 deletion alters the regulation of SOX9 activity by phosphorylation (Huang et al., 2000) or translocation (Malki et al., 2005) in addition to the actual level of the SOX9 protein.

\subsubsection{RAB5C is a potential target that enhances chondrogenesis in CPCs}

Previous studies have focused on altering the ECM synthesis of chondrocytes and CPCs through stimulation with growth factors (Janssen et al., 2019, Gelse et al., 2008, Wagner et al., 2019). However, the complexity of the underlying mechanisms often leads to ambiguous results, as the same ligand may trigger different responses (Grafe et al., 2018, Kozhemyakina et al., 2015). Here, we successfully avoided this issue by identifying RAB5C as potential co-regulator of SOX9. RAB proteins are attractive drug targets (Russell, 2007, Coxon et al., 2005), highlighting our findings that the deletion of RAB5C resulted in a substantial increase in the expression of several chondrogenic markers, including the SOX trio. Increased expression of chondrogenic marker genes has produced promising results in vivo in previous studies (Jeong et al., 2020, Im and Kim, 2011). Consistent with the findings from our previous study (Koelling et al., 2009), a reduction in RUNX2 expression in CPCRAB5C- 
1-, although it was not significant, correlated with increased expression of chondrogenic markers. Furthermore, the loss of RAB5C did not impair ACAN and COL2 deposition, cell proliferation and the formation of cell clusters in 3D beads retrieved from mice. These clusters are also observed in OA tissue (Poole et al., 1991), and their formation has been proposed as the initial step of cartilage regeneration (Lotz et al., 2010).

In addition to the increased deposition of COL2, the amount of fibrotic COL1 was not affected by the loss of RAB5C. Thus, an upregulation of chondrogenic markers does not necessarily suppress the fibrotic traits of CPCs, and therapies simply aiming to increase the chondrogenic potential of CPCs would not result in the complete absence of fibrocartilage in patients. Nevertheless, the deposition of more chondrogenic fibrocartilage would postpone the total loss of joint function and thus improve the quality of life of patients.

\subsubsection{The loss of RAB5C alters receptor expression in CPCs}

The increased expression of several chondrogenic markers observed after the loss of RAB5C indicated an upstream repressor function of RAB5C. The further characterization of this interaction did not reveal the co-localization of SOX9 and RAB5C in vitro, although RAB5C was identified using the SOX9-His pull down. Furthermore, the loss of RAB5C did not alter the localization of RUNX2, a known modulator of SOX9 function (Zhou et al., 2006). A limitation of our study is that the levels of SOX9 and RUNX2 activity, e.g., phosphorylation, were not measured. As no additional literature is available that describes a physical interaction between RAB5C and one or both regulators, we assume that the pro-chondrogenic effect results from altered signaling events. Although RAB5C has been linked to EGF signaling (Miaczynska et al., 2004) and another RAB protein, RAB23, indirectly regulates SOX9 through SHH signaling (Yang et al., 2008), our data suggested alterations in BMP, Notch and IL signaling in CPCs.

First, BMP receptors bind to multiple ligands involved in chondrogenesis (Grafe et al., 2018), and activate SMADs (Mummery, 2001). Interestingly, BMPR1B was described to have overlapping functions with BMPR1A in mice, and decreased expression of the SOX trio was observed in Bmpr1aCKO; $\mathrm{Bmpr}^{\mathrm{C}} \mathrm{b}^{-/}$mice (Yoon et al., 2005). However, according to Kaps et al. (2004), BMPR1B is unlikely to play a role in chondrogenesis of mesenchymal progenitors. Furthermore, the analysis of SMAD7, a downstream target of BMPR signaling, was ambiguous, which may be explained by 
different methodological biases. Due to its co-localization to early endosomes (Rajagopal et al., 2007) and its inhibitory function in BMP signaling (Mummery, 2001), future studies should include analyses of the levels of the total and phosphorylated SMAD7 protein.

As shown in the study by Green et al. (2015), transient NOTCH signaling is necessary for chondrogenesis, as $\mathrm{NOTCH}$ receptors are present in chondroprogenitors but their spatial expression changes during cartilage development. Consistent with this finding, Oldershaw et al. (2008) observed the peak level of NOTCH3 in hMSC 2D monoculture, but decreased levels were observed in the subsequent 3D chondrogenic pellet culture; thus, this pathway is important for initiation of chondrogenesis and must be inhibited after the initial step. In contrast, our 3D alginate culture is characterized by few cell-cell contacts on which NOTCH signaling usually depends. Therefore, the downregulation of $\mathrm{NOTCH} 3$ in confluent cells exerts a pro-chondrogenic effect that is usually not observed in 3D alginate culture, and the loss of RAB5C in 3D alginate culture mimics this effect through the downregulation of NOTCH3. However, soluble ligands of Notch receptors have also recently been identified (D'Souza et al., 2008).

IL4-mediated activation of JAK/STAT signaling has been investigated in chondrocytes from healthy and OA cartilage, but the authors of this study proposed that the crosstalk with integrins and other cytokine signaling pathways rather than the level of IL4R expression play important roles in mechanotransduction and cartilage degradation (Millward-Sadler et al., 2006). Assirelli et al. (2014) did not detect differences in IL4R expression in healthy and OA cartilage specimens and highlighted the difference in the expression level of the ligand IL4. Finally, Vargiolu et al. (2010) identified IL4R as susceptibility loci for hand OA.

Finally, additional studies on the protein levels of the candidate genes are required to elucidate the mechanism underlying the effect of RAB5C on the aforementioned signaling pathways. The loss of RAB5C potentially affects endosomal processing and the downregulation of these pathways, followed by the increased expression of chondrogenic markers. On the other hand, the loss of RAB5C may primarily affect the expression of major chondrogenic regulators, resulting in the downregulation of the aforementioned signaling molecules.

Taken together, our study highlights the pro-chondrogenic effect of the osteogenic regulator RUNX2, whose deletion negatively regulates ECM synthesis in CPCs. 
Furthermore, RAB5C was newly identified as a candidate protein that enhances chondrogenesis. Its deletion enhances the chondrogenic potential of CPCs in vitro, an effect that is likely mediated by altered BMP, NOTCH and IL signaling. More research on the in vivo phenotype and the underlying signaling pathways is necessary to further endorse this candidate as potential target for future OA therapies. 


\section{Bibliography}

ALBUS, E., SINNINGEN, K., WINZER, M., THIELE, S., BASCHANT, U., HANNEMANN, A., FANTANA, J., TAUSCHE, A. K., WALLASCHOFSKI, H., NAUCK, M., VÖLZKE, H., GROSSKLAUS, S., CHAVAKIS, T., UDEY, M. C., HOFBAUER, L. C. \& RAUNER, M. 2016. Milk Fat Globule-Epidermal Growth Factor 8 (MFG-E8) Is a Novel Anti-inflammatory Factor in Rheumatoid Arthritis in Mice and Humans. J Bone Miner Res, 31, 596-605.

ALLEN, K. D. 2010. Racial and ethnic disparities in osteoarthritis phenotypes. Curr Opin Rheumatol, 22, 528-32.

ALTMAN, R., ASCH, E., BLOCH, D., BOLE, G., BORENSTEIN, D., BRANDT, K., CHRISTY, W., COOKE, T. D., GREENWALD, R., HOCHBERG, M. \& ET AL. 1986. Development of criteria for the classification and reporting of osteoarthritis. Classification of osteoarthritis of the knee. Diagnostic and Therapeutic Criteria Committee of the American Rheumatism Association. Arthritis Rheum, 29, 1039-49.

AMANO, K., HATA, K., SUGITA, A., TAKIGAWA, Y., ONO, K., WAKABAYASHI, M., KOGO, M., NISHIMURA, R. \& YONEDA, T. 2009. Sox9 family members negatively regulate maturation and calcification of chondrocytes through upregulation of parathyroid hormone-related protein. Mol Biol Cell, 20, 4541-51.

AMEYE, L., ARIA, D., JEPSEN, K., OLDBERG, A., XU, T. \& YOUNG, M. F. 2002. Abnormal collagen fibrils in tendons of biglycan/fibromodulin-deficient mice lead to gait impairment, ectopic ossification, and osteoarthritis. Faseb j, 16, 673-80.

ANDERS, S. \& HUBER, W. 2010. Differential expression analysis for sequence count data. Genome Biol, 11, R106.

ANDERS, S., MCCARTHY, D. J., CHEN, Y., OKONIEWSKI, M., SMYTH, G. K., HUBER, W. \& ROBINSON, M. D. 2013. Count-based differential expression analysis of RNA sequencing data using R and Bioconductor. Nat Protoc, 8, 1765-86.

ANDREWS, S. 2010. FastQC: a quality control tool for high throughput sequence data [Online]. Available: http://www.bioinformatics.babraham.ac.uk/projects/fastqc.

ASsiRelli, E., PULSATElli, L., DOLZANI, P., PLATANO, D., OliVOTTO, E., FILARDO, G., TRISOLINO, G., FACCHINI, A., BORZÌ, R. M. \& MELICONI, R. 2014. Human osteoarthritic cartilage shows reduced in vivo expression of IL-4, a chondroprotective cytokine that differentially modulates IL-1 $\beta$-stimulated production of chemokines and matrix-degrading enzymes in vitro. PLoS One, 9, e96925.

BATSCHKUS, S., ATANASSOV, I., LENZ, C., MEYER-MARCOTTY, P., CINGÖZ, G., KIRSCHNECK, C., URLAUB, H. \& MIOSGE, N. 2017. Mapping the secretome of human chondrogenic progenitor cells with mass spectrometry. Ann Anat, 212, 4-10.

BI, W., DENG, J. M., ZHANG, Z., BEHRINGER, R. R. \& DE CROMBRUGGHE, B. 1999. Sox9 is required for cartilage formation. Nat Genet, 22, 85-9.

BI, W., HUANG, W., WHITWORTH, D. J., DENG, J. M., ZHANG, Z., BEHRINGER, R. R. \& DE CROMBRUGGHE, B. 2001. Haploinsufficiency of Sox9 results in defective cartilage primordia and premature skeletal mineralization. Proc Natl Acad Sci U S A, 98, 6698-703.

BI, Y., EHIRCHIOU, D., KILTS, T. M., INKSON, C. A., EMBREE, M. C., SONOYAMA, W., LI, L., LEET, A. I., SEO, B. M., ZHANG, L., SHI, S. \& 
YOUNG, M. F. 2007. Identification of tendon stem/progenitor cells and the role of the extracellular matrix in their niche. Nat Med, 13, 1219-27.

BLACK, M. 1984. Acetaminophen hepatotoxicity. Annu Rev Med, 35, 577-93.

BLAGOJEVIC, M., JINKS, C., JEFFERY, A. \& JORDAN, K. P. 2010. Risk factors for onset of osteoarthritis of the knee in older adults: a systematic review and meta-analysis. Osteoarthritis Cartilage, 18, 24-33.

BLALOCK, D., MILLER, A., TILLEY, M. \& WANG, J. 2015. Joint Instability and Osteoarthritis. Clinical Medicine Insights: Arthritis and Musculoskeletal Disorders, 8, CMAMD.S22147.

BLANEY DAVIDSON, E. N., SCHARSTUHL, A., VITTERS, E. L., VAN DER KRAAN, P. M. \& VAN DEN BERG, W. B. 2005. Reduced transforming growth factorbeta signaling in cartilage of old mice: role in impaired repair capacity. Arthritis Res Ther, 7, R1338-47.

BOCK, H. C., MICHAELI, P., BODE, C., SCHULTZ, W., KRESSE, H., HERKEN, R. \& MIOSGE, N. 2001. The small proteoglycans decorin and biglycan in human articular cartilage of late-stage osteoarthritis. Osteoarthritis Cartilage, 9, 65463.

BORASCHI-DIAZ, I., WANG, J., MORT, J. S. \& KOMAROVA, S. V. 2017. Collagen Type I as a Ligand for Receptor-Mediated Signaling. Frontiers in Physics, 5.

BOYAN, B. D., HART, D. A., ENOKA, R. M., NICOLELLA, D. P., RESNICK, E., BERKLEY, K. J., SLUKA, K. A., KWOH, C. K., TOSI, L. L., O'CONNOR, M. I., COUTTS, R. D. \& KOHRT, W. M. 2013. Hormonal modulation of connective tissue homeostasis and sex differences in risk for osteoarthritis of the knee. Biol Sex Differ, 4, 3.

BRIOT, A., JAROSZEWICZ, A., WARREN, C. M., LU, J., TOUMA, M., RUDAT, C., HOFMANN, J. J., AIRIK, R., WEINMASTER, G., LYONS, K., WANG, Y., KISPERT, A., PELLEGRINI, M. \& IRUELA-ARISPE, M. L. 2014. Repression of Sox 9 by Jag1 is continuously required to suppress the default chondrogenic fate of vascular smooth muscle cells. Dev Cell, 31, 707-21.

BRITTBERG, M., LINDAHL, A., NILSSON, A., OHLSSON, C., ISAKSSON, O. \& PETERSON, L. 1994. Treatment of deep cartilage defects in the knee with autologous chondrocyte transplantation. N Engl J Med, 331, 889-95.

BRODSKY, B., THIAGARAJAN, G., MADHAN, B. \& KAR, K. 2008. Triple-helical peptides: an approach to collagen conformation, stability, and self-association. Biopolymers, 89, 345-53.

BRUCKNER, P. \& VAN DER REST, M. 1994. Structure and function of cartilage collagens. Microscopy Research and Technique, 28, 378-384.

BRUDERER, M., RICHARDS, R. G., ALINI, M. \& STODDART, M. J. 2014. Role and regulation of RUNX2 in osteogenesis. Eur Cell Mater, 28, 269-86.

BUCKWALTER, J. A. \& MANKIN, H. J. 1998a. Articular cartilage: degeneration and osteoarthritis, repair, regeneration, and transplantation. Instr Course Lect, 47, 487-504.

BUCKWALTER, J. A. \& MANKIN, H. J. 1998b. Articular cartilage: tissue design and chondrocyte-matrix interactions. Instr Course Lect, 47, 477-86.

BURCH, M. L., YANG, S. N., BALLINGER, M. L., GETACHEW, R., OSMAN, N. \& LITTLE, P. J. 2010. TGF-beta stimulates biglycan synthesis via p38 and ERK phosphorylation of the linker region of Smad2. Cell Mol Life Sci, 67, 2077-90.

BURGESS, A. W., CHO, H. S., EIGENBROT, C., FERGUSON, K. M., GARRETT, T. P., LEAHY, D. J., LEMMON, M. A., SLIWKOWSKI, M. X., WARD, C. W. \& YOKOYAMA, S. 2003. An open-and-shut case? Recent insights into the activation of EGF/ErbB receptors. Mol Cell, 12, 541-52. 
BURR, D. B. 2004. The importance of subchondral bone in the progression of osteoarthritis. J Rheumatol Suppl, 70, 77-80.

BUSH, J. R. \& BEIER, F. 2013. TGF-beta and osteoarthritis--the good and the bad. Nat Med, 19, 667-9.

CHEN, H., GHORI-JAVED, F. Y., RASHID, H., ADHAMI, M. D., SERRA, R., GUTIERREZ, S. E. \& JAVED, A. 2014. Runx2 regulates endochondral ossification through control of chondrocyte proliferation and differentiation. $J$ Bone Miner Res, 29, 2653-65.

CHEN, N. M., SINGH, G., KOENIG, A., LIOU, G. Y., STORZ, P., ZHANG, J. S., REGUL, L., NAGARAJAN, S., KUHNEMUTH, B., JOHNSEN, S. A., HEBROK, M., SIVEKE, J., BILLADEAU, D. D., ELLENRIEDER, V. \& HESSMANN, E. 2015. NFATc1 Links EGFR Signaling to Induction of Sox9 Transcription and Acinar-Ductal Transdifferentiation in the Pancreas. Gastroenterology, 148, 1024-1034.e9.

CHUNG, U. I., SCHIPANI, E., MCMAHON, A. P. \& KRONENBERG, H. M. 2001. Indian hedgehog couples chondrogenesis to osteogenesis in endochondral bone development. J Clin Invest, 107, 295-304.

CICUTTINI, F. M., BAKER, J., HART, D. J. \& SPECTOR, T. D. 1996. Association of pain with radiological changes in different compartments and views of the knee joint. Osteoarthritis Cartilage, 4, 143-7.

COXON, F. P., EBETINO, F. H., MULES, E. H., SEABRA, M. C., MCKENNA, C. E. \& ROGERS, M. J. 2005. Phosphonocarboxylate inhibitors of Rab geranylgeranyl transferase disrupt the prenylation and membrane localization of Rab proteins in osteoclasts in vitro and in vivo. Bone, 37, 349-58.

D'SOUZA, B., MIYAMOTO, A. \& WEINMASTER, G. 2008. The many facets of Notch ligands. Oncogene, 27, 5148-67.

DAHAGHIN, S., BIERMA-ZEINSTRA, S. M., GINAI, A. Z., POLS, H. A., HAZES, J. M. \& KOES, B. W. 2005. Prevalence and pattern of radiographic hand osteoarthritis and association with pain and disability (the Rotterdam study). Ann Rheum Dis, 64, 682-7.

DAHLIN, R. L., NI, M., MERETOJA, V. V., KASPER, F. K. \& MIKOS, A. G. 2014. TGF-beta3-induced chondrogenesis in co-cultures of chondrocytes and mesenchymal stem cells on biodegradable scaffolds. Biomaterials, 35, 12332.

DAI, H., CHEN, R., GUI, C., TAO, T., GE, Y., ZHAO, X., QIN, R., YAO, W., GU, S., JIANG, Y. \& GUI, J. 2020. Eliminating senescent chondrogenic progenitor cells enhances chondrogenesis under intermittent hydrostatic pressure for the treatment of OA. Stem Cell Res Ther, 11, 199.

DANFELTER, M., ONNERFJORD, P. \& HEINEGÅRD, D. 2007. Fragmentation of proteins in cartilage treated with interleukin-1: specific cleavage of type IX collagen by matrix metalloproteinase 13 releases the NC4 domain. $J$ Biol Chem, 282, 36933-41.

DE CROMBRUGGHE, B., LefEBVRE, V. \& NAKASHIMA, K. 2001. Regulatory mechanisms in the pathways of cartilage and bone formation. Curr Opin Cell Biol, 13, 721-7.

DEGROOT, J., VERZIJL, N., BANK, R. A., LAFEBER, F. P., BIJLSMA, J. W. \& TEKOPPELE, J. M. 1999. Age-related decrease in proteoglycan synthesis of human articular chondrocytes: the role of nonenzymatic glycation. Arthritis Rheum, 42, 1003-9.

DIEKMAN, B. O., ESTES, B. T. \& GUILAK, F. 2010. The effects of BMP6 overexpression on adipose stem cell chondrogenesis: Interactions with 
dexamethasone and exogenous growth factors. J Biomed Mater Res A, 93, 994-1003.

DOBIN, A., DAVIS, C. A., SCHLESINGER, F., DRENKOW, J., ZALESKI, C., JHA, S., BATUT, P., CHAISSON, M. \& GINGERAS, T. R. 2013. STAR: ultrafast universal RNA-seq aligner. Bioinformatics, 29, 15-21.

DOCHEVA, D., PADULA, D., POPOV, C., WEISHAUPT, P., PRÄGERT, M., MIOSGE, N., HICKEL, R., BÖCKER, W., CLAUSEN-SCHAUMANN, H. \& SCHIEKER, M. 2010. Establishment of immortalized periodontal ligament progenitor cell line and its behavioural analysis on smooth and rough titanium surface. Eur Cell Mater, 19, 228-41.

DOUGLASS, S., GOYAL, A. \& IOZZO, R. V. 2015. The role of perlecan and endorepellin in the control of tumor angiogenesis and endothelial cell autophagy. Connect Tissue Res, 56, 381-91.

DROGUETT, R., CABELLO-VERRUGIO, C., SANTANDER, C. \& BRANDAN, E. 2010. TGF-beta receptors, in a Smad-independent manner, are required for terminal skeletal muscle differentiation. Exp Cell Res, 316, 2487-503.

EGGLI, P. S., HERRMANN, W., HUNZIKER, E. B. \& SCHENK, R. K. 1985. Matrix compartments in the growth plate of the proximal tibia of rats. Anat Rec, 211, 246-57.

ELDRIDGE, S., NALESSO, G., ISMAIL, H., VICENTE-GRECO, K., KABOURIDIS, P., RAMACHANDRAN, M., NIEMEIER, A., HERZ, J., PITZALIS, C., PERRETTI, M. \& DELL'ACCIO, F. 2016. Agrin mediates chondrocyte homeostasis and requires both LRP4 and alpha-dystroglycan to enhance cartilage formation in vitro and in vivo. Ann Rheum Dis, 75, 1228-35.

EMBREE, M. C., CHEN, M., PYLAWKA, S., KONG, D., IWAOKA, G. M., KALAJZIC, I., YAO, H., SHI, C., SUN, D., SHEU, T. J., KOSLOVSKY, D. A., KOCH, A. \& MAO, J. J. 2016. Exploiting endogenous fibrocartilage stem cells to regenerate cartilage and repair joint injury. Nat Commun, 7, 13073.

EMBREE, M. C., KILTS, T. M., ONO, M., INKSON, C. A., SYED-PICARD, F., KARSDAL, M. A., OLDBERG, A., BI, Y. \& YOUNG, M. F. 2010. Biglycan and fibromodulin have essential roles in regulating chondrogenesis and extracellular matrix turnover in temporomandibular joint osteoarthritis. $A m \mathrm{~J}$ Pathol, 176, 812-26.

ERDMANN, J., THÖMING, J. G., POHL, S., PICH, A., LENZ, C. \& HÄUSSLER, S. 2019. The Core Proteome of Biofilm-Grown Clinical Pseudomonas aeruginosa Isolates. Cells, 8.

EYRE, D. R. 1991. The collagens of articular cartilage. Semin Arthritis Rheum, 21, 211.

EYRE, D. R. 2004. Collagens and cartilage matrix homeostasis. Clin Orthop Relat Res, S118-22.

FELSON, D. T. 2004. Risk factors for osteoarthritis: understanding joint vulnerability. Clin Orthop Relat Res, S16-21.

FELSON, D. T. 2006. Osteoarthritis of the Knee. New England Journal of Medicine, 354, 841-848.

FISCHER, M., ZILKENAT, S., GERLACH, R. G., WAGNER, S. \& RENARD, B. Y. 2014. Pre- and post-processing workflow for affinity purification mass spectrometry data. J Proteome Res, 13, 2239-49.

FOX, A. J. S., BEDI, A. \& RODEO, S. A. 2009. The basic science of articular cartilage: structure, composition, and function. Sports Health, 1, 461-8.

FUCHS, E., TUMBAR, T. \& GUASCH, G. 2004. Socializing with the neighbors: stem cells and their niche. Cell, 116, 769-78. 
GARNERO, P., ROUSSEAU, J. C. \& DELMAS, P. D. 2000. Molecular basis and clinical use of biochemical markers of bone, cartilage, and synovium in joint diseases. Arthritis Rheum, 43, 953-68.

GASSMANN, M., GRENACHER, B., ROHDE, B. \& VOGEL, J. 2009. Quantifying Western blots: pitfalls of densitometry. Electrophoresis, 30, 1845-55.

GELSE, K., MÜHLE, C., KNAUP, K., SWOBODA, B., WIESENER, M., HENNIG, F., OLK, A. \& SCHNEIDER, H. 2008. Chondrogenic differentiation of growth factor-stimulated precursor cells in cartilage repair tissue is associated with increased HIF-1alpha activity. Osteoarthritis Cartilage, 16, 1457-65.

GOLDRING, M. B. 2012. Articular cartilage degradation in osteoarthritis. Hss j, 8, 79.

GOLDRING, M. B. \& GOLDRING, S. R. 2007. Osteoarthritis. J Cell Physiol, 213, 626-34.

GOLDRING, M. B. \& GOLDRING, S. R. 2010. Articular cartilage and subchondral bone in the pathogenesis of osteoarthritis. Ann N Y Acad Sci, 1192, 230-7.

GRAFE, I., ALEXANDER, S., PETERSON, J. R., SNIDER, T. N., LEVI, B., LEE, B. \& MISHINA, Y. 2018. TGF- $\beta$ Family Signaling in Mesenchymal Differentiation. Cold Spring Harb Perspect Biol, 10.

GREEN, J. D., TOLLEMAR, V., DOUGHERTY, M., YAN, Z., YIN, L., YE, J., COLLIER, Z., MOHAMMED, M. K., HAYDON, R. C., LUU, H. H., KANG, R., LEE, M. J., HO, S. H., HE, T. C., SHI, L. L. \& ATHIVIRAHAM, A. 2015. Multifaceted signaling regulators of chondrogenesis: Implications in cartilage regeneration and tissue engineering. Genes Dis, 2, 307-327.

GRIMONT, A., PINHO, A. V., COWLEY, M. J., AUGEREAU, C., MAWSON, A., GIRY-LATERRIERE, M., VAN DEN STEEN, G., WADDELL, N., PAJIC, M., SEMPOUX, C., WU, J., GRIMMOND, S. M., BIANKIN, A. V., LEMAIGRE, F. P., ROOMAN, I. \& JACQUEMIN, P. 2015. SOX9 regulates ERBB signalling in pancreatic cancer development. Gut, 64, 1790-9.

GUBBIOTTI, M. A., NEILL, T. \& IOZZO, R. V. 2017. A current view of perlecan in physiology and pathology: A mosaic of functions. Matrix Biol, 57-58, 285-298.

HANLEY, K. P., OAKLEY, F., SUGDEN, S., WILSON, D. I., MANN, D. A. \& HANLEY, N. A. 2008. Ectopic SOX9 mediates extracellular matrix deposition characteristic of organ fibrosis. J Biol Chem, 283, 14063-71.

HANNAN, M. T., FELSON, D. T. \& PINCUS, T. 2000. Analysis of the discordance between radiographic changes and knee pain in osteoarthritis of the knee. $J$ Rheumatol, 27, 1513-7.

HARA, T., YOSHIDA, E., SHINKAI, Y., YAMAMOTO, C., FUJIWARA, Y., KUMAGAI, Y. \& KAJI, T. 2017. Biglycan Intensifies ALK5-Smad2/3 Signaling by TGFbeta1 and Downregulates Syndecan-4 in Cultured Vascular Endothelial Cells. J Cell Biochem, 118, 1087-1096.

HÄUSELMANN, H. J., FERNANDES, R. J., MOK, S. S., SCHMID, T. M., BLOCK, J. A., AYDELOTTE, M. B., KUETTNER, K. E. \& THONAR, E. J. 1994. Phenotypic stability of bovine articular chondrocytes after long-term culture in alginate beads. J Cell Sci, 107 ( Pt 1), 17-27.

HAYFLICK, L. 1984. Intracellular determinants of cell aging. Mech Ageing Dev, 28, 177-85.

HEEGAARD, A. M., XIE, Z., YOUNG, M. F. \& NIELSEN, K. L. 2004. Transforming growth factor beta stimulation of biglycan gene expression is potentially mediated by sp1 binding factors. J Cell Biochem, 93, 463-75.

HEINEGARD, D. \& SAXNE, T. 2011. The role of the cartilage matrix in osteoarthritis. Nat Rev Rheumatol, 7, 50-6. 
HILDEBRAND, A., ROMARÍS, M., RASMUSSEN, L. M., HEINEGÅRD, D., TWARDZIK, D. R., BORDER, W. A. \& RUOSLAHTI, E. 1994. Interaction of the small interstitial proteoglycans biglycan, decorin and fibromodulin with transforming growth factor beta. Biochem J, 302 ( Pt 2), 527-34.

HOllandeR, A. P., PIDOUX, I., REINER, A., RORABECK, C., BOURNE, R. \& POOLE, A. R. 1995. Damage to type II collagen in aging and osteoarthritis starts at the articular surface, originates around chondrocytes, and extends into the cartilage with progressive degeneration. J Clin Invest, 96, 2859-69.

HOOTMAN, J. M., HELMICK, C. G., BARBOUR, K. E., THEIS, K. A. \& BORING, M. A. 2016. Updated Projected Prevalence of Self-Reported Doctor-Diagnosed Arthritis and Arthritis-Attributable Activity Limitation Among US Adults, 20152040. Arthritis Rheumatol, 68, 1582-7.

HORTON, W. E., JR., BENNION, P. \& YANG, L. 2006. Cellular, molecular, and matrix changes in cartilage during aging and osteoarthritis. $J$ Musculoskelet Neuronal Interact, 6, 379-81.

HUANG, W., ZHOU, X., LEFEBVRE, V. \& DE CROMBRUGGHE, B. 2000. Phosphorylation of SOX9 by cyclic AMP-dependent protein kinase $A$ enhances SOX9's ability to transactivate a Col2a1 chondrocyte-specific enhancer. Mol Cell Biol, 20, 4149-58.

HUANG, Y. H., JANKOWSKI, A., CHEAH, K. S., PRABHAKAR, S. \& JAUCH, R. 2015. SOXE transcription factors form selective dimers on non-compact DNA motifs through multifaceted interactions between dimerization and highmobility group domains. Sci Rep, 5, 10398.

HUNTER, D. J. \& FELSON, D. T. 2006. Osteoarthritis. Bmj, 332, 639-42.

IACOB, S. \& CS-SZABO, G. 2010. Biglycan regulates the expression of EGF receptors through EGF signaling pathways in human articular chondrocytes. Connect Tissue Res, 51, 347-58.

IKEDA, T., KAMEKURA, S., MABUCHI, A., KOU, I., SEKI, S., TAKATO, T., NAKAMURA, K., KAWAGUCHI, H., IKEGAWA, S. \& CHUNG, U.-I. 2004. The combination of SOX5, SOX6, and SOX9 (the SOX trio) provides signals sufficient for induction of permanent cartilage. Arthritis \& Rheumatism, 50, 3561-3573.

IM, G. I. \& KIM, H. J. 2011. Electroporation-mediated gene transfer of SOX trio to enhance chondrogenesis in adipose stem cells. Osteoarthritis Cartilage, 19, 449-57.

INADA, M., YASUI, T., NOMURA, S., MIYAKE, S., DEGUCHI, K., HIMENO, M., SATO, M., YAMAGIWA, H., KIMURA, T., YASUI, N., OCHI, T., ENDO, N., KITAMURA, Y., KISHIMOTO, T. \& KOMORI, T. 1999. Maturational disturbance of chondrocytes in Cbfa1-deficient mice. Dev Dyn, 214, 279-90.

IOAN-FACSINAY, A. \& KLOPPENBURG, M. 2013. An emerging player in knee osteoarthritis: the infrapatellar fat pad. Arthritis Res Ther, 15, 225.

ISCHENKO, I., LIU, J., PETRENKO, O. \& HAYMAN, M. J. 2014. Transforming growth factor-beta signaling network regulates plasticity and lineage commitment of lung cancer cells. Cell Death Differ, 21, 1218-28.

IZZI, V., LAKKALA, J., DEVARAJAN, R., KÄÄRIÄINEN, A., KOIVUNEN, J., HELJASVAARA, R. \& PIHLAJANIEMI, T. 2019. Pan-Cancer analysis of the expression and regulation of matrisome genes across 32 tumor types. Matrix Biology Plus, 1, 1-13.

JANSSEN, J. N., BATSCHKUS, S., SCHIMMEL, S., BODE, C., SCHMINKE, B. \& MIOSGE, N. 2019. The Influence of TGF- $\beta 3$, EGF, and BGN on SOX9 and 
RUNX2 Expression in Human Chondrogenic Progenitor Cells. J Histochem Cytochem, 67, 117-127.

JENEI-LANZL, Z., GRÄSSEL, S., PONGRATZ, G., KEES, F., MIOSGE, N., ANGELE, P. \& STRAUB, R. H. 2014. Norepinephrine Inhibition of Mesenchymal Stem Cell and Chondrogenic Progenitor Cell Chondrogenesis and Acceleration of Chondrogenic Hypertrophy. Arthritis \& Rheumatology, 66, 2472-2481.

JEONG, S. Y., KANG, M. L., PARK, J. W. \& IM, G. I. 2020. Dual functional nanoparticles containing SOX duo and ANGPT4 shRNA for osteoarthritis treatment. J Biomed Mater Res B Appl Biomater, 108, 234-242.

JO, A., DENDULURI, S., ZHANG, B., WANG, Z., YIN, L., YAN, Z., KANG, R., SHI, L. L., MOK, J., LEE, M. J. \& HAYDON, R. C. 2014. The versatile functions of Sox9 in development, stem cells, and human diseases. Genes Dis, 1, 149161.

JOOS, H., WILDNER, A., HOGREFE, C., REICHEL, H. \& BRENNER, R. E. 2013. Interleukin-1 beta and tumor necrosis factor alpha inhibit migration activity of chondrogenic progenitor cells from non-fibrillated osteoarthritic cartilage. Arthritis Res Ther, 15, R119.

KALKREUTH, R. H., KRÜGER, J. P., LAU, S., NIEMEYER, P., ENDRES, M., KREUZ, P. C. \& KAPS, C. 2014. Fibronectin stimulates migration and proliferation, but not chondrogenic differentiation of human subchondral progenitor cells. Regen Med, 9, 759-73.

KAPLAN, O., JAROSZEWSKI, J. W., FAUSTINO, P. J., ZUGMAIER, G., ENNIS, B. W., LIPPMAN, M. \& COHEN, J. S. 1990. Toxicity and effects of epidermal growth factor on glucose metabolism of MDA-468 human breast cancer cells. $\checkmark$ Biol Chem, 265, 13641-9.

KAPS, C., HOFFMANN, A., ZILBERMAN, Y., PELLED, G., HÄUPL, T., SITTINGER, M., BURMESTER, G., GAZIT, D. \& GROSS, G. 2004. Distinct roles of BMP receptors Type $\mathrm{IA}$ and $\mathrm{IB}$ in osteo-/chondrogenic differentiation in mesenchymal progenitors (C3H10T1/2). Biofactors, 20, 71-84.

KIM, I. S., OTTO, F., ZABEL, B. \& MUNDLOS, S. 1999. Regulation of chondrocyte differentiation by Cbfa1. Mech Dev, 80, 159-70.

KINNEY, R. C., SCHWARTZ, Z., WEEK, K., LOTZ, M. K. \& BOYAN, B. D. 2005. Human articular chondrocytes exhibit sexual dimorphism in their responses to 17beta-estradiol. Osteoarthritis Cartilage, 13, 330-7.

KOELLING, S., KRUEGEL, J., IRMER, M., PATH, J. R., SADOWSKI, B., MIRO, X. \& MIOSGE, N. 2009. Migratory chondrogenic progenitor cells from repair tissue during the later stages of human osteoarthritis. Cell Stem Cell, 4, 324-35.

KOELLING, S. \& MIOSGE, N. 2010. Sex differences of chondrogenic progenitor cells in late stages of osteoarthritis. Arthritis Rheum, 62, 1077-87.

KOPYLOVA, E., NOÉ, L. \& TOUZET, H. 2012. SortMeRNA: fast and accurate filtering of ribosomal RNAs in metatranscriptomic data. Bioinformatics, 28, 3211-7.

KOTLARZ, H., GUNNARSSON, C. L., FANG, H. \& RIZZO, J. A. 2009. Insurer and out-of-pocket costs of osteoarthritis in the US: evidence from national survey data. Arthritis Rheum, 60, 3546-53.

KOZHEMYAKINA, E., LASSAR, A. B. \& ZELZER, E. 2015. A pathway to bone: signaling molecules and transcription factors involved in chondrocyte development and maturation. Development, 142, 817-831. 
KUMAR, D. \& LASSAR, A. B. 2009. The transcriptional activity of Sox9 in chondrocytes is regulated by RhoA signaling and actin polymerization. $\mathrm{Mol}$ Cell Biol, 29, 4262-73.

LAMBERT, J. P., IVOSEV, G., COUZENS, A. L., LARSEN, B., TAIPALE, M., LIN, Z. Y., ZHONG, Q., LINDQUIST, S., VIDAL, M., AEBERSOLD, R., PAWSON, T., BONNER, R., TATE, S. \& GINGRAS, A. C. 2013. Mapping differential interactomes by affinity purification coupled with data-independent mass spectrometry acquisition. Nat Methods, 10, 1239-45.

LAMPLOT, J. D., BANSAL, A., NGUYEN, J. T. \& BROPHY, R. H. 2018. Risk of Subsequent Joint Arthroplasty in Contralateral or Different Joint After Index Shoulder, Hip, or Knee Arthroplasty: Association with Index Joint, Demographics, and Patient-Specific Factors. J Bone Joint Surg Am, 100, 1750-1756.

LEFEBVRE, V., HUANG, W., HARLEY, V. R., GOODFELlOW, P. N. \& DE CROMBRUGGHE, B. 1997. SOX9 is a potent activator of the chondrocytespecific enhancer of the pro alpha1(II) collagen gene. Mol Cell Biol, 17, 233646.

LIAO, L., ZHANG, S., ZHOU, G. Q., YE, L., HUANG, J., ZHAO, L. \& CHEN, D. 2019a. Deletion of Runx2 in condylar chondrocytes disrupts TMJ tissue homeostasis. J Cell Physiol, 234, 3436-3444.

LIAO, Y., SMYTH, G. K. \& SHI, W. 2014. featureCounts: an efficient general purpose program for assigning sequence reads to genomic features. Bioinformatics, 30, 923-30.

LIAO, Y., WANG, J., JAEHNIG, E. J., SHI, Z. \& ZHANG, B. 2019b. WebGestalt 2019: gene set analysis toolkit with revamped Uls and APIs. Nucleic Acids Res, 47, W199-w205.

LIM, K. \& LAU, C. S. 2011. Perception is everything: OA is exciting. International Journal of Rheumatic Diseases, 14, 111-112.

LIN, M. E., CHEN, T., LEAF, E. M., SPEER, M. Y. \& GIACHELLI, C. M. 2015. Runx2 Expression in Smooth Muscle Cells Is Required for Arterial Medial Calcification in Mice. Am J Pathol, 185, 1958-69.

LING, S., CHANG, X., SCHULTZ, L., LEE, T. K., CHAUX, A., MARCHIONNI, L., NETTO, G. J., SIDRANSKY, D. \& BERMAN, D. M. 2011. An EGFR-ERKSOX9 signaling cascade links urothelial development and regeneration to cancer. Cancer Res, 71, 3812-21.

LIU, H., CHEN, Y., ZHOU, F., JIE, L., PU, L., JU, J., LI, F., DAI, Z., WANG, X. \& ZHOU, S. 2014. Sox9 regulates hyperexpression of Wnt1 and Fzd1 in human osteosarcoma tissues and cells. Int J Clin Exp Pathol, 7, 4795-805.

LIVAK, K. J. \& SCHMITTGEN, T. D. 2001. Analysis of relative gene expression data using real-time quantitative PCR and the 2(-Delta Delta $\mathrm{C}(\mathrm{T})$ ) Method. Methods, 25, 402-8.

LOESER, R. F., YAMMANI, R. R., CARLSON, C. S., CHEN, H., COLE, A., IM, H. J., BURSCH, L. S. \& YAN, S. D. 2005. Articular chondrocytes express the receptor for advanced glycation end products: Potential role in osteoarthritis. Arthritis Rheum, 52, 2376-85.

LOHMANDER, L. S. \& ROOS, E. M. 2007. Clinical update: treating osteoarthritis. Lancet, 370, 2082-4.

LOTZ, M. K., OTSUKI, S., GROGAN, S. P., SAH, R., TERKELTAUB, R. \& D'LIMA, D. 2010. Cartilage cell clusters. Arthritis Rheum, 62, 2206-18.

LOVE, M. I., HUBER, W. \& ANDERS, S. 2014. Moderated estimation of fold change and dispersion for RNA-seq data with DESeq2. Genome Biol, 15, 550. 
LUCERO, C. M., VEGA, O. A., OSORIO, M. M., TAPIA, J. C., ANTONELLI, M., STEIN, G. S., VAN WIJNEN, A. J. \& GALINDO, M. A. 2013. The cancerrelated transcription factor Runx2 modulates cell proliferation in human osteosarcoma cell lines. J Cell Physiol, 228, 714-23.

LUNDGREN, D. H., HWANG, S. I., WU, L. \& HAN, D. K. 2010. Role of spectral counting in quantitative proteomics. Expert Rev Proteomics, 7, 39-53.

MACRI, L., SILVERSTEIN, D. \& CLARK, R. A. 2007. Growth factor binding to the pericellular matrix and its importance in tissue engineering. Adv Drug Deliv Rev, 59, 1366-81.

MAETZEL, A., LI, L. C., PENCHARZ, J., TOMLINSON, G. \& BOMBARDIER, C. 2004. The economic burden associated with osteoarthritis, rheumatoid arthritis, and hypertension: a comparative study. Ann Rheum Dis, 63, 395-401.

MALKI, S., NEF, S., NOTARNICOLA, C., THEVENET, L., GASCA, S., MÉJEAN, C., BERTA, P., POULAT, F. \& BOIZET-BONHOURE, B. 2005. Prostaglandin D2 induces nuclear import of the sex-determining factor SOX9 via its CAMP-PKA phosphorylation. Embo j, 24, 1798-809.

MATTA, C., BOOCOCK, D. J., FELLOWS, C. R., MIOSGE, N., DIXON, J. E., LIDDELL, S., SMITH, J. \& MOBASHERI, A. 2019. Molecular phenotyping of the surfaceome of migratory chondroprogenitors and mesenchymal stem cells using biotinylation, glycocapture and quantitative LC-MS/MS proteomic analysis. Sci Rep, 9, 9018.

MCCOY, A. M. 2015. Animal Models of Osteoarthritis: Comparisons and Key Considerations. Vet Pathol, 52, 803-18.

MENDLER, M., EICH-BENDER, S. G., VAUGHAN, L., WINTERHALTER, K. H. \& BRUCKNER, P. 1989. Cartilage contains mixed fibrils of collagen types II, IX, and XI. J Cell Biol, 108, 191-7.

MIACZYNSKA, M., CHRISTOFORIDIS, S., GINER, A., SHEVCHENKO, A., UTTENWEILER-JOSEPH, S., HABERMANN, B., WILM, M., PARTON, R. G. \& ZERIAL, M. 2004. APPL proteins link Rab5 to nuclear signal transduction via an endosomal compartment. Cell, 116, 445-56.

MILLER, L. E., FREDERICSON, M. \& ALTMAN, R. D. 2020. Hyaluronic Acid Injections or Oral Nonsteroidal Anti-inflammatory Drugs for Knee Osteoarthritis: Systematic Review and Meta-analysis of Randomized Trials. Orthop J Sports Med, 8, 2325967119897909.

MILLWARD-SADLER, S. J., KHAN, N. S., BRACHER, M. G., WRIGHT, M. O. \& SALTER, D. M. 2006. Roles for the interleukin-4 receptor and associated JAK/STAT proteins in human articular chondrocyte mechanotransduction. Osteoarthritis Cartilage, 14, 991-1001.

MIOSGE, N., HARTMANN, M., MAELICKE, C. \& HERKEN, R. 2004. Expression of collagen type I and type II in consecutive stages of human osteoarthritis. Histochem Cell Biol, 122, 229-36.

MIOSGE, N., WALETZKO, K., BODE, C., QUONDAMATTEO, F., SCHULTZ, W. \& HERKEN, R. 1998. Light and electron microscopic in-situ hybridization of collagen type I and type II mRNA in the fibrocartilaginous tissue of late-stage osteoarthritis. Osteoarthritis Cartilage, 6, 278-85.

MOAZEDI-FUERST, F. C., HOFNER, M., GRUBER, G., WEINHAEUSEL, A., STRADNER, M. H., ANGERER, H., PEISCHLER, D., LOHBERGER, B., GLEHR, M., LEITHNER, A., SONNTAGBAUER, M. \& GRANINGER, W. B. 2014. Epigenetic differences in human cartilage between mild and severe OA. J Orthop Res, 32, 1636-45. 
MOBASHERI, A. 2011. Applications of proteomics to osteoarthritis, a musculoskeletal disease characterized by aging. Front Physiol, 2, 108.

MUHAMMAD, H., SCHMINKE, B., BODE, C., ROTH, M., ALBERT, J., VON DER HEYDE, S., ROSEN, V. \& MIOSGE, N. 2014. Human migratory meniscus progenitor cells are controlled via the TGF-beta pathway. Stem Cell Reports, 3, 789-803.

MUMMERY, C. L. 2001. Transforming growth factor $\beta$ and mouse development. Microscopy Research and Technique, 52, 374-386.

MUSUMECI, G., AIELLO, F. C., SZYCHLINSKA, M. A., DI ROSA, M., CASTROGIOVANNI, P. \& MOBASHERI, A. 2015. Osteoarthritis in the XXIst century: risk factors and behaviours that influence disease onset and progression. Int J Mol Sci, 16, 6093-112.

MYREN, M., KIRBY, D. J., NOONAN, M. L., MAEDA, A., OWENS, R. T., RICARDBLUM, S., KRAM, V., KILTS, T. M. \& YOUNG, M. F. 2016. Biglycan potentially regulates angiogenesis during fracture repair by altering expression and function of endostatin. Matrix Biol, 52-54, 141-150.

NASTASE, M. V., YOUNG, M. F. \& SCHAEFER, L. 2012. Biglycan: a multivalent proteoglycan providing structure and signals. J Histochem Cytochem, 60, 96375.

NEFLA, M., SUDRE, L., DENAT, G., PRIAM, S., ANDRE-LEROUX, G., BERENBAUM, F. \& JACQUES, C. 2015. The pro-inflammatory cytokine 14-3$3 \varepsilon$ is a ligand of CD13 in cartilage. $J$ Cell Sci, 128, 3250-62.

NONAKA, K., SHUM, L., TAKAHASHI, I., TAKAHASHI, K., IKURA, T., DASHNER, R., NUCKOLLS, G. H. \& SLAVKIN, H. C. 1999. Convergence of the BMP and EGF signaling pathways on Smad1 in the regulation of chondrogenesis. Int $J$ Dev Biol, 43, 795-807.

OLDBERG, A., ANTONSSON, P., HEDBOM, E. \& HEINEGARD, D. 1990. Structure and function of extracellular matrix proteoglycans. Biochemical Society Transactions, 18, 789-792.

OLDERSHAW, R. A., TEW, S. R., RUSSELL, A. M., MEADE, K., HAWKINS, R., MCKAY, T. R., BRENNAN, K. R. \& HARDINGHAM, T. E. 2008. Notch signaling through Jagged-1 is necessary to initiate chondrogenesis in human bone marrow stromal cells but must be switched off to complete chondrogenesis. Stem Cells, 26, 666-74.

OTTO, F., THORNELL, A. P., CROMPTON, T., DENZEL, A., GILMOUR, K. C., ROSEWELL, I. R., STAMP, G. W., BEDDINGTON, R. S., MUNDLOS, S., OLSEN, B. R., SELBY, P. B. \& OWEN, M. J. 1997. Cbfa1, a candidate gene for cleidocranial dysplasia syndrome, is essential for osteoblast differentiation and bone development. Cell, 89, 765-71.

PEREZ-RIVEROL, Y., CSORDAS, A., BAI, J., BERNAL-LLINARES, M., HEWAPATHIRANA, S., KUNDU, D. J., INUGANTI, A., GRISS, J., MAYER, G., EISENACHER, M., PÉREZ, E., USZKOREIT, J., PFEUFFER, J., SACHSENBERG, T., YILMAZ, Ş., TIWARY, S., COX, J., AUDAIN, E., WALZER, M., JARNUCZAK, A. F., TERNENT, T., BRAZMA, A. \& VIZCAÍNO, J. A. 2018. The PRIDE database and related tools and resources in 2019: improving support for quantification data. Nucleic Acids Research, 47, D442D450.

PFAFFL, M. W. 2001. A new mathematical model for relative quantification in realtime RT-PCR. Nucleic Acids Res, 29, e45.

PIRMOHAMED, M., JAMES, S., MEAKIN, S., GREEN, C., SCOTT, A. K., WALLEY, T. J., FARRAR, K., PARK, B. K. \& BRECKENRIDGE, A. M. 2004. Adverse 
drug reactions as cause of admission to hospital: prospective analysis of 18 820 patients. Bmj, 329, 15-9.

POMBO-SUAREZ, M., CASTANO-OREJA, M. T., CALAZA, M., GOMEZ-REINO, J. \& GONZALEZ, A. 2009. Differential upregulation of the three transforming growth factor beta isoforms in human osteoarthritic cartilage. Ann Rheum Dis, $68,568-71$.

POOLE, C. A. 1997. Articular cartilage chondrons: form, function and failure. J Anat, 191 ( Pt 1), 1-13.

POOLE, C. A., MATSUOKA, A. \& SCHOFIELD, J. R. 1991. Chondrons from articular cartilage. III. Morphologic changes in the cellular microenvironment of chondrons isolated from osteoarthritic cartilage. Arthritis Rheum, 34, 22-35.

PRATAP, J., LIAN, J. B. \& STEIN, G. S. 2011. Metastatic bone disease: role of transcription factors and future targets. Bone, 48, 30-6.

PRITCHETT, J., ATHWAL, V., ROBERTS, N., HANLEY, N. A. \& HANLEY, K. P. 2011. Understanding the role of SOX9 in acquired diseases: lessons from development. Trends Mol Med, 17, 166-74.

PRITZKER, K. P., GAY, S., JIMENEZ, S. A., OSTERGAARD, K., PELLETIER, J. P., REVELL, P. A., SALTER, D. \& VAN DEN BERG, W. B. 2006. Osteoarthritis cartilage histopathology: grading and staging. Osteoarthritis Cartilage, 14, 1329.

PUIG-JUNOY, J. \& RUIZ ZAMORA, A. 2015. Socio-economic costs of osteoarthritis: a systematic review of cost-of-illness studies. Semin Arthritis Rheum, 44, 531541.

QIN, L. \& BEIER, F. 2019. EGFR Signaling: Friend or Foe for Cartilage? JBMR Plus, 3, e10177.

RAJAGOPAL, R., ISHII, S. \& BEEBE, D. C. 2007. Intracellular mediators of transforming growth factor beta superfamily signaling localize to endosomes in chicken embryo and mouse lenses in vivo. BMC Cell Biol, 8, 25.

REGINSTER, J. Y. 2002. The prevalence and burden of arthritis. Rheumatology (Oxford), 41 Supp 1, 3-6.

REYNARD, L. N. \& LOUGHLIN, J. 2012. Genetics and epigenetics of osteoarthritis. Maturitas, 71, 200-4.

RICE, S. J., BEIER, F., YOUNG, D. A. \& LOUGHLIN, J. 2020. Interplay between genetics and epigenetics in osteoarthritis. Nat Rev Rheumatol, 16, 268-281.

ROSSIGNOL, M., LECLERC, A., HILLIQUIN, P., ALLAERT, F. A., ROZENBERG, S., VALAT, J. P., AVOUAC, B., COSTE, P., SAVARIEAU, B. \& FAUTREL, B. 2003. Primary osteoarthritis and occupations: a national cross sectional survey of 10412 symptomatic patients. Occup Environ Med, 60, 882-6.

ROUGHLEY, P. J. 2001. Articular cartilage and changes in arthritis: noncollagenous proteins and proteoglycans in the extracellular matrix of cartilage. Arthritis Res, 3, 342-7.

RUSSELL, R. G. 2007. Bisphosphonates: mode of action and pharmacology. Pediatrics, 119 Suppl 2, S150-62.

RYDER, J. J., GARRISON, K., SONG, F., HOOPER, L., SKINNER, J., LOKE, Y., LOUGHLIN, J., HIGGINS, J. P. \& MACGREGOR, A. J. 2008. Genetic associations in peripheral joint osteoarthritis and spinal degenerative disease: a systematic review. Ann Rheum Dis, 67, 584-91.

SANDELL, L. J. \& AIGNER, T. 2001. Articular cartilage and changes in arthritis. An introduction: cell biology of osteoarthritis. Arthritis Res, 3, 107-13.

SANGHI, D., MISHRA, A., SHARMA, A. C., RAJ, S., MISHRA, R., KUMARI, R., NATU, S. M., AGARWAL, S. \& SRIVASTAVA, R. N. 2015. Elucidation of 
dietary risk factors in osteoarthritis knee-a case-control study. J Am Coll Nutr, 34, 15-20.

SCANZELLO, C. R. \& GOLDRING, S. R. 2012. The role of synovitis in osteoarthritis pathogenesis. Bone, 51, 249-57.

SCHMINKE, B., FRESE, J., BODE, C., GOLDRING, M. B. \& MIOSGE, N. 2016a. Laminins and Nidogens in the Pericellular Matrix of Chondrocytes: Their Role in Osteoarthritis and Chondrogenic Differentiation. Am J Pathol, 186, 410-8.

SCHMINKE, B. \& MIOSGE, N. 2014. Cartilage repair in vivo: the role of migratory progenitor cells. Curr Rheumatol Rep, 16, 461.

SCHMINKE, B., MUHAMMAD, H., BODE, C., SADOWSKI, B., GERTER, R., GERSDORFF, N., BURGERS, R., MONSONEGO-ORNAN, E., ROSEN, V. \& MIOSGE, N. 2014. A discoidin domain receptor 1 knock-out mouse as a novel model for osteoarthritis of the temporomandibular joint. Cell Mol Life Sci, 71, 1081-96.

SCHMINKE, B., TRAUTMANN, S., MAI, B., MIOSGE, N. \& BLASCHKE, S. 2016b. Interleukin 17 inhibits progenitor cells in rheumatoid arthritis cartilage. Eur $J$ Immunol, 46, 440-5.

SCHULZE-TANZIL, G. 2019. Intraarticular Ligament Degeneration Is Interrelated with Cartilage and Bone Destruction in Osteoarthritis. Cells, 8.

SEOL, D., MCCABE, D. J., CHOE, H., ZHENG, H., YU, Y., JANG, K., WALTER, M. W., LEHMAN, A. D., DING, L., BUCKWALTER, J. A. \& MARTIN, J. A. 2012. Chondrogenic progenitor cells respond to cartilage injury. Arthritis Rheum, 64, 3626-37.

SETTON, L. A., ELLIOTT, D. M. \& MOW, V. C. 1999. Altered mechanics of cartilage with osteoarthritis: human osteoarthritis and an experimental model of joint degeneration. Osteoarthritis Cartilage, 7, 2-14.

SHEN, J., LI, S. \& CHEN, D. 2014. TGF-beta signaling and the development of osteoarthritis. Bone Res, 2.

SHEPARD, J. B., JEONG, J. W., MAIHLE, N. J., O'BRIEN, S. \& DEALY, C. N. 2013. Transient anabolic effects accompany epidermal growth factor receptor signal activation in articular cartilage in vivo. Arthritis Res Ther, 15, R60.

SIBILIA, M., WAGNER, B., HOEBERTZ, A., ELLIOTT, C., MARINO, S., JOCHUM, W. \& WAGNER, E. F. 2003. Mice humanised for the EGF receptor display hypomorphic phenotypes in skin, bone and heart. Development, 130, 4515-25.

SIMKIN, P. A. 2004. Bone pain and pressure in osteoarthritic joints. Novartis Found Symp, 260, 179-86; discussion 186-90, 277-9.

SMITS, P., DY, P., MITRA, S. \& LEFEBVRE, V. 2004. Sox5 and Sox6 are needed to develop and maintain source, columnar, and hypertrophic chondrocytes in the cartilage growth plate. J Cell Biol, 164, 747-58.

SOFAT, N. 2009. Analysing the role of endogenous matrix molecules in the development of osteoarthritis. Int J Exp Pathol, 90, 463-79.

TAKEDA, S., BONNAMY, J. P., OWEN, M. J., DUCY, P. \& KARSENTY, G. 2001. Continuous expression of Cbfa1 in nonhypertrophic chondrocytes uncovers its ability to induce hypertrophic chondrocyte differentiation and partially rescues Cbfa1-deficient mice. Genes Dev, 15, 467-81.

THOMAS, A. C., HUBBARD-TURNER, T., WIKSTROM, E. A. \& PALMIERI-SMITH, R. M. 2017. Epidemiology of Posttraumatic Osteoarthritis. J Athl Train, 52, 491-496.

UNTERGASSER, A., CUTCUTACHE, I., KORESSAAR, T., YE, J., FAIRCLOTH, B. C., REMM, M. \& ROZEN, S. G. 2012. Primer3--new capabilities and interfaces. Nucleic Acids Res, 40, e115. 
VALENTI, M. T., SERAFINI, P., INNAMORATI, G., GILI, A., CHERI, S., BASSI, C. \& DALLE CARBONARE, L. 2016. Runx2 expression: A mesenchymal stem marker for cancer. Oncol Lett, 12, 4167-4172.

VAN DER KRAAN, P. M. 2017. The changing role of TGFbeta in healthy, ageing and osteoarthritic joints. Nat Rev Rheumatol, 13, 155-163.

VAN DER KRAAN, P. M. 2018. Differential Role of Transforming Growth Factor-beta in an Osteoarthritic or a Healthy Joint. J Bone Metab, 25, 65-72.

VARGIOLU, M., SILVESTRI, T., BONORA, E., DOLZANI, P., PULSATELLI, L., ADDIMANDA, O., MANCARELLA, L., PUNZI, L., FIORAVANTI, A., FACCHINI, A., ROMEO, G. \& MELICONI, R. 2010. Interleukin-4/interleukin-4 receptor gene polymorphisms in hand osteoarthritis. Osteoarthritis Cartilage, $18,810-6$.

VASILIADIS, H. S. \& TSIKOPOULOS, K. 2017. Glucosamine and chondroitin for the treatment of osteoarthritis. World J Orthop, 8, 1-11.

VERZIJL, N., DEGROOT, J., BEN, Z. C., BRAU-BENJAMIN, O., MAROUDAS, A., BANK, R. A., MIZRAHI, J., SCHALKWIJK, C. G., THORPE, S. R., BAYNES, J. W., BIJLSMA, J. W., LAFEBER, F. P. \& TEKOPPELE, J. M. 2002. Crosslinking by advanced glycation end products increases the stiffness of the collagen network in human articular cartilage: a possible mechanism through which age is a risk factor for osteoarthritis. Arthritis Rheum, 46, 114-23.

WAGNER, G., LEHMANN, C., BODE, C., MIOSGE, N. \& SCHUBERT, A. 2019. High Mobility Group Box 1 Protein in Osteoarthritic Knee Tissue and Chondrogenic Progenitor Cells: An Ex Vivo and In Vitro Study. Cartilage, 1947603519835897.

WAGNER, T., WIRTH, J., MEYER, J., ZABEL, B., HELD, M., ZIMMER, J., PASANTES, J., BRICARELLI, F. D., KEUTEL, J., HUSTERT, E., WOLF, U., TOMMERUP, N., SCHEMPP, W. \& SCHERER, G. 1994. Autosomal sex reversal and campomelic dysplasia are caused by mutations in and around the SRY-related gene SOX9. Cell, 79, 1111-20.

WANG, K., LI, J., LI, Z., WANG, B., QIN, Y., ZHANG, N., ZHANG, H., SU, X., WANG, Y. \& ZHU, H. 2019. Chondrogenic Progenitor Cells Exhibit Superiority Over Mesenchymal Stem Cells and Chondrocytes in Platelet-Rich Plasma Scaffold-Based Cartilage Regeneration. Am J Sports Med, 47, 2200-2215.

WANG, R., JIANG, W., ZHANG, L., XIE, S., ZHANG, S., YUAN, S., JIN, Y. \& ZHOU, G. 2020. Intra-articular delivery of extracellular vesicles secreted by chondrogenic progenitor cells from MRL/MpJ superhealer mice enhances articular cartilage repair in a mouse injury model. Stem Cell Res Ther, 11, 93.

WHO. 2013. Priority diseases and reason for inclusion. Available: http://www.who.int/medicines/areas/priority_medicines/Ch6_12Osteo.pdf.

WITTENAUER, R., SMITH, L. \& ADEN, K. 2013. WHO Background Paper 6.12 Osteoarthritis.

XU, L., PENG, H., WU, D., HU, K., GOLDRING, M. B., OLSEN, B. R. \& LI, Y. 2005. Activation of the discoidin domain receptor 2 induces expression of matrix metalloproteinase 13 associated with osteoarthritis in mice. J Biol Chem, 280, 548-55.

YAMMANI, R. R., CARLSON, C. S., BRESNICK, A. R. \& LOESER, R. F. 2006. Increase in production of matrix metalloproteinase 13 by human articular chondrocytes due to stimulation with S100A4: Role of the receptor for advanced glycation end products. Arthritis Rheum, 54, 2901-11. 
YANG, L., CLINTON, J. M., BLACKBURN, M. L., ZHANG, Q., ZOU, J., ZIELINSKAKWIATKOWSKA, A., TANG, B. L. \& CHANSKY, H. A. 2008. Rab23 regulates differentiation of ATDC5 chondroprogenitor cells. J Biol Chem, 283, 10649-57.

YOON, B. S., OVCHINNIKOV, D. A., YOSHII, I., MISHINA, Y., BEHRINGER, R. R. \& LYONS, K. M. 2005. Bmpr1a and Bmpr1b have overlapping functions and are essential for chondrogenesis in vivo. Proc Natl Acad Sci U S A, 102, 5062-7.

ZAMLI, Z. \& SHARIF, M. 2011. Chondrocyte apoptosis: a cause or consequence of osteoarthritis? Int $J$ Rheum Dis, 14, 159-66.

ZEMMYO, M., MEHARRA, E. J., KÜHN, K., CREIGHTON-ACHERMANN, L. \& LOTZ, M. 2003. Accelerated, aging-dependent development of osteoarthritis in a1 integrin-deficient mice. Arthritis \& Rheumatism, 48, 2873-2880.

ZHANG, W., MOSKOWITZ, R. W., NUKI, G., ABRAMSON, S., ALTMAN, R. D., ARDEN, N., BIERMA-ZEINSTRA, S., BRANDT, K. D., CROFT, P., DOHERTY, M., DOUGADOS, M., HOCHBERG, M., HUNTER, D. J., KWOH, K., LOHMANDER, L. S. \& TUGWELL, P. 2008. OARSI recommendations for the management of hip and knee osteoarthritis, Part II: OARSI evidencebased, expert consensus guidelines. Osteoarthritis Cartilage, 16, 137-62.

ZHANG, W., OUYANG, H., DASS, C. R. \& XU, J. 2016. Current research on pharmacologic and regenerative therapies for osteoarthritis. Bone Res, 4, 15040.

ZHANG, X., ZHU, J., LI, Y., LIN, T., SICLARI, V. A., CHANDRA, A., CANDELA, E. M., KOYAMA, E., ENOMOTO-IWAMOTO, M. \& QIN, L. 2013. Epidermal growth factor receptor (EGFR) signaling regulates epiphyseal cartilage development through beta-catenin-dependent and -independent pathways. $J$ Biol Chem, 288, 32229-40.

ZHANG, X., ZHU, J., LIU, F., LI, Y., CHANDRA, A., LEVIN, L. S., BEIER, F., ENOMOTO-IWAMOTO, M. \& QIN, L. 2014. Reduced EGFR signaling enhances cartilage destruction in a mouse osteoarthritis model. Bone Res, 2, 14015.

ZHOU, G., CHEN, Y., ZHOU, L., THIRUNAVUKKARASU, K., HECHT, J., CHITAYAT, D., GELB, B. D., PIRINEN, S., BERRY, S. A., GREENBERG, C. R., KARSENTY, G. \& LEE, B. 1999. CBFA1 Mutation Analysis and Functional Correlation with Phenotypic Variability in Cleidocranial Dysplasia. Human Molecular Genetics, 8, 2311-2316.

ZHOU, G., ZHENG, Q., ENGIN, F., MUNIVEZ, E., CHEN, Y., SEBALD, E., KRAKOW, D. \& LEE, B. 2006. Dominance of SOX9 function over RUNX2 during skeletogenesis. Proc Natl Acad Sci U S A, 103, 19004-9.

ZMISTOWSKI, B., KARAM, J. A., DURINKA, J. B., CASPER, D. S. \& PARVIZI, J. 2013. Periprosthetic joint infection increases the risk of one-year mortality. $J$ Bone Joint Surg Am, 95, 2177-84. 


\section{Supplemental materials}

\section{Chapter II}

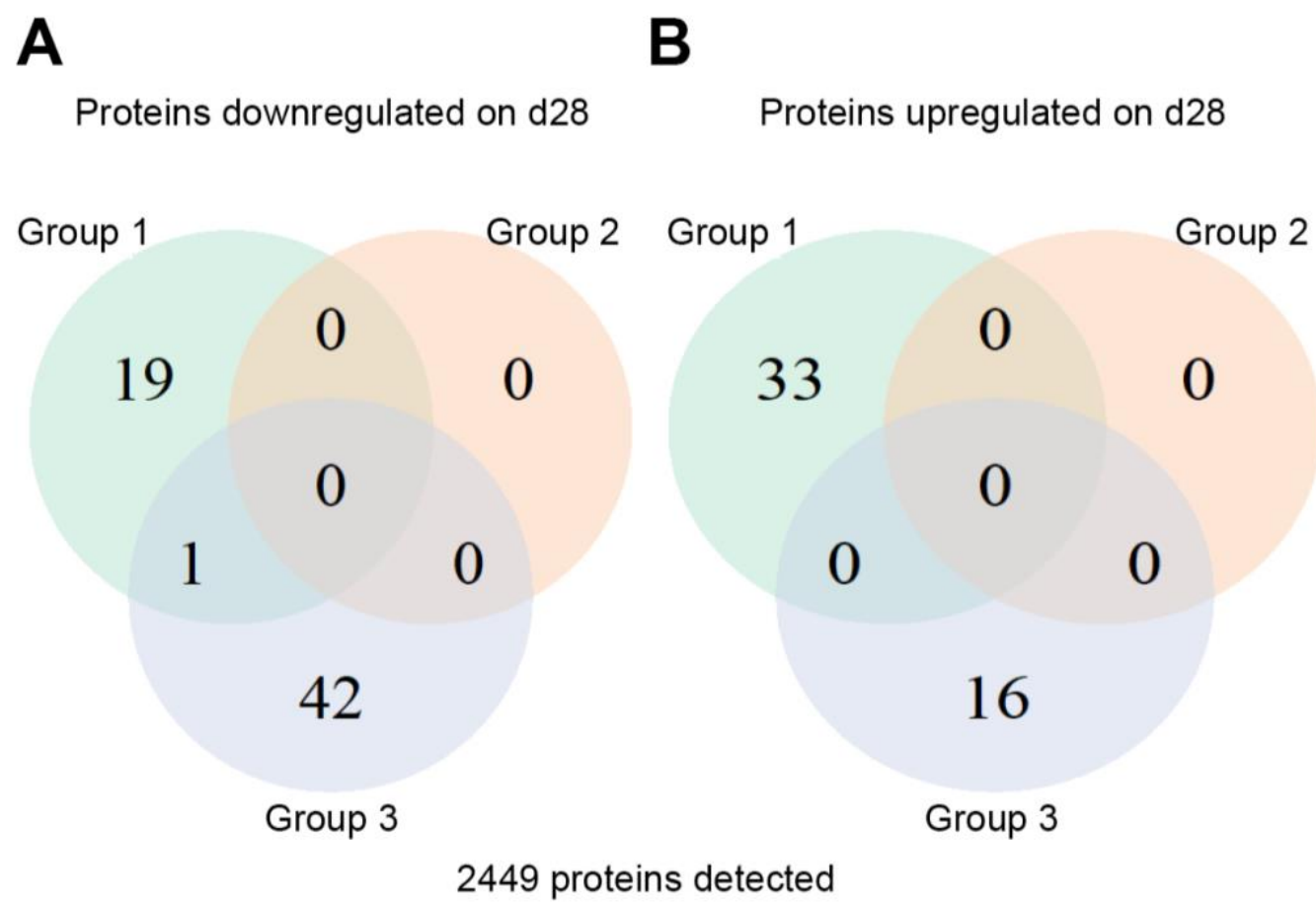

Figure S2.1: Comparison of primary and immortalized CPCs using data-independent acquisition mass spectrometry (DIA-MS). Analysis of differentially expressed proteins in samples collected after 28 days of chondrogenic differentiation. A total of 2449 proteins were detected. Cell lines were grouped together (group 1: CPC677 and CPC241hT; group 2: CPC674 and CPC674hT; group 3: CPC678 and $\mathrm{CPC678hT)}$. Venn diagram of (A) down- and (B) upregulated proteins after immortalization. 


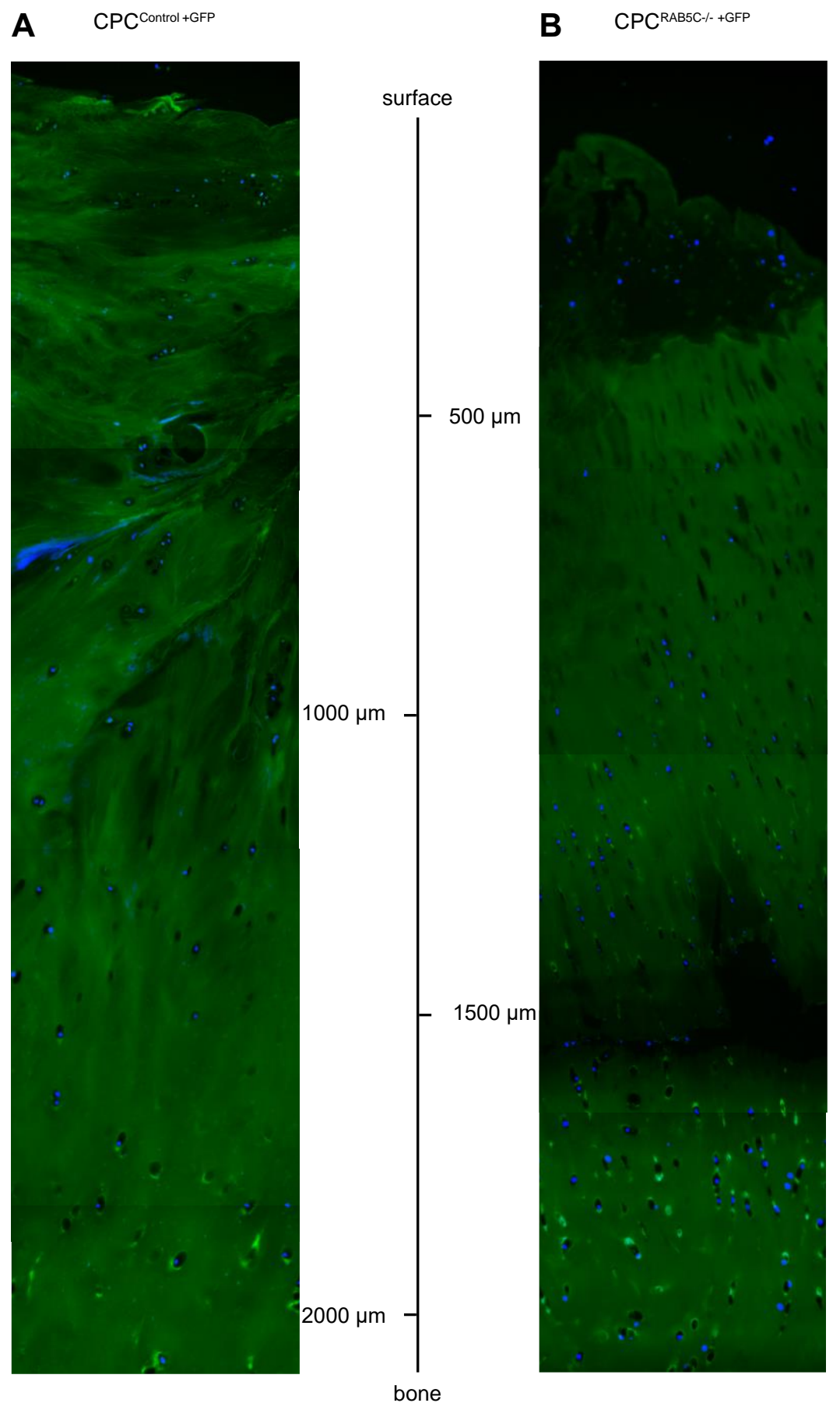

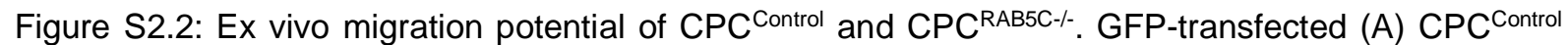

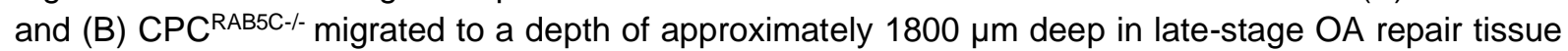
samples after 4 days. Surface fissures were observed in all specimens. DAPI was used to stain the nucleus. The figure is assembled from individual images. 


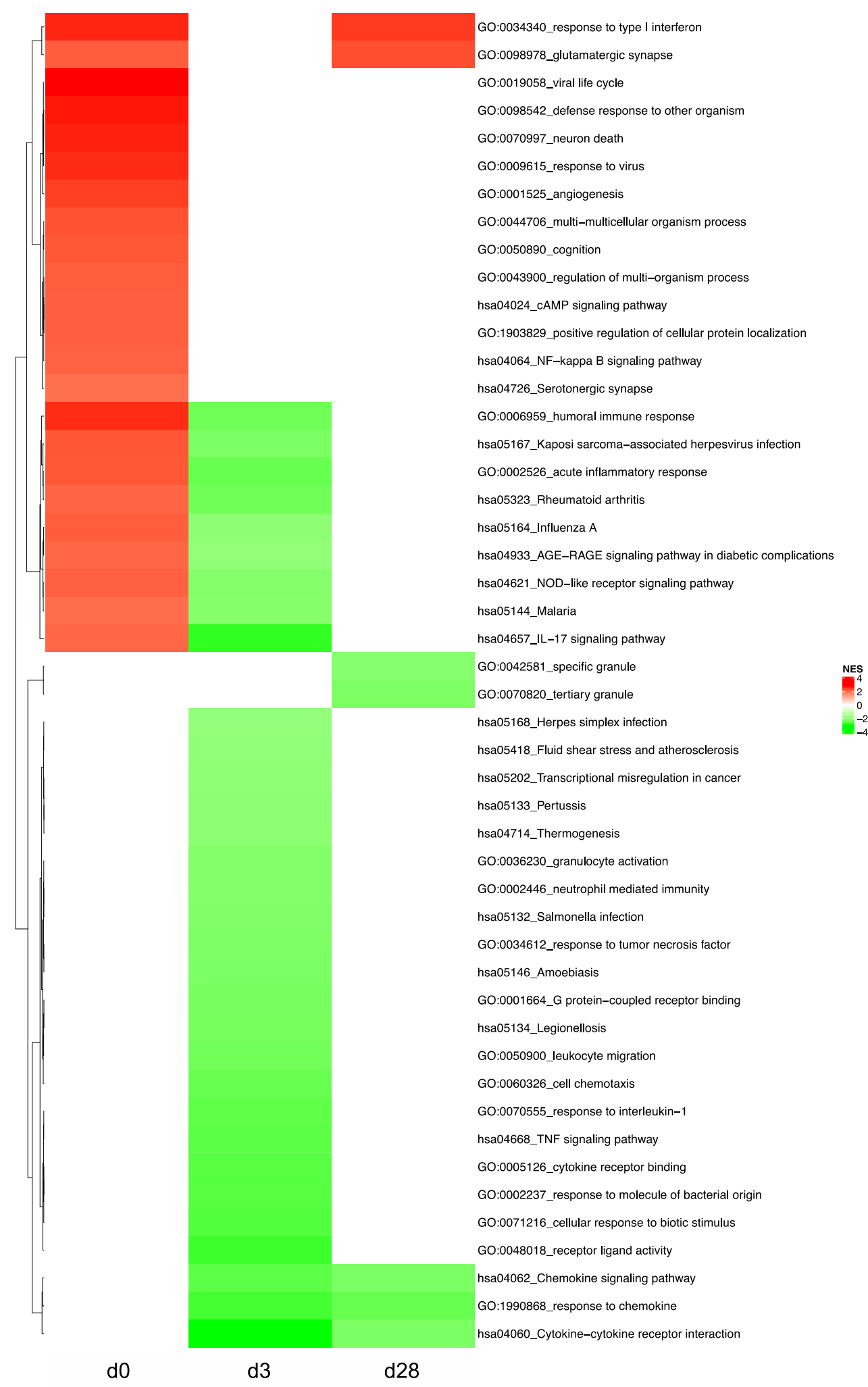

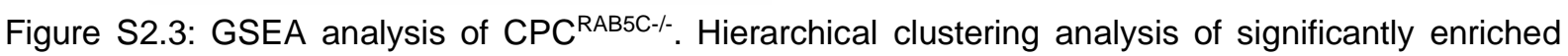
Gene Ontology (GO) terms and KEGG pathways for genes that were differentially expressed at days 0,3 and 28 of chondrogenic differentiation between CPC ${ }^{\text {Control }}$ and CPC ${ }^{\text {RAB5C-- }}$ samples. Genes are derived from the RNA-Seq differential expression analysis and enrichment is calculated as the ratio of observed over expected genes and log2 fold change. The magnitude of deregulation in each term is displayed in colors ranging from green (downregulated) to red (upregulated). 


\section{Digital appendix}

The following supplemental tables S2.1-S2.4 are available on the following link:

https://owncloud.gwdg.de/index.php/s/pKkj1aGDKq2Nmbu

The password is "JJ_Thesis2020".

Table S2.1: List of deregulated proteins after immortalization.

Table S2.2: Genes that are assumed to be involved in chondrogenesis and are affected by the loss of RAB5C.

Table S2.3: Differentially expressed genes in $\mathrm{CPC}^{\text {Control }}$ and $\mathrm{CPC}^{\mathrm{RAB5C}-\mathrm{-}-\text { identified by }}$ the GSEA.

Table S2.4: List of qPCR primers. 


\section{Acknowledgments}

Firstly, I express my gratitude to my supervisor Prof. Dr. Nicolai Miosge for his constant support, excellent advice and comfortable working atmosphere during my thesis. Thank you for the many opportunities to gain new experience abroad and sharing your immense knowledge in countless lab meetings and journal clubs helping me to understand the bigger picture.

A big thank you goes to the colleagues from the Miosge lab. Thank you Christa for always taking care of everything, immensely facilitating my project and for all your hiking gear! I thank (Prof) Elvira Henze for reminding me that you need "es nicht nur hier, sondern auch hier" and I extend my gratitude to her haircut for spreading joy in the lab on a daily basis.

I express my gratitude to the TAC members Prof. Dr. Jörg Stülke and Prof. Dr. Sigrid Hoyer-Fender for the helpful advice and the friendly and productive atmosphere. A big thank you to Prof. Dr. Gerhard Braus, Prof. Dr. Susanne Lutz and Prof. Dr. Detlef Doenecke for their time to join on my examination board.

Next, I thank Prof. Dr. Vicki Rosen for the chance to work in her lab, and for the great scientific support during my stay, and finally for her kitchen utensils. I extend my gratitude to her lab members, Dr. Laura Gamer, Dr. Marina Feigenson, Dr. David Maridas and Linda Ross for interesting discussions, new insights and a kind atmosphere.

I thank Dr. Valerio Izzi for descending straight from heaven and enlightening inferior forms of life with his divine wisdom including the necessity of a human sacrifice for Mama T.

I owe a big thank you to Boris, Andrea and Susanne for the enjoyable atmosphere and the support during my PhD.

I thank Viktoria and the GGNB office for their commitment. Without their friendly and patient help, I would still be struggling with all the formalities.

I owe a big thank you to all the fellow students and friends in the lab, especially Ruth and the first floor veterans Jochen and Fabian for the highly pleasant and productive atmosphere.

My gratitude goes to the TAL and Core Facility Proteomics for their help and expertise.

Thank you Dawid and Eric, both friends in need and deed. I highly appreciated your professional criticism on my drafts, including my thesis.

I thank my brothers Patrick and René for their open ear. I am grateful for your constant and patient support.

I express my gratitude to Haiko, my fellow "Bekenner seiner Kinglichkeit Alexander Marcus". Thank you for almost 10 amazing years in Göttingen. I also thank my Gocher friends for all the good times and for providing me with a home. 
A big thank you goes to my Boston roommates for all the good company and the eventful time. My particular gratitude goes to Eike for emotional support, academic feedback and vivid discussions about everything; but mainly the tough choices over Phoenix Landing and Lansdowne Pub.

Thank you Pushpenders; especially curly Laura, Schmuwe and Andres for many eventful nights, concerts and festivals. I thank Jeroen, Stefan and René for their friendship in hard times.

Furthermore, I am as grateful as humanly possible for Rachel pointing out all my mistakes! Thanks for proofreading, for elucidating me with your existence and for showing me the city.

I also would like to thank the mice that have been sacrificed during my thesis.

Finally, my sincere gratitude goes to the mensa team being significantly involved in making my day. 